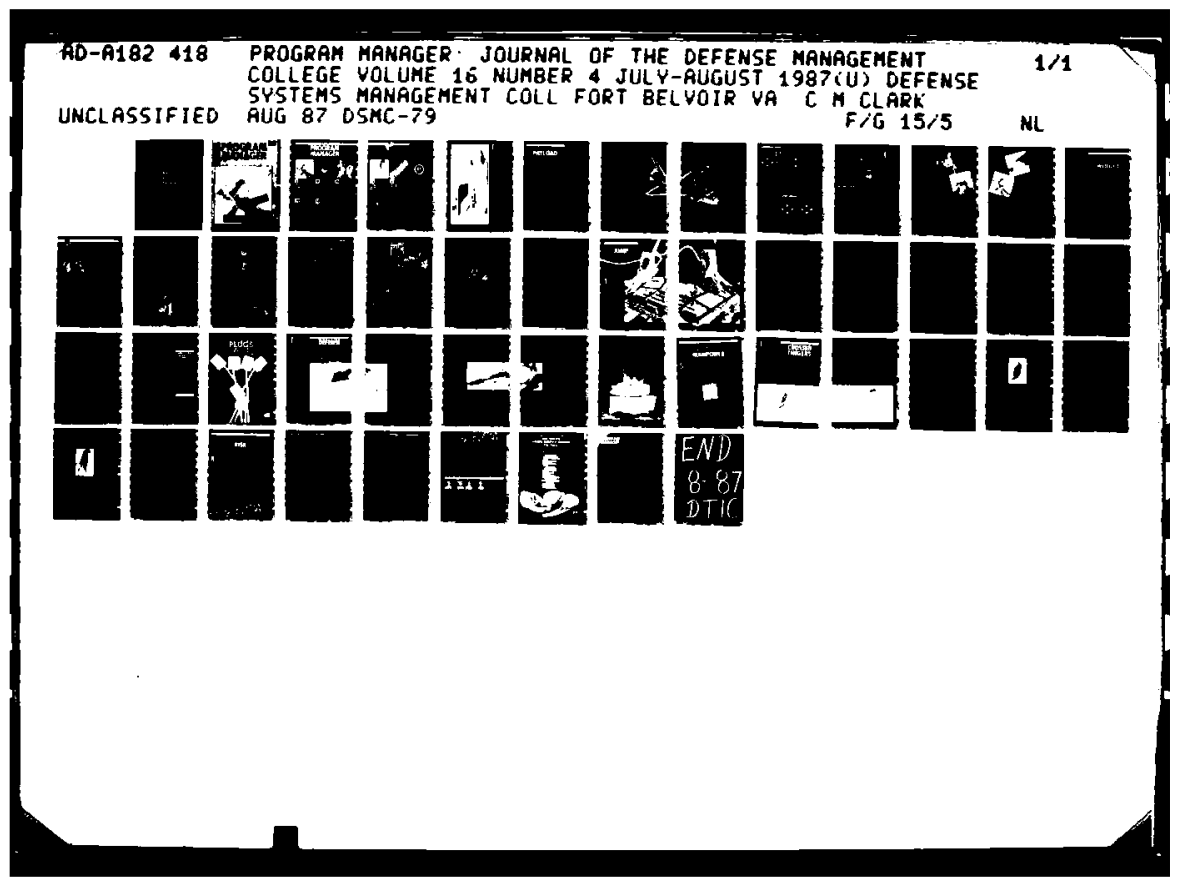




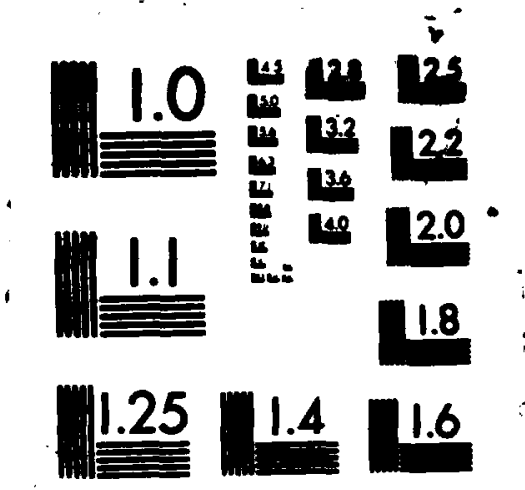

MICROCOPY RESOLUTION TEST CMART MTIONAL gUREAU OF STMMOARPS 1969-A 


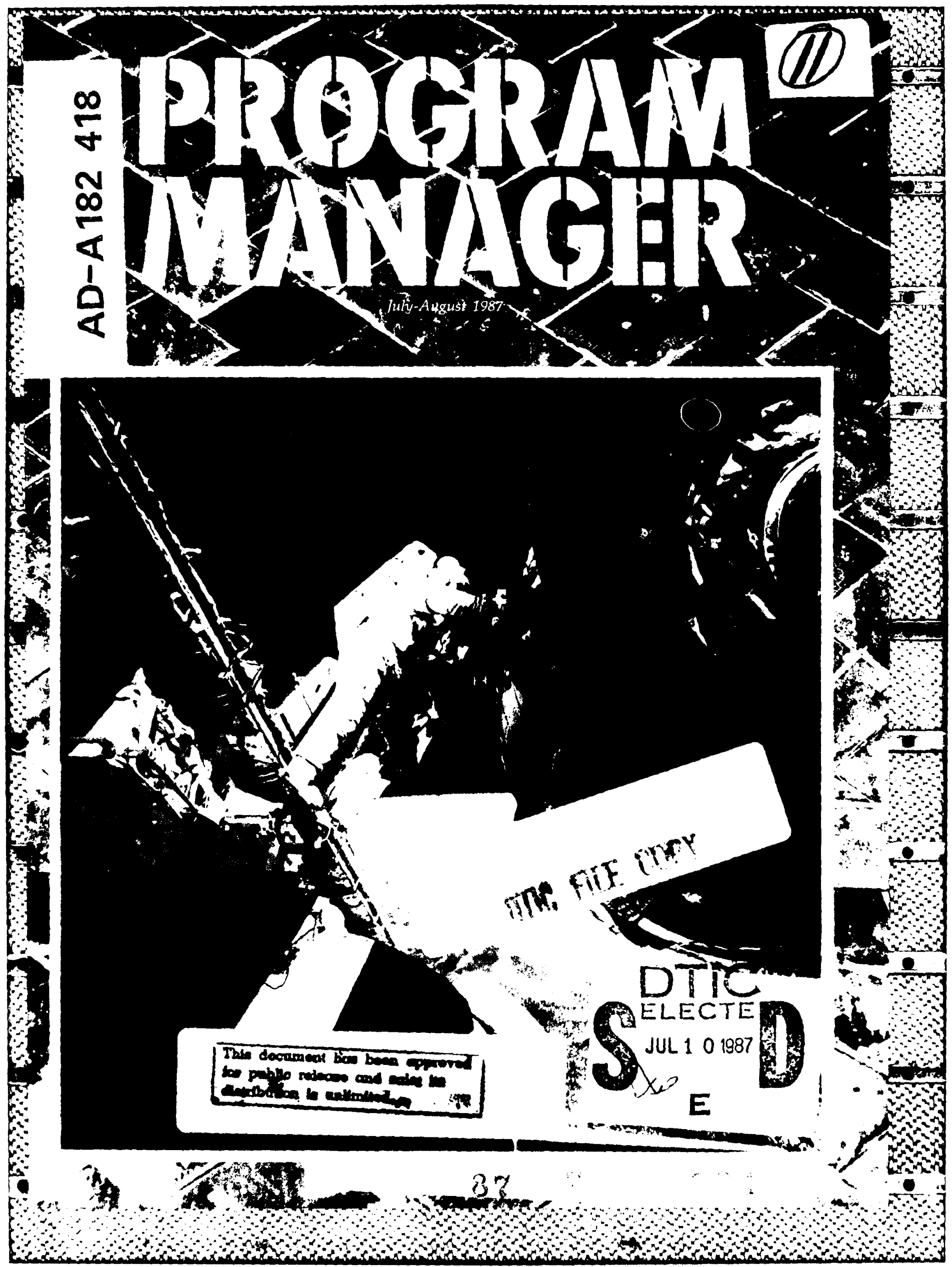




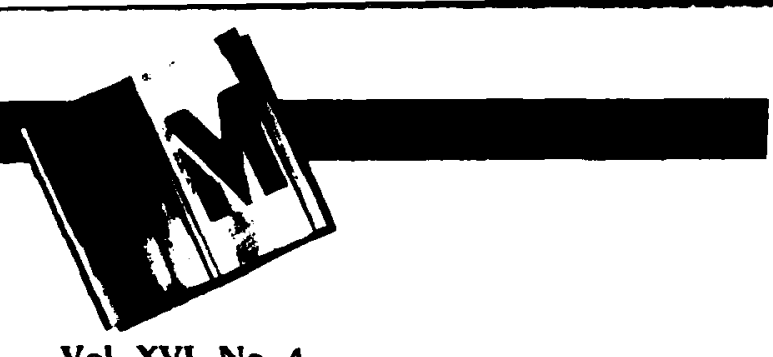

Cover: An astronaut performs extravehicular activity on space transportation system satellite payload.

Background: Shuttle thermal protection tiles.

Vol. XVI, No. 4

DSMC 79

July-August

1987

\section{MANAGEMENT COLLEGE}

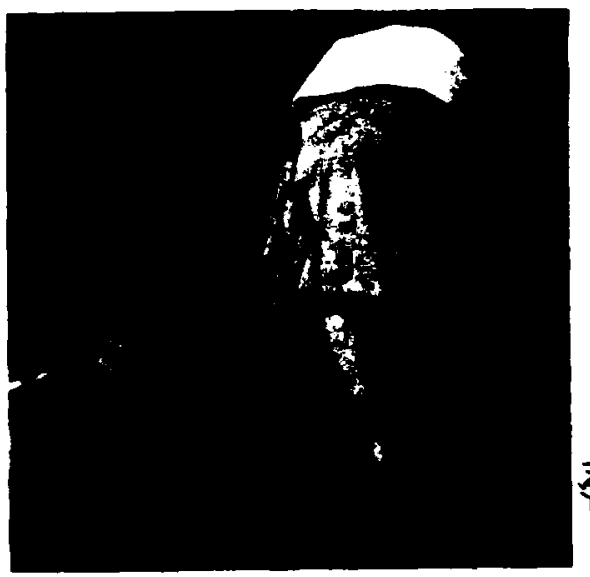

\section{4}

- Gounod mincors:

The Enongla: Denemos es

Rlim in

Gomerevalue",

Troy V. Caver

Reacting to the system.

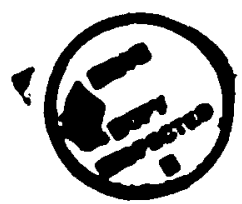

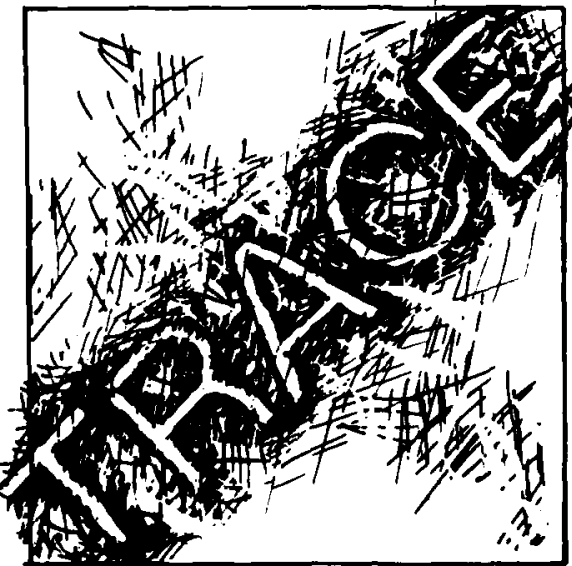
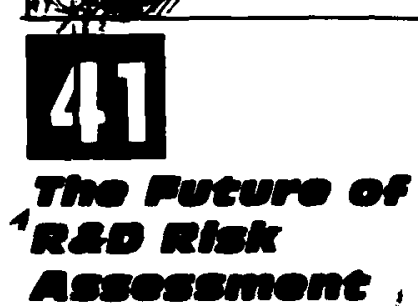

Colonel Gordon W. Arbogast, USA

Dr. Anthony Czajkowski

Study shows important management implications.

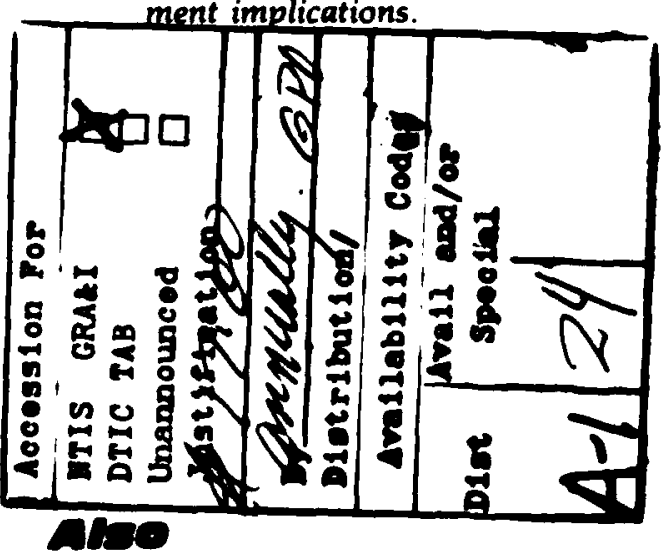

AFSC Accepts System - 26

New Version of Mine Clearing - 26

Gante Medal - 40

Inside DSMC - 4

Program Manager

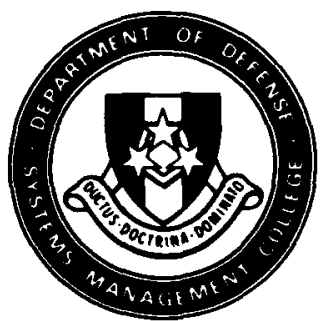

\section{DEFENSE SYSTEMS MANAGEMENT COLLEGE}

\section{Commandant}

Brigadier General Charles P. Cabell Ir., USAF

Provont

Gregary T. Wierzbicki

Dean, Department of

Rewearch and informetion

Captain George K. Coyne, Jr., USN

Dtrector of Publicution

Robert W. Ball

PROGRAM MANAGER

Manmeine Editor Catherine M. Clark

Edthorial Ambetant Deborah A Lewis

Devien Director

Greg Caruth

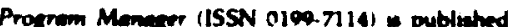
bimonthly by the Deterno Syuems Manemement Col. he For Belvour VA 22060-5120 Non towernmem employers and oreanisations may subacrite at $\$ 17$ annually through the Supertiniondeme of Documents. US

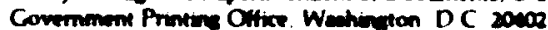
Second clem pouere pand at fort Bivou VA

POSTMASTER Sind eddrew cheneses in Progrem

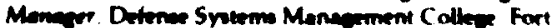
Delrour VA 220005420

Iuly-August 1987 


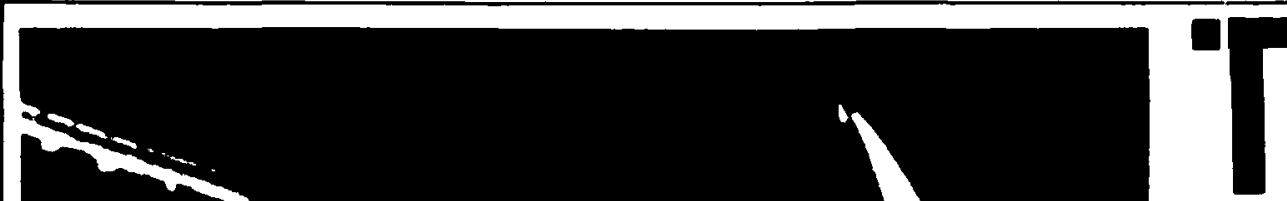

he U.S. Army Space Agency (USASA) was formed in August 1986 as a Field Operation Agency of the Office of the Deputy Chief of Staff for Operations and Plans (ODCSOPS), Department of the Army, and serves as the Army component to the United States Space Command (USSPACECOM), Peterson Air Force Base, Colo.

It was established to plan Army participation in and operation of space systems in support of the national space programs, and to ensure space support for Army strategic, operational and tactical forces. Most recently, it has been concentrating on developing space awareness throughout the Army (along with several other Army space offices), assisting Army forces in determining requirements for space support, coordinating these requirements with USSPACECOM, promoting the effort necessary to produce and maintain a useful and coherent Army Space Master Plan, and providing Army input to strategic defense planning.

In the future, the USASA has the charter to command evolving Army space and strategic defense operational elements and provide the personnel to work with the Air Force on satellite control and the Consolidated Space Operations Center (CSOC) at Falcon Air Force Base, Colo.

To satisfy the requirements of the operational and tactical commanders adequately, future Army space systems must be tailored, available, dedicated, and operated to support the AirLand Battle mission. Measurements of landpower must take into account all the geographic features, installations, and technologies that enable a nation to use force on land. Any technology or organization that plays a role in this exercise of landpower, landbased or not, is an instrument of landpower. This technology, when incorporated into the commander's force structure, will have a far-reaching effect on land force operating capabilities. ${ }^{1}$ The Army commanders cannot afford the interruption of vital information and data flow, nor be denied the use of space defense to support AirLand Battle plans. Therefore. the full range of beneficial space operations must be realized by the Army commander to capitalize on all com- 
D 0 D
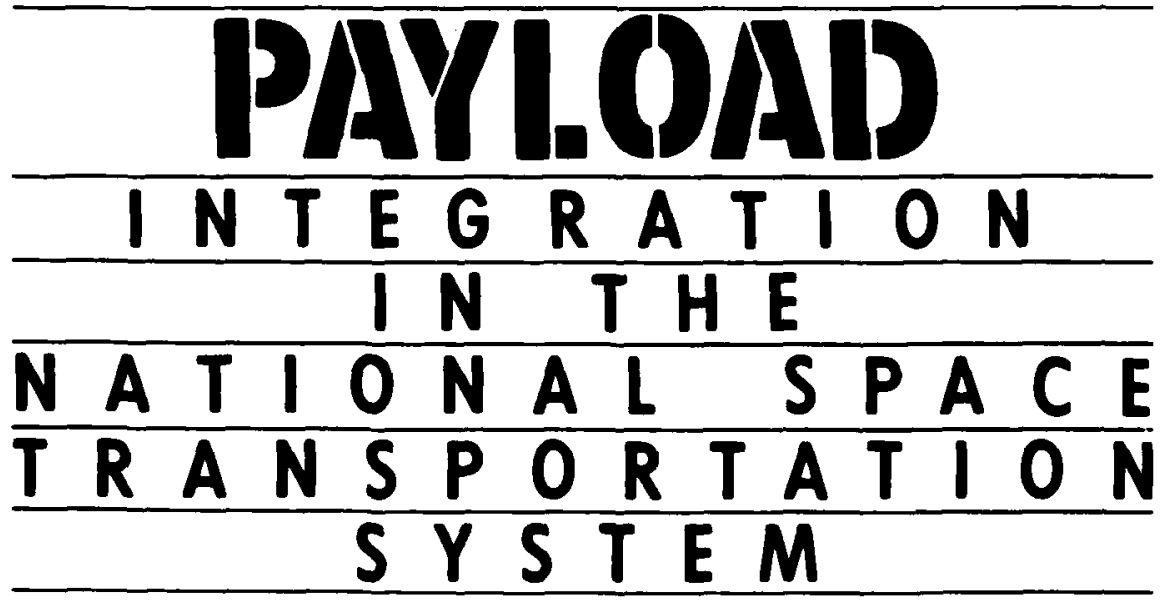

Major Linas Roe, USA

bat assets available to See Deep, Attack Deep, and Talk Deep. ${ }^{2}$ This advocates a set of Army-unique space systems designed to guarantee responsiveness to the War-fighter and tailored to the operational/tactical commander's AirLand Battle requirements.

The Army and national space assets must have an on-orbit delivery system which provides a reliable, low-cost delivery of a variety of satellite payloads into space, makes space more accessible to Army/DOD payloads. provides a technology base to ensure the nation's readiness to support space initiatives, ensures a system which can accommodate both simple and complex satellite payloads, and allows some degree of cooperative venture with other nations or industry in space exploration and commercialization. The current initiatives to ensure continuity of future DOD satellite systems revolve around a suite of expendable launch vehicles (ELV) and the National Space Transportation System (NSTS). The former is provided by the U.S. Air Force and the latter by the National Aeronautics and Space Administration (NASA); although, the USAF is chartered as the executive agent for DOD payload integration with NASA. The latter is principally addressed in this article.

The Air Force and the Navy have the organizational structure and experience-base, not only in design and development of their own service- tailored space systems, but the maturity to interface effectively with the payload integration and orbital delivery systems and organizations. The Army has been historically a customer/user of the space assets of other organizations. This approach served the Army during an era in which it preferred to remain a nonoperational controller/owner of satellite systems. ${ }^{3}$

With the advent of the USASA, more confidence with the satellite system operational community, and more confidence with a set of Army-unique system requirements, the greater need will surface to understand the payload integration community. Hence, the requirement exists to understand and describe the NSTS payload integration architecture and those payload accommodations which are available to the Army/DOD customers. This architecture and the accommudations it provides will ensure any perspective customer's satellite system processed through the NSTS will be properly handled.

\section{Payloed Accommodations} may use a number of different acommodations provided by the NSTS These payload accommodations will depend upon the complexity, environmental requirements, and intended employment of the Army satellite payloads. To the NSTS, the
The U.S. Army shuttle payloads words "payload accommodations" draw reference to three categories of services available for payloads: small, middle, and standard. Many payloads, including most of the communication satellites carried by the Space Shuttle, use the standard accommodations. The small payload accommodations are for cargo bay payloads which require significantly fewer services than those provided by standard accommodations. Some DOD customers are familiar with a sub-category of small payload accommodations called Get Away Specials (GAS), which are selfcontained experiments requiring a ride into space and no special services. The middeck accommodations are provided for payloads which require the pressurized crew compartment environment as a general rule, late stowage or early removal, or which benefit from the simplified nature of being available to direct crew operations. Accommodations other than those noted can be provided by the NSTS through negotiations.

\section{Payload Integration Architecture}

Fundamentally, the NSTS has established three processes which, when merged, will guarantee the Army payload customer of a streamlined and realistic approach to payload integration from initiation of plans to fly on the Shuttle to the deployment phase in space. The three processes have been identified as the Integration Process, the Review Process, and the Flight Process. All three linked together form an overall NSTS Payload Integration Architecture.

The NSTS Payload Integration Architecture will be tailored to support the Army payload customer through the establishment of a technical team of experts to provide an interface to the customer throughout the three processes. The team will be lead by a Payload Integration Manager (PIM). usually of ASI 3Y/3E/6T or the Civil Service counterpart, and will assist in preparing the Payload Integration Plan (PIP), defining the Interface Control Document (ICD) for the interfaces

- Major Roe series in the National Space Transportation Office at Johnson Space Center, Houston. Texas. He is Proiect Manager for design and development of two ser ondary communications payloads for integration into the Space Shutfle Or biter. as well as for ground systems 
defined in the PIP, gathering the necessary data via PIP annexes to configure the STS flight and ground systems, support the customer in proper interpretation of the safety requirements, and conduct reviews with the customer to interpret properly and implement flight requirements. For most DOD customers, the mechanism to secure this assistance will be via the STS Support Program Office in the U.S. Air Force Space Division, Los Angeles, Calif. Under certain circumstances, the Army may work directly with NASA in developing its integration plans, but in all instances the initial point-of-contact remains the USAF STS Support Program Office.

The National Space Transportation System is a national asset designed to serve civil and defense users in a manner consistent with applicable space policy directives, statutes, and executive orders. The NASA is responsible for the overall management of the NSTS. The DOD is the agency within the U.S. Government with the larger responsibility to represent national security interests in the NSTS and, therefore, is participating as a partner in its development, acquisition, and operations.

The DOD Directive 5160.32, September 8, 1970, designated the USAF as its executive agent (in broad terms) for the NSTS. This was followed with the signing of a joint memorandum of understanding (MOU) between the USAF and NASA. It defined the broad policies and principles that govern the relationship between the two organizations relative to the NSTS, and delineated their roles and responsibilities in its development, acquisition, and operation. The Army has surfaced as a .ninor participant in the NSTS through the astronaut program, SDI payloads, mission planning. flight operations, and the payload integration program. The Army role as a partner in future DOD/NSTS operations has been laid through the joint sponsorship of the United Space Command.

As the DOD uses of the primary and secondary payload capabilities of the NSTS continue to increase, the potential exists that the Army will find a number of primary and secondary payload programs desiring payload specialists on board the Shuttle to oversee and, perhaps, operate their payloads. This represents a natural evolution of the use of the Shuttle for the Army but requires clarification on flight manifest procedures and interfaces. The USAF, as the executive agent within DOD for the NSTS and the prime interface with NASA on matters affecting a particular or prospective NSTS mission, is most likely responsible to arrange the manifesting of any personnel required by primary or secondary Army payloads. The requirement for payload security and proper manifesting of the entire cargo and crew dictate that the single focal point established by DOD for interface with NASA be employed. This same focal point should make the job of any prospective Army-NSTS user easier by simplifying interfaces with NASA and, thus, should have benefit to both NASA and any prospective Army payload customer. The extent to which this applies will be dictated by the level of detail interface required with NASA and the complexity of the future Army-unique satellite systems.

\section{Integration Process}

The Integration Process encompasses those technical and programmatic activities which ensure the Army customer receives the full complement of support of the NSTS. It spans the full breadth of activities from the formulation of the Payload Integration Plan with supporting engineering annexes and ICDs and interleaves itself with the Review and Flight Processes to guarantee sufficient overlap and linkage to support the Army customer's requirements.

The PIP development process begins with pre-coordination discussions with the Army/DOD payload customer. The customer usually prepares a set of inputs to the PIP which defines the payload's structural/mechanical, avionics/electrical, thermal, EMI, launch-site flow, flight operations support, and ascent/orbital parametric requirements. From this input, the NSTS Office prepares a draft document which encompasses the payload and NSTS integration requirements and provides the format and general depth of content required for the particular payload. The draft PIP is distributed to the NSTS and the customer before the initial integration meeting at Johnson Space Center (JSC). The purpose of the initial meeting at JSC is to review mutually the draft PIP; and to familiarize the customer with the payload integration requirements flow and review processes. As a result of this initial meeting, the NSTS and the Army/DOD customer ensure that the resultant PIP is properly identifying the payload's orbital requirements and constraints, ground flow

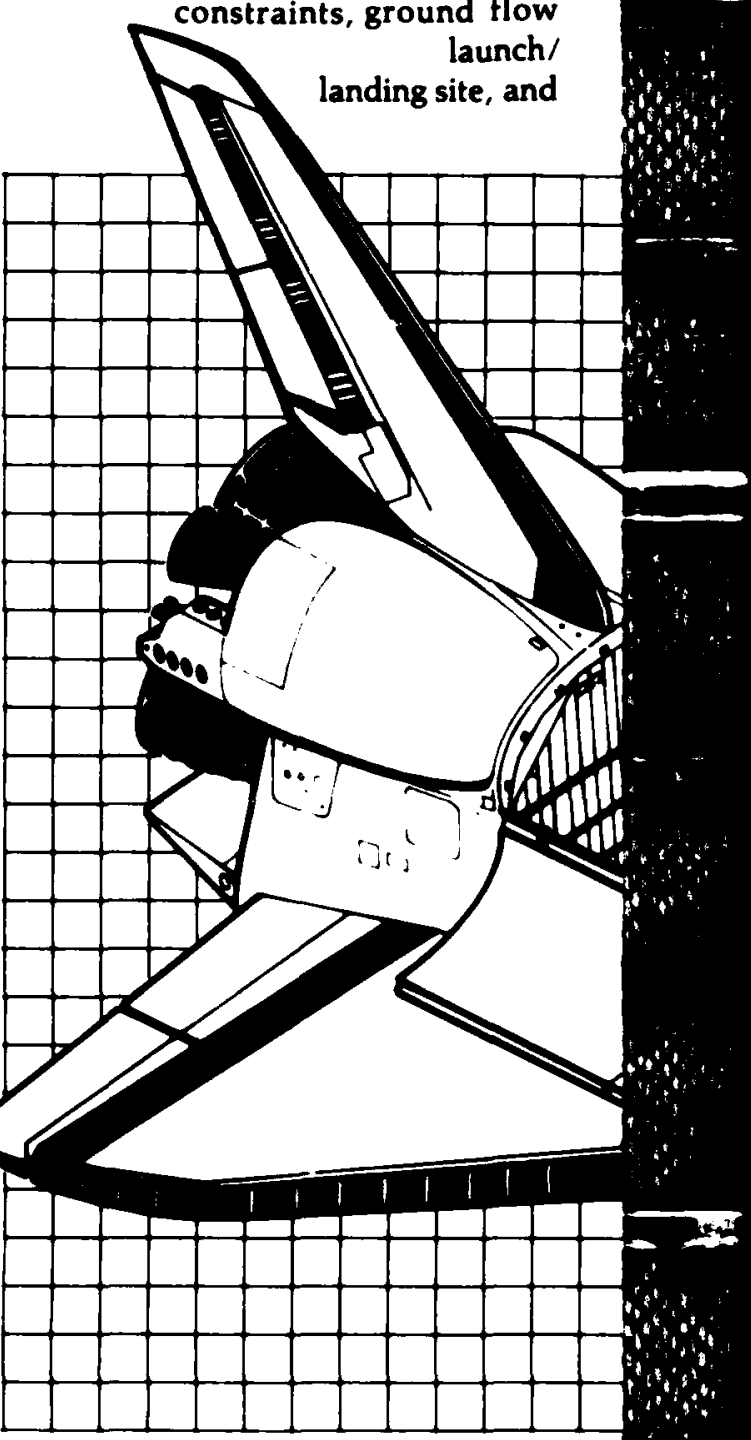

ing and operational analyses required to further define the STS/payload interfaces and optional/non-standard services. Additionally, development of the integration activities schedule is initiated. A second draft PIP is prepared based on results of this meeting. If necessary, further development of the PIP. interface requirements, and implementing data are accomplished by individual engineering working groups and by discussions between the NSTS payload integration manager and the Army/DOD Payload project manager. The engineering working groups encompass the following principal disciplines : 
-Structural/Mechanical Working Group

- Thermal Working Group

- Electrical/Avionics Working Group

-Ground Operations Working Group

-Flight Op/Flight Plan Group.

The resulting PIP, including preliminary pricing data, is prepared and distributed to

the customer for review and to the implementing NSTS organizations for information. Customer comments are distributed to the NSTS implementing organizations and a teleconference or meeting is scheduled, if necessary, to resolve any comments or issues. After the final PIP is approved and signed by the NSTS program office manager, the signature sheet is sent to the customer for approval. When the customer has signed

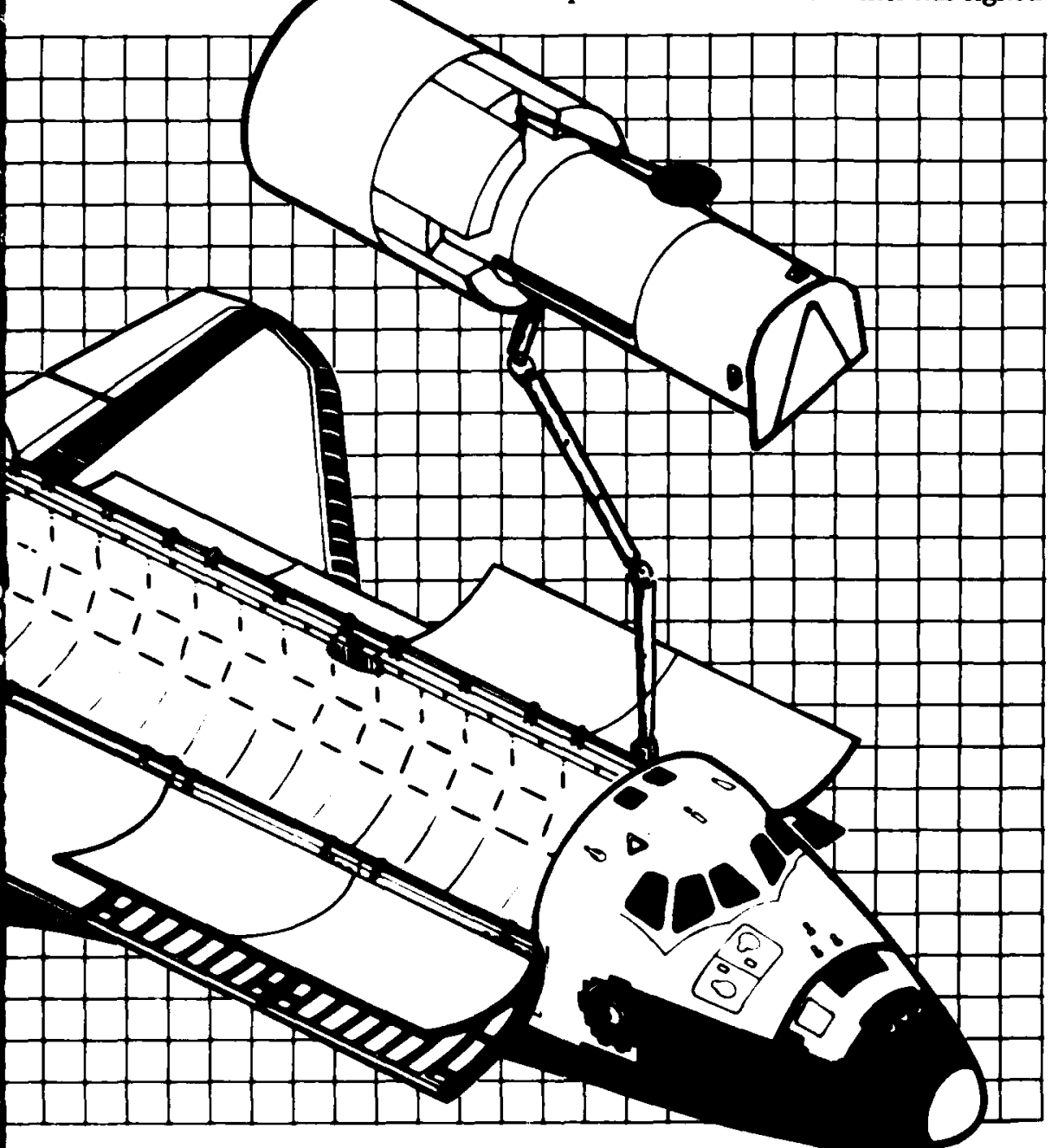

Fundamentally, the Integration, Review and Flight process are linked together to form an overall National Payload Integration Architecture. the signature sheet, the PIP is distributed for implementation to NSTS organizations, NASA Headquarters, and the DOD Payload customer. This sets the stage for the next activity in the Integration Process-formulation of the interface control document.

The Interface Control Document defines the detailed design interface specifications for Payload-to-Shuttle operations. As in the case of PIPs, "generic/standard" interface definition documents (IDD) are available for small, middeck, or standard payloads and are being used as ICDs in today's integration process. From these generic/standard IDDs, the NSTS prepares a draft IDD with data provided by the Army/DOD customer. The draft is distributed to the NSTS and the DOD customer's organization before the initial ICD engineering working group meeting at the Johnson Space Center. At this meeting, various sections of the ICD are reviewed in depth, corrected, and submitted to management for approval. The working groups are principally as delineated in discussion of the PIP review with the exception of the addition of a Crew Station/Crew Interface Working Group. Once approval is secured, the NSTS Cargo Engineering Office and the Army/DOD Payload Program Office sign the ICD for baselining.

As an inherit element of the ICD and flight compatibility assessment process, key engineering analyses are conducted by the NSTS and DOD payload customers to ensure that the interface environments are within the agreed limits and do not exceed the Shuttle's capabilities. These analyses principally govern software tapes built for the Shuttle and Mission Control Center (MCC) operations, structural/mechanical loads, and thermal predictions. All are extremely important from a mission safety standpoint to guarantee a successful flight. Subsequent to the formulation of ICD/IDDs and supporting many of the engineering analyses are the preparation of several key supporting annexes of the PIP.

Annexes to the basic PIP are established as the method for each DOD customer to provide detailed data required by the NSTS to configure flight and ground systems and to provide a mechanism for implementing other integration functions highlighted in respective sections of the PIP. The PIP annexes are delineated as:

-Annex 1: Payload Physical Data

-Annex 2: Flight Planning/Trajectory Data

-Annex 3: Flight Operations Support (plans, procedures, checklists, schematics)

-Annex 4: Command and Data Characteristics

-Annex 5: Payload Operations Control Center Services/Interfaces 


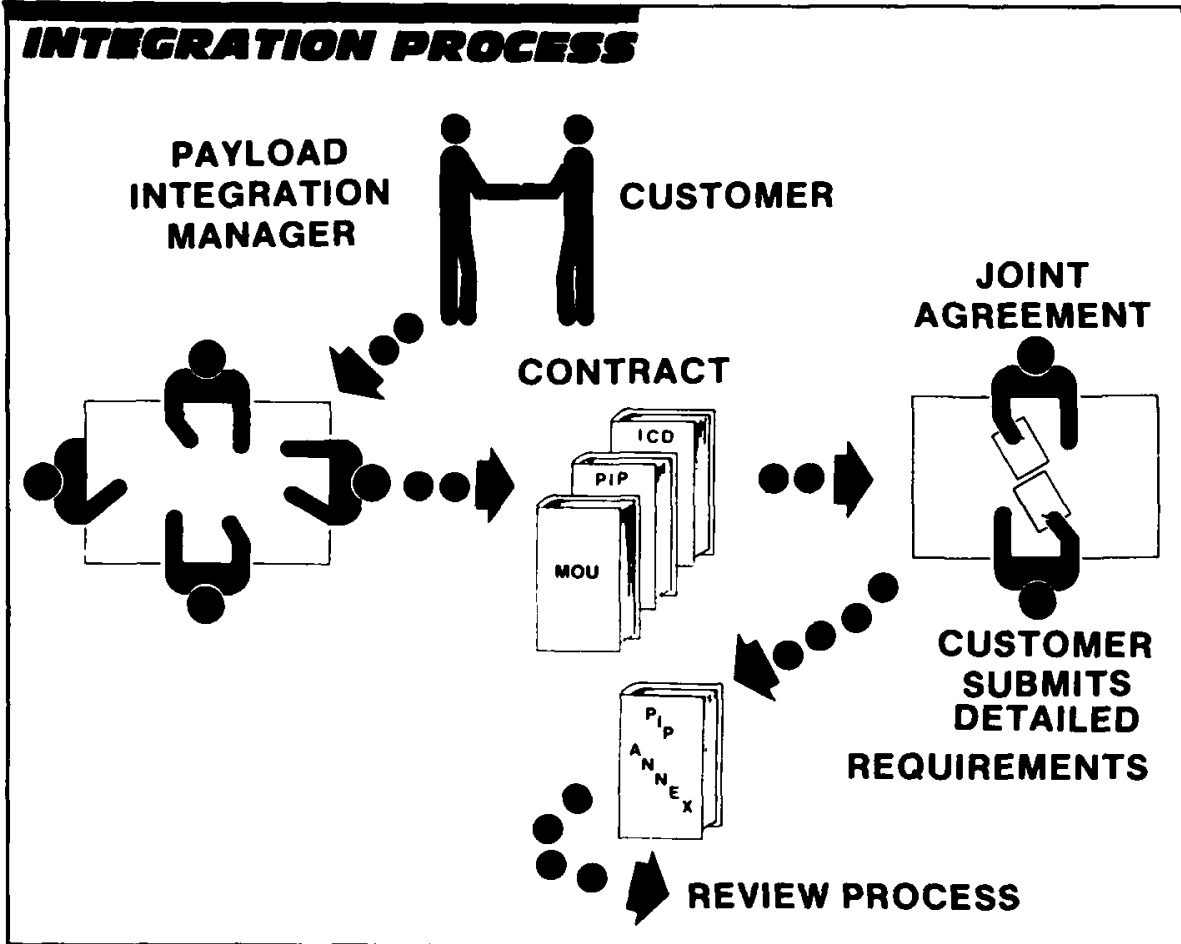

-Annex 6: Orbiter Crew Compartment Layout/Nomenclature

-Annex 7: Training Facility/Simutions

-Annex 8: Launch Site Support Plan (KSC or VLS)

-Annex 9: Payload Interface Verification/End-to-End Testing

-Annex 10: No Longer Used

-Annex 11: Extravehicular Activity (EVA) Interface/Operations Definition.

To facilitate development of required annexes, a standard format is provided by each annex to assist the Army/ DOD customer in preparing inputs. Payload data from these annexes are used by the NSTS to, in turn, prepare the standard flight and ground operations procedures for implementation. Detail of data in the annexes is a function of the complexity of a given Army payload. The delivery dates for the annexes are defined in the payload schedule section of the PIP.

\section{Review Process}

Inherent in the NSTS Payload Integration Architecture and integrated with the Integration and Flight Processes is a Review Process. It is principally impacted by a number of safety, integration, and flight reviews designed to serve as the watchdog mechanism of the Architecture.
The NSTS payload safety review panels are established to assist the Johnson Space Center NSTS Program Office and the KSC Director of Safety in their responsibility for safety. The safety panels, chaired by JSC and KSC, as applicable, ensure the phased safety aspects of payload design, flight operations, ground support equipment (GSE) design, and ground operations are reviewed. Phased safety reviews are normally conducted at four levels of payload design maturity: Phase $\mathrm{O}$ identifies hazards at about the time of the payload's System Requirements Review (SRR); Phase I identifies hazard controls at about the time of the payload's Preliminary Design Review (PDR); Phase II verifies design and implements controls at about the time of payload Critical Design Review (CDR); Phase III verifies hardware asbuilt and implements controls at about the time of payload hardware delivery. The objectives are to verify the incorporation of all previous safety review agreements, ensure completion of all safety activities, and agreement to proceed to the Cargo Integration and Flight Reviews.

A Cargo Integration Review (CIR) is held approximately 10 months before flight to ensure that the payload(s) selected to make up the cargo can be physically and functionally integrated into a flight which is within the NSTS flight and ground capability. Additionally, the CIR establishes the baseline flight event sequence and provides the Army/DOD customers with insight into the integration of their requirements at the cargo/mission level. The cargo/mission level constitutes all payloads which fill the cargo bay of the Shuttle; this gives rise to a mission number such as Mission 51L. The CIR is chaired by the NSTS program office manager with board members from the

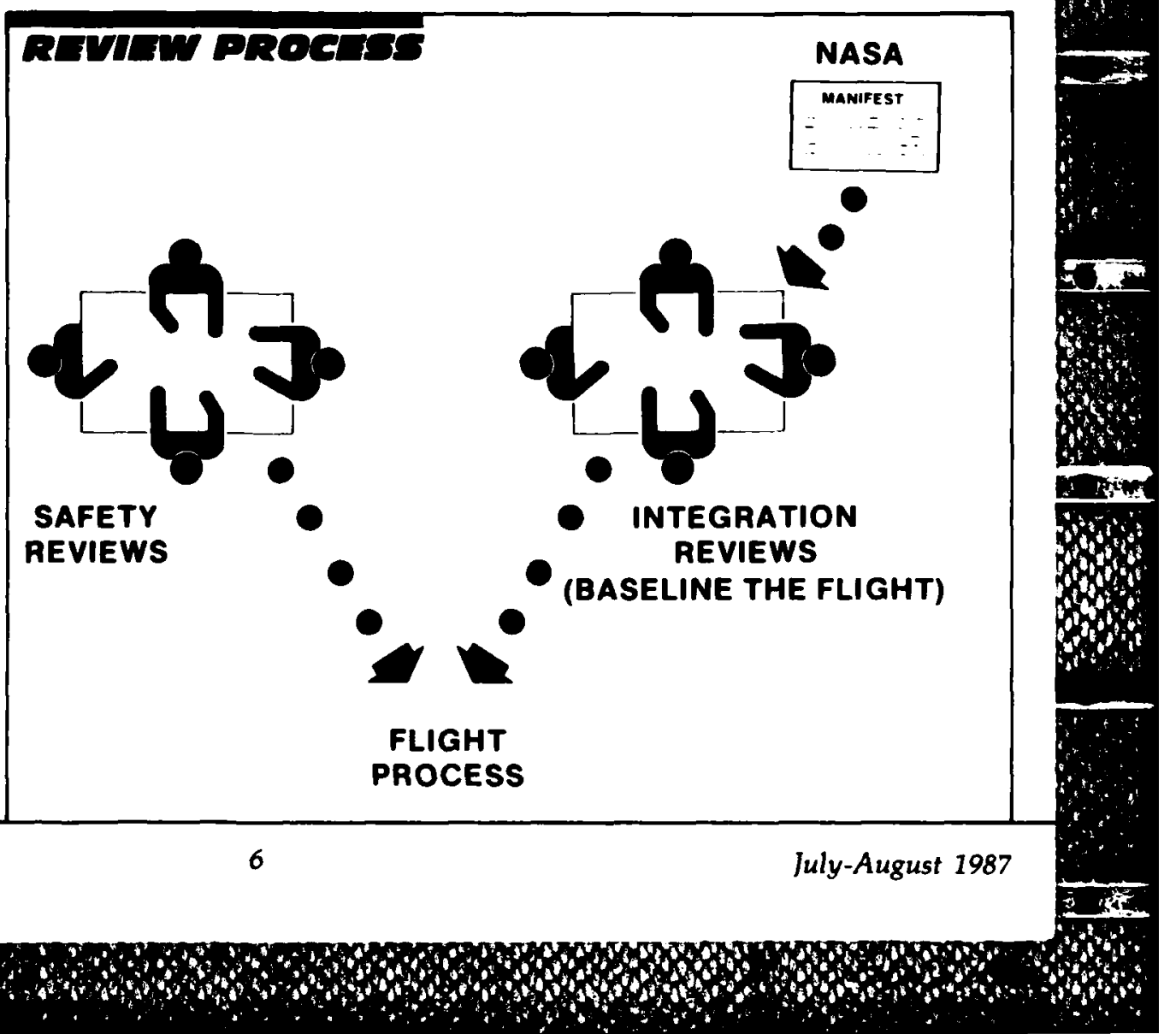


NSTS elements and the customers. The results of the CIR provide the implementing organization with the basic engineering, operational, and support guidelines to initiate the flight and ground implementing activities. A flight implementation schedule is prepared which contains the dates when key implementing documents, reviews, verification ${ }^{4}$ and analyses, and hardware and software are to be provided.

The purpose of the Flight Operations Review (FOR), conducted at approximately I.-3 months, is to determine the status of the NSTS flight operations implementation and to ensure that the astronaut crew training requirements are being met. Additionally, the FOR will validate if the $\mathrm{MCC} /$ Payload Operations Control Center (POCC) facilities, to include operational documentation, will be ready to support the final phase of training of astronaut crew and flight operations support personnel. The POCC is the payload-unique facilities used by the payload customer to control his spacecraft after deployment.

\section{mLVMT PROAFBs}

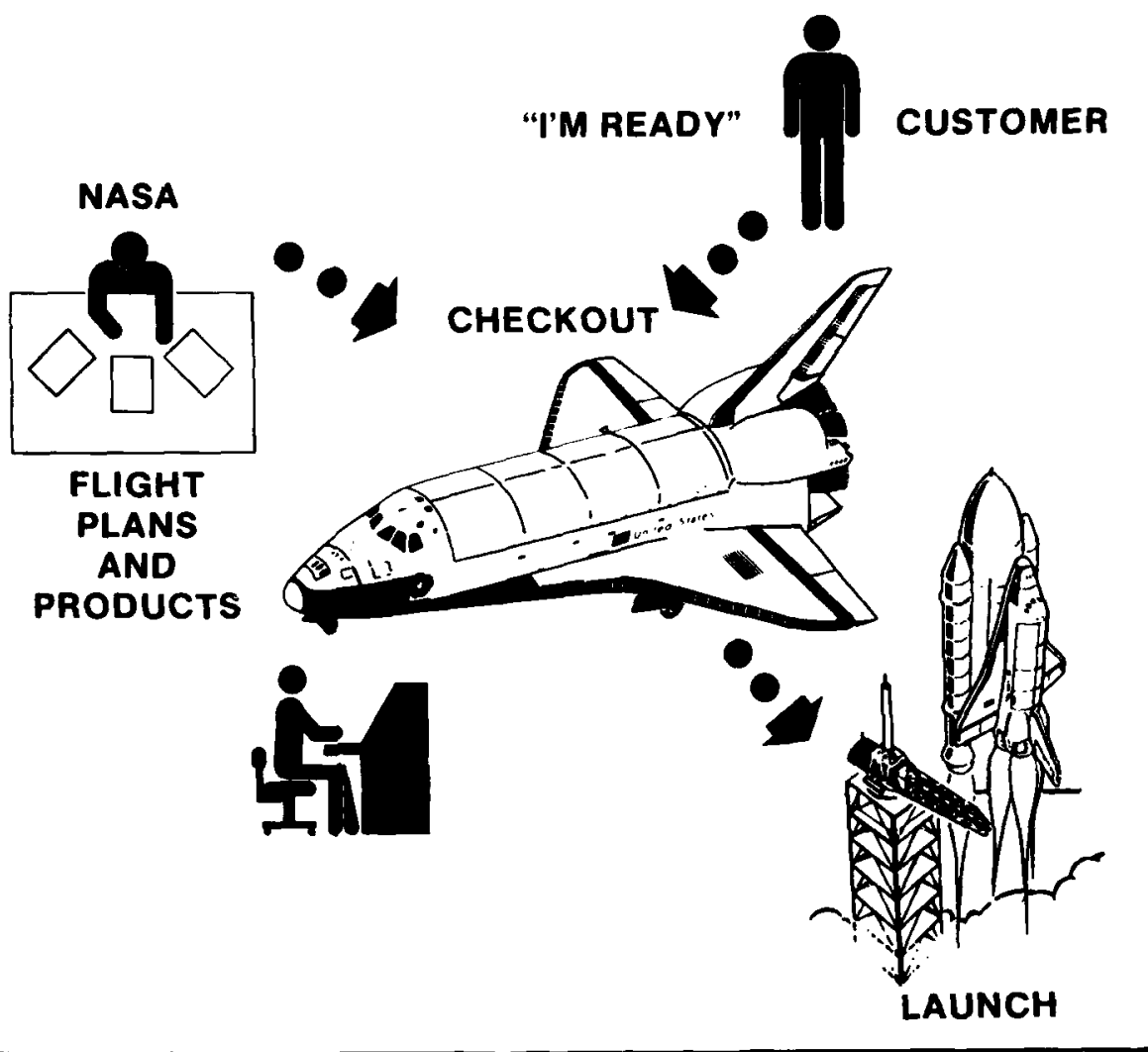

hOM LONG IT TARTES

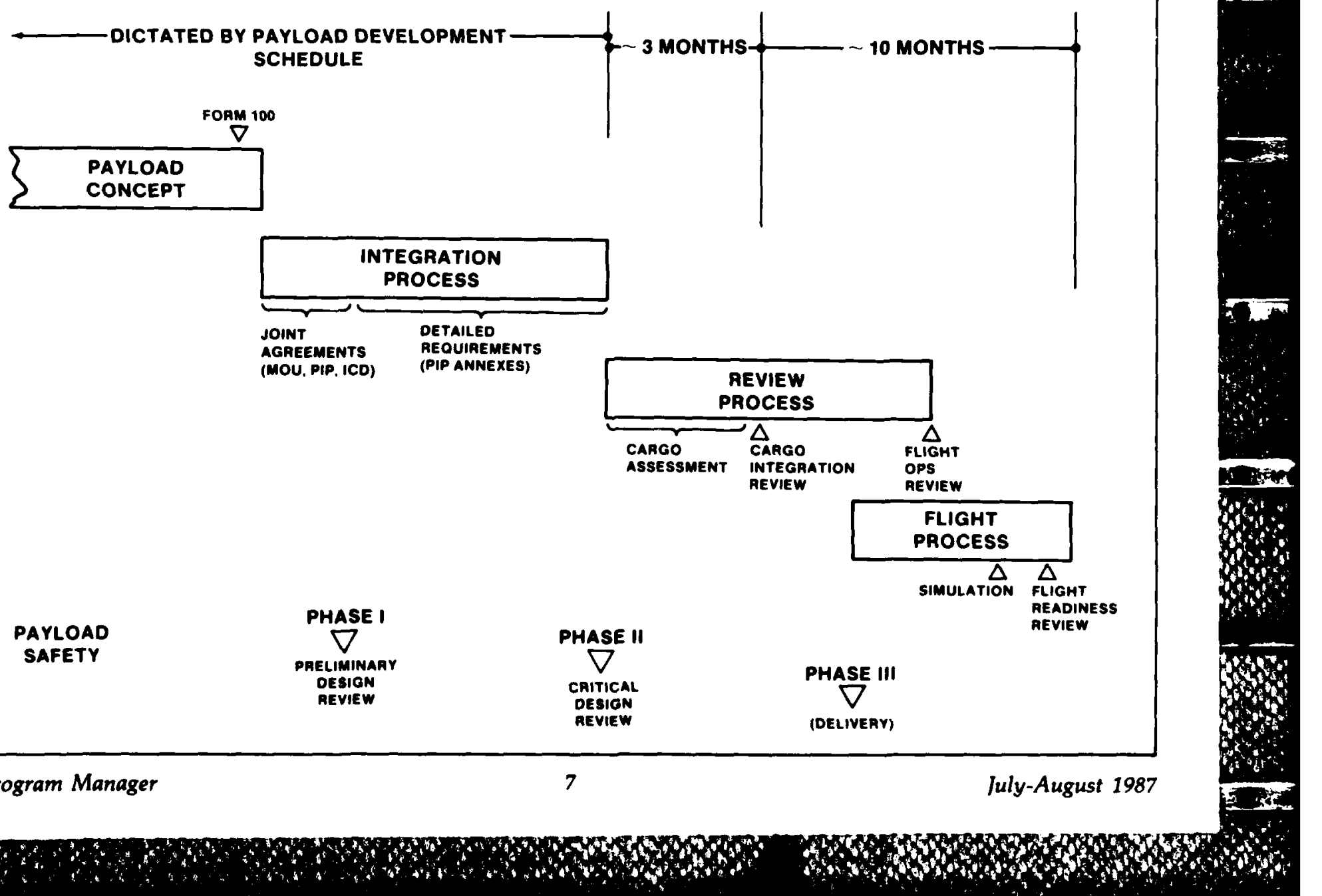


The Flight Readiness Review (FRR) is conducted at approximately L-1 month to verify that all cargo integration activities are complete and to certify that all flight elements are ready to perform the mission. Before the FRR, the Army/DOD customer and NSTS determine and verify their respective readiness to launch. The FRR is conducted by NASA Headquarters and is supported by all of the major NSTS elements. The cargo integration/safety assessment is presented by the Shuttle Integration and Operations Office.

\section{Flight Process}

The NSTS Flight Process is the last link in the Payload Integration Process but remains closely interleaved with the Review Process and carries through to deployment. After deployment, the nominal role for the NSTS largely ends unless a stationkeeping or contingency requirement exists. It begins with the delivery of the customer's payload to the Shuttle Payload Integration Facility (SPIF) at the Cape Canaveral Air Force Station (CCAFS). The SPIF is nominally the first stop in the ground flow process at the launch site for a primary payload. It is the location at Cape Canaveral where payload servicing, testing, and preparation for transport to the launch pad occurs.

The servicing usually entails the careful removal of the payload from its transport container and transfer to a servicing cell where the payload can be processed by the payload/spacecraft integrating contractor, either in a vertical or horizontal configuration. The length of time of processing in the SPIF is a function of spacecraft complexity, but a customer might expect something on the order of 1 month's time. The type of servicing also is a function of the spacecraft complexity, but normally it involves the validation testing of avionic circuitry, clocks, gyros, antennas, solar cells, structural integrity, and propellant loading of reaction control system and main orbital adjust thrusters or upper stages. Many DOD customers typically receive an end-toend validation test of the simulated command and telemetry nets from the spacecraft to the POCC and MCC, and return. When the spacecraft contractor's mission in the SPIF is complete, the payload/spacecraft is closedout and placed in a payload canister for transport to the launch pad.

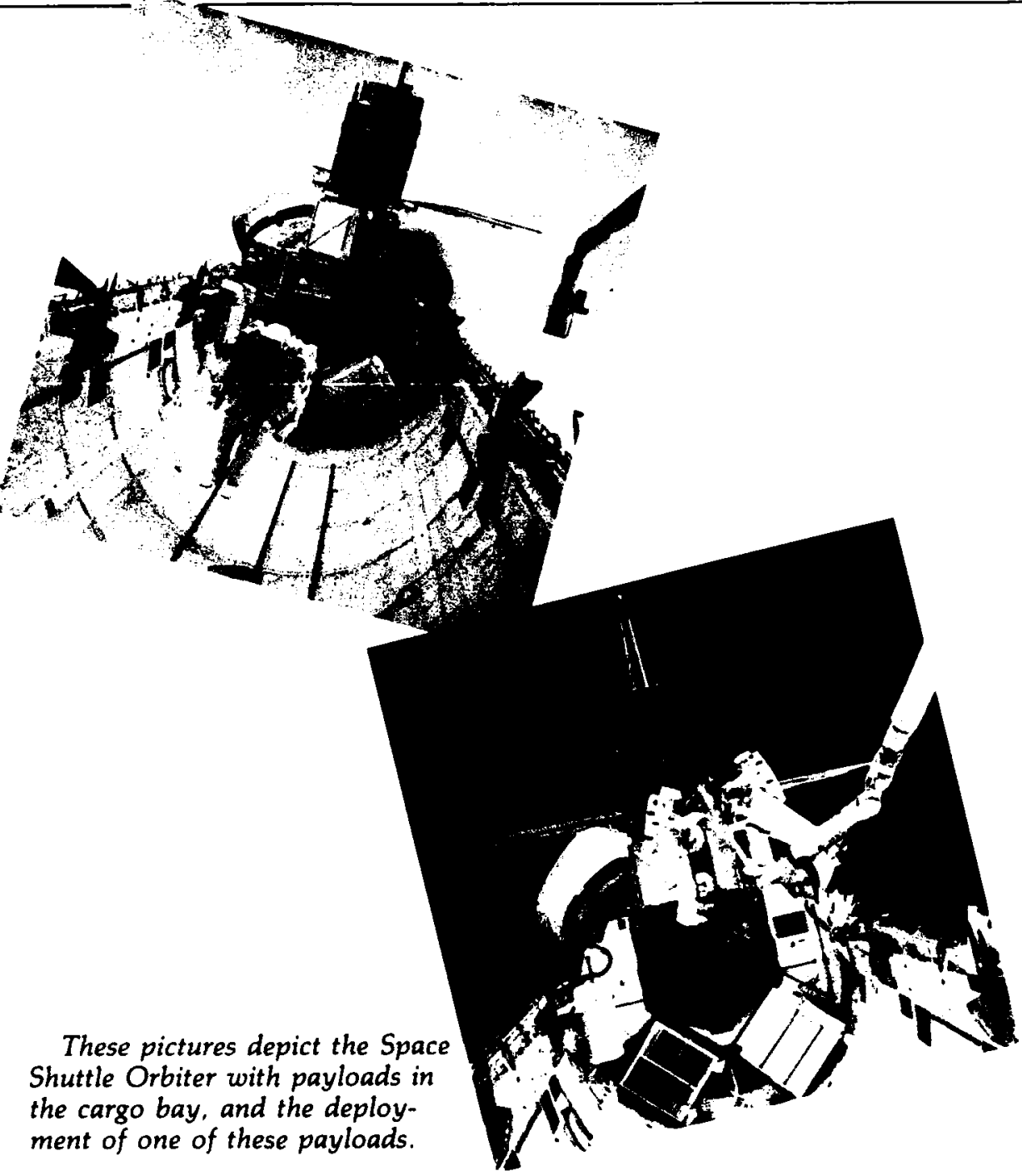

The typical launch site ground flow requires the payload to arrive at the launch pad several days in advance of the Shuttle Orbiter. This scenario allows for any final payload processing/testing to occur so that when the Shuttle arrives, the combination will be ready to launch in approximately 2 days. The spacecraft is transferred from the payload canister to the payload changeout room (PCR) via the payload ground handling mechanism (PGHM) on the launch tower. Once in the PCR, cargopeculiar testing and checks can be completed.

When the Shuttle-Orbiter arrives at the pad, it begins its closeout servicing and propellant loading. The spacecraft/payload is again attached to the PGHM for retraction from the PCR and transferred to the cargo bay of the Shuttle where it is secured for launching, mechanical closeout, protective cover removal, final switch settings, and Orbiter-payload interface verification testing occurs. Upon completion of this testing, the cargo bay doors are closed to the Shuttle. Once this is complete, the payload should be capable of remaining in this configuration indefinitely without creating any hazards or requiring additional servicing.

To assist the Army/DOD customer in preparing for the launch site flow, the Kennedy Space Center and the USAF Aerospace Test Group conduct several ground operations and payload working group meetings. These sessions are supported by the integration contractor and DOD program office responsible for integrating the payload. These groups work together in a joint forum to produce the required documentation, procedures, safety monitoring, coordination, and flight readiness reviews to ensure a successful launch. 


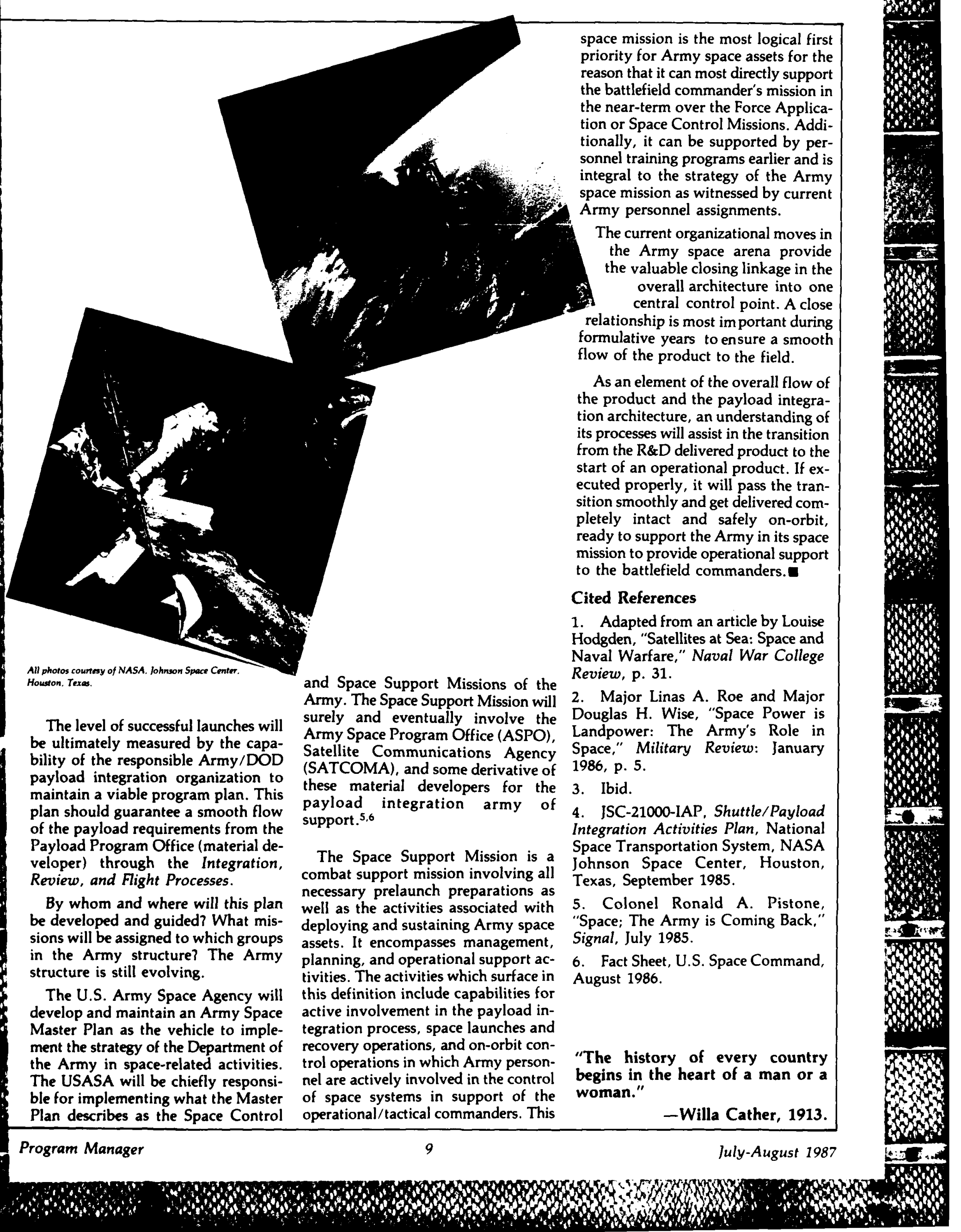


he United States Widget Bureau is a hypothetical organization in the federal government. The structure and mission resemble those of bona fide agencies. Analysis of this agency's functions should provide insight into management problems.

For our purpose here, the Widget Bureau is a commodity management agency responsible for satisfying the Department of Gadgetry's material requirements. Personnel are inventory managers, controllers, engineers, production specialists, and procurement specialists. There also is a staff common to most organizations, consisting mainly of personnel and management specialists. Responsibilities will be discussed and those of production and the procurement specialists will be examined in detail.

Two particular characteristics of any organization will be analyzed while studying the Widget Bureau and its procurement activity. Attention will be given to the separation of the planning and implementation processes; and to informal power relationships and how this affects planning and implementation processes.

What is the meaning of these characteristics? Division of labor, a modern phenomenon, contributes to the growth of the industrial economy, but poses problems of its own. A special attempt should be made to understand and overcome problems created by the division of labor; particularly, processes of planning and implementation are separate and distinct. As a result, the planner and implementor are not in the same immediate work unit.

This separation presents a communications problem, because a planner wishing to know thoughts and behavior of the implementor (or vice versa) must make an extraordinary attempt to communicate and, in the end, doesn't have to live with the plans. Furthermore, if the final approach to problem resolution is to resemble the course of events specified in the plan. it will be necessary to coordinate the transition from planner to executor.

Division of labor provides the planner with authority to analyze a given problem and develop a theoretically
RELATIONSHIPS

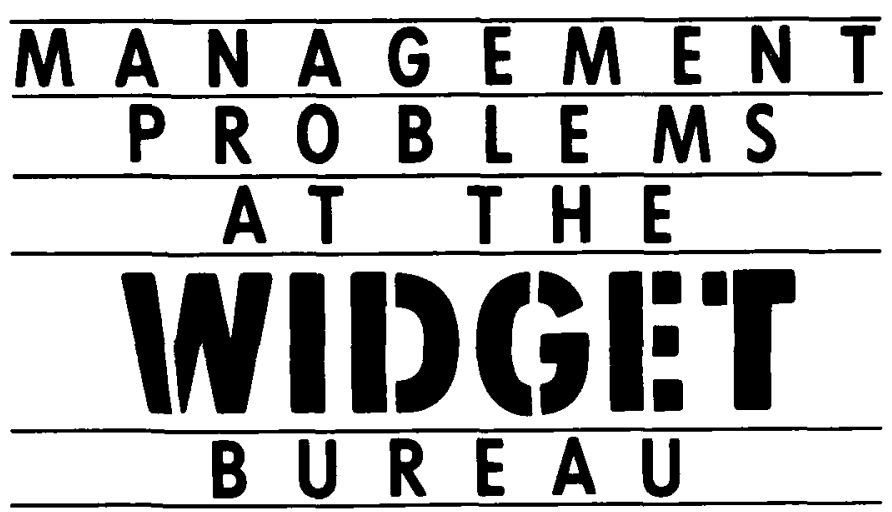

Charles J. Modzinski

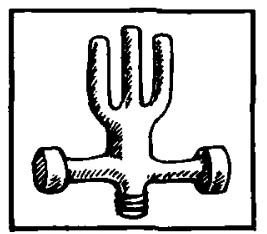

Widget: an unnamed article considered for purpose of hypothetical example. Webster's Ninth New Collegiate Dictionary, 1983, p. 1348.

desirable approach to solve it. Planning, as Simon, Smithburg, and Thompson assert, is:

...that activity that concerns itself with proposals for the future, with the evaluation of alternative proposals and with the methods by which these proposals may be achieved. Planning is rational, adaptive thought applied to the future and to matters over which the planners, or the administrative organizations with which they are associated, have some degree of control. ${ }^{1}$

Planners, with no control of what they "plan for," examine the problem via an ivory-tower approach, prescribing the most prudent course of action.

Division of labor provides the implementor with the responsibility to confront the problem and find a solution. The implementor may not have the time or information to address the problem in a rational fashion as did the planner, and may not be able to examine all solutions. Because of constraints on resources, the implementator may settle for a solution not acceptable to the planner.
For the planner or implementor to be effective, they must understand each other's job by working together. Douglas Bunker, expanding coordination of effort, maintains that:

A high degree of integration of the administrative staff in the policy process facilitates implementation because it allows for the generation of understanding and commitment through participation, provides for lead time in the development of operating capacity, and improves linkage for subsequent feedback. ${ }^{2}$

This need for interaction between planners and executors leads to the next organizational characteristic to be studied: informal power relationships.

Informal power, not easy to define, may best be described as influence exerted without reliance upon formal or legal authority. It is necessary to understand the meaning of power and its formal use. Power is defined as "the capability of doing or accomplishing something; the possession of control or command over others; authority." ${ }^{\prime 3} \mathrm{~A}$ political scientist attributes more to power than does the layman and the following is a definition offered by Dr. Eugene Kolb: 

if he can obtain funds and confers with the controller; succeeding, he sees the procurement specialist, who will ask the engineer to prepare a package outlining physical characteristics of the item. Now, the procurement specialist solicits industry and if a satisfactory offer is received awards a contract. The item ultimately enters the Widget Bureau's inventory.

This is a simplified explanation of functions. Much is done before this actually takes place because the inventory manager cannot go to the controller and expect to receive money for every requirement. The inventory manager, controller, procurement and production specialists, and engineer must budget for these anticipated requirements.

In budget preparation, each must answer questions. The inventory manager must decide at what point, if ever, it will be necessary to replenish certain widgets; also, which widget types should receive a higher priority. The controller must decide the amount of money to budget for these widgets. The engineer must determine if a widget should be redesigned. The production specialist must determine how the widget will be procured, and how long it takes to buy, produce, and place in the inventory. This is the planning process, which will be further examined in the budget review.

\section{Budget Review}

Representatives from the Department of Gadgetry and the Widget Bureau attend semiannual budget reviews. Primary participants from the Widget Bureau are the inventory manager, controller, engineer, and production specialist. It is essential for the Widget Bureau to prove the need for programs so that the Department of Gadgetry may do likewise when submitting the budget proposal to the U.S. Office of Management and Budget (OMB). Representatives from the Department of Gadgetry and the Widget Bureau must be prepared to answer questions that OMB, the President, and the Congress might ask. Answers are formulated during these semiannual reviews.

The inventory manager, before budget review, determines items to be included in the agenda, essentially proposing only items that may require a new procurement; the inventory

\section{FIGURE I. THE WIDGET BUREAU}

\section{EXECUTIVE}

OFFICE
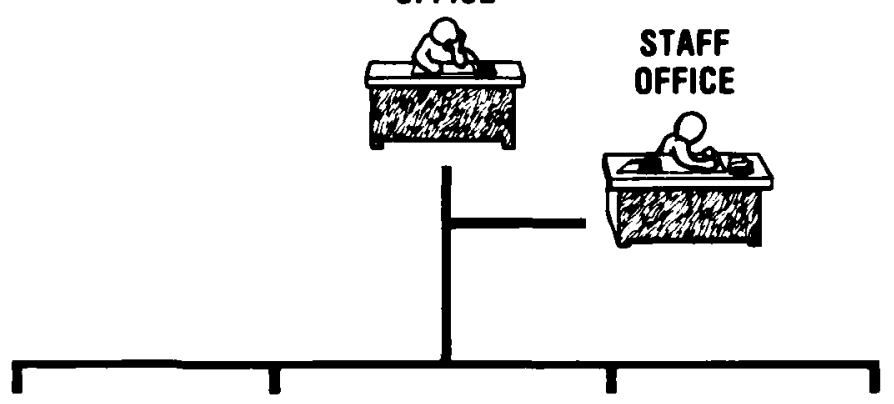

\section{INVENTORY MANAGEMENT ACTIVITY \\ ENGINEERING ACTIVITY}

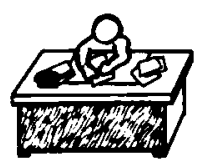

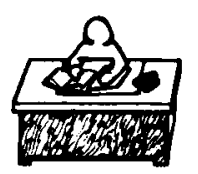

\section{CONTROLLER ACTIVITY}

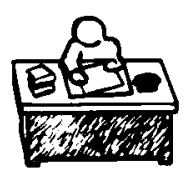

PROCUREMENT ACTIVITY

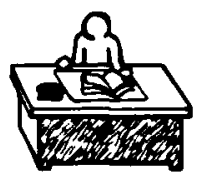

manager compares inventory objective, determined by an office within the Department of Gadgetry, with the assets in his inventory. If the manager's inventory is below his objective, he will propose a procurement to increase his asset level. The inventory manager makes this assessment for the budget year and for the following year.

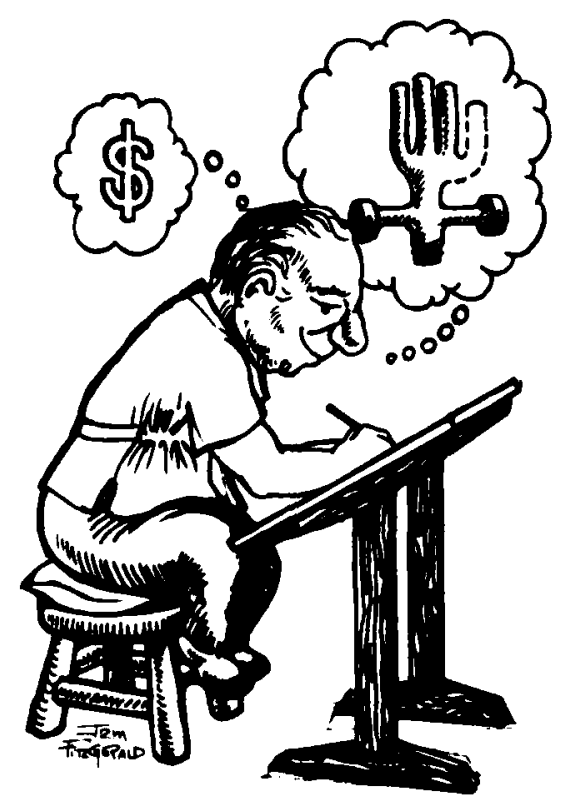

WIDGET ENGINEER
The controller obtains from the inventory manager the list of items that will be proposed for funding and determines the budget cost for each. To arrive at these costs, he may consult the procurement specialist for procurement history, and the engineer for required engineering effort. With all the data, the controller forecasts the item's cost in the budget and for the subsequent year. This forecast is based on a table of indices published by an office within the Department of Gadgetry specializing in projecting price changes that may occur.

The engineer determines if a specification can be prepared suitable for procurement and finds the cost of the engineering support required to procure the item proposed in the budget. If specification is not forthcoming, the budget proposal will be postponed.

The production specialist will prepare plans for each item on the agenda and outline how each will be procured and delivered. In preparation, he may supply the controller with cost data based on a previous procurement. The procurement plan affects content of the budget for it may recommend that funds be programmed for 2 years. This would be done when a multiyear contract would be economical. 
Work of each specialist helps determine items that will be included in the final agenda for budget review. Up to this point, much decision-making was based on measurement of objective criteria. During the review, however, when demands must invariably be reduced, the decision-making process may not rely upon measurement of objective criteria. It may be necessary to make trade-offs. In another instance, but not in this one, it would be interesting to analyze the decisionmaking processes of the budgeting system.

With general functions of the Widget Bureau and the budgeting process summarized, let's proceed to an in-depth analysis of the procurement mission. The gap between planning and implementing and of informal power will be addressed.

\section{The Procurement Activity}

The Procurement Activity is responsible for obtaining materials the Widget Bureau must supply to the Department of Gadgetry. The Procurement Activity has personnel and regulations responsible for purchasing an item from a commercial vendor to satisfy government needs. Commercial widgets don't need drawings. After receiving a purchase order, the procurement specialist must solicit proposals from industry and award a contract to the lowest bidder.

There are procurement specialists, production specialists, price analysts, budget analysts, policy analysts, and a small staff office (see Figure 2). Only those involved directly with planning an $l$ implementing a procurement will be discussed so that procurement specialists and production specialists can be examined closely. The gap between the planning and implementation phases of the procurement activity will become evident; you will see the presence of informal power relationships existing within this vacuum.

\section{Planning}

The production specialist is responsible for attending semiannual budget reviews and preparing most supplementary documents to support budget submission. This function is assigned to a few production specialists; other production specialists are involved in contract administration. These few collect information from other elements within the procurement

\section{PRODUCTION SPECIALIST}

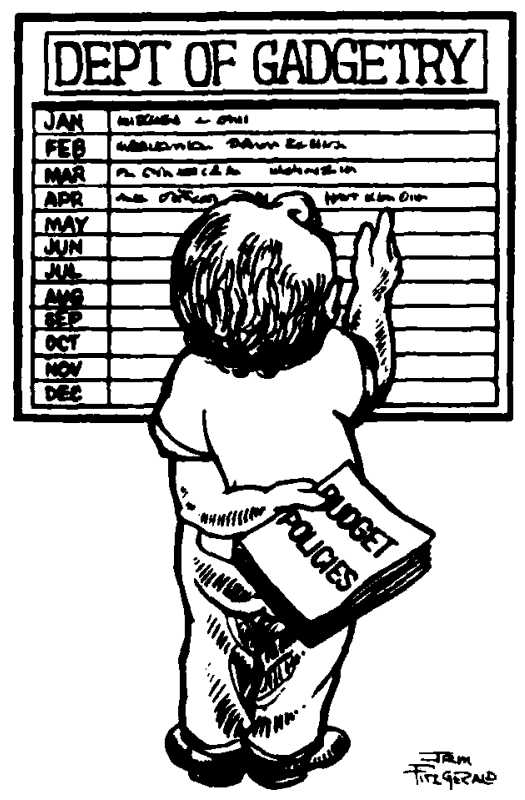

activity and have data ready for the budget review, where opinions of the production specialist are interpreted as the policy of the procurement activity.

The production specialist is responsible for determining how an item will be procured and how long it will take to be delivered. Policies addressing planning the budget help the planner to determine the nature of the contract. These policies are designed to help the Widget Bureau plan an economical procurement schedule. The planner, whose schedule could affect the Widget should interact. The procurement specialist should be consulted if the plan proposed at the budget review is to be realistic. Once this need for interaction is perceived, the first step is taken to form an informal power relationship.

Even though not directly involved in planning, the procurement specialist may demonstrate considerable influence by virtue of expertise. Not only is power informal, but meetings are informal. The production specialist uses discretion and may incorporate the procurement specialist's suggestions. The greater the implementor's informal power, expertise and reputation, greater is the chance the planner will use the suggestions.

This coordination by planner and implementor does not always happen. If there is antagonism, the planner may not solicit the executor's recommendations even though other attributes of informal power are present. Remember, personality constitutes informal power. Again, there are no formal guidelines or powers directing the planner and implementor to overcome personality conflicts. Personality conflicts are present in the procurement activity of the Widget Bureau, but this is not a significant disruption of informal power relationships. The greatest obstacle the planner must overcome to obtain recommendations and maintain an informal power relationship is getting the executor to exercise informal influence.

\section{The greater the implementor's informal}

power, expertise and reputation, greater is the chance the planner will use the implementor's suggestions.

Bureau's budget proposal, may submit that rather than spreading the widget requirements over 2 consecutive years and 2 contracts, it may be less expensive to procure the item in a single year under a single contract. This would be contingent on availability of funds.

The planner's guidelines do not dictate consulting people procuring the item. Nothing, technically, precludes the planner from using past experience and intuition. Although guidelines do not instruct the production specialist to consult with the procurement specialist, common sense suggests they

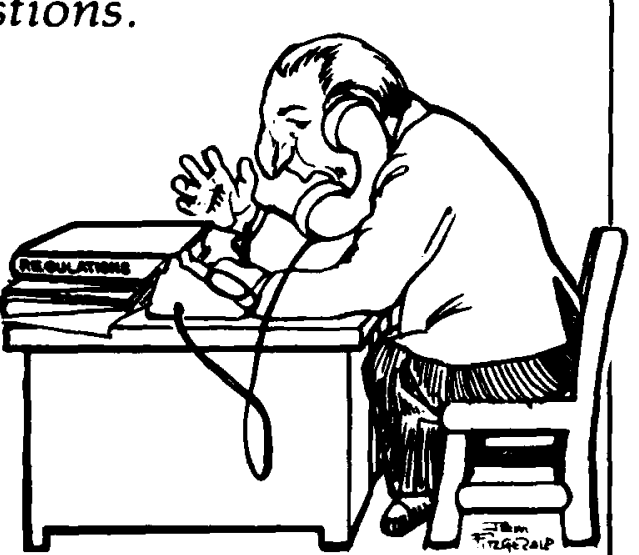

PROCUREMENT SPECIALIST 
The production specialist may not be able to consult with the procurement specialist because the latter may be indifferent to the production specialist's needs. This problem is inherent in the organizational structure because:

...the rest of the organization is pre-occupied with day-to-day problems and (it) gives insufficient attention to the long-range problems....Administrators preoccupied with everyday concerns may not wish to be disturbed by the planning unit, and may attach great weight to the shortterm inconvenience of making planned changes, even if longterm benefits can be demonstrated. 6

The production specialist encountering this resistance continuously either prepares the plan without consulting the procurement specialist or resorts to using informal power or influence. The production specialist may obtain recommendations of the reticent procurement specialist by cultivating friendship or convincing the procurement specialist of problems in the future if there is no cooperation. These roles can be reversed.

During this planning process, the production specialist used informal power based on personality and perceived status to obtain procurement specialist assistance. The procurement specialist used informal power based on special knowledge and skill to influence the procurement plan. When the implementation process is studied. it will be seen that these roles will be reversed; that is, the procurement specialist will seek to obtain assistance and knowledge of the production specialist, but not of the same one doing the planning.

\section{Implementation}

After a budget has been approved by the Congress and the President. funds are apportioned to agencies at the start of the fiscal year. Funds are distributed from the Department of Gadgetry to its subordinate agencies. like the Widget Bureau, where controlkers regieter the money. The inventory manager formally submits a request for funds to increase the inventory. The controller assigns the apportioned money to the given requeat sent to the procurement activity.

FIGURE 2. PROCUREMEWT ACTIVITY -PERSOMUEL

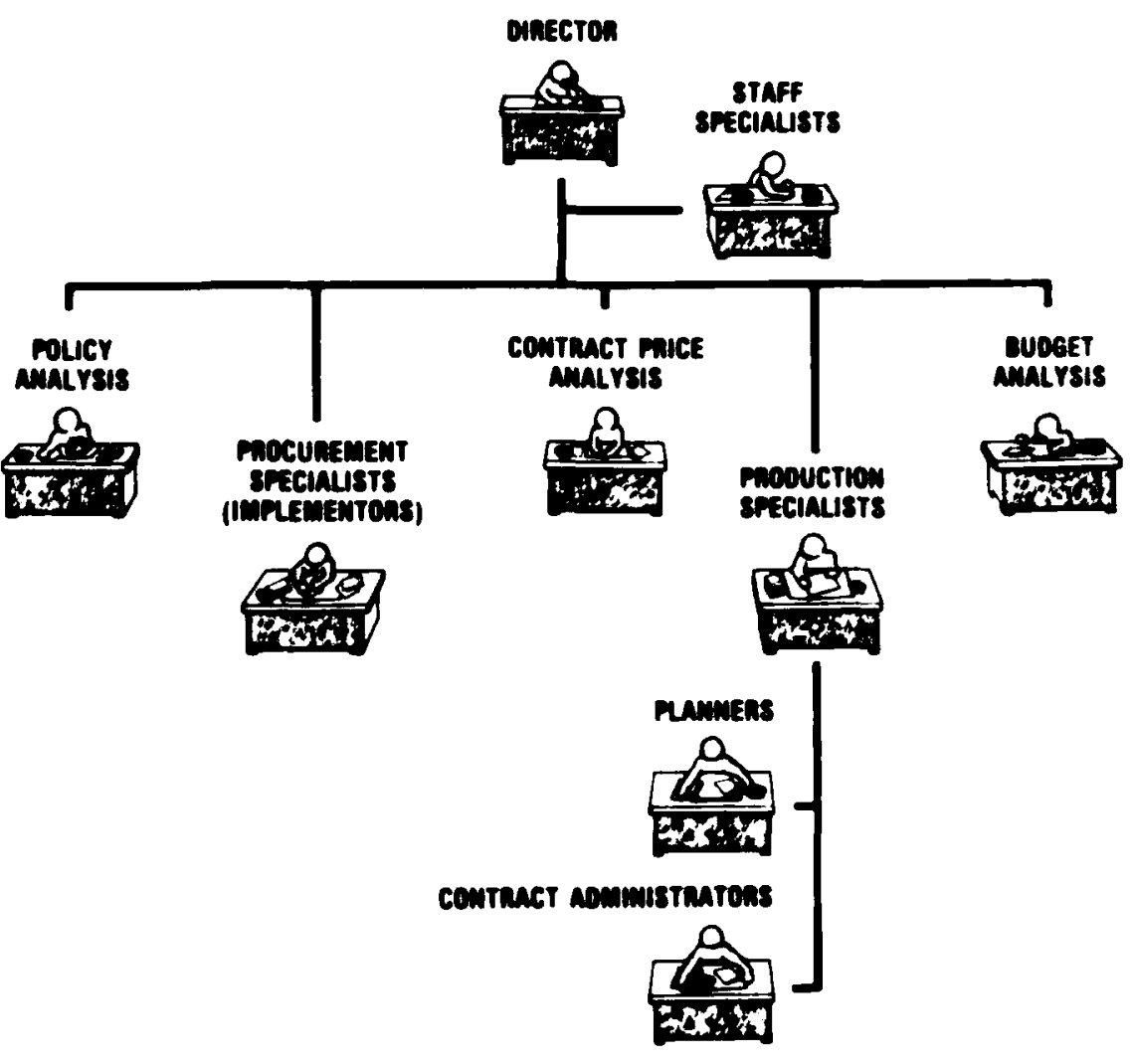

The funded requirement or work directive goes firt to budget analysts in the procurement activity. They record the entry of the work directive and the money limited for the directive's application. When completed, the budget andyat ands the funded work directive to the procurement specialist who may initiate the procurement action after obtaining an

\section{The procurement specialist may award a contract without seeing the procurement plan submitted in the budget proposal.}

Mr. Modzinski is an Industrial Specialist, TACOM, Warren, Mich. encineering specification. The production specialiat ascertains the date of specification availability. The procure ment specialist solicits bids from industry on the requirement of ultimately awarding a contract to the lowest bidder repondive to government needs as specified in the contract.

In practice, all of this does not transpire immediately after the beginning of the fixcal year. Flow of work directives may be incremental and the proces may not begin until halfway through the first quarter of the fiscal year. Some engineering specifications may be available to the procurement specialist at this time; others may not become available until the second quarter. Regardless, the procurement specialist is supposed to award a contract before the end of the fixcal year in order to obligate the appropriated funds.

The procurement specialist may award a contract without seeing the procurement plan submitted in the budaet proposal. When funds are received at the procurement activity. the budoet analyet receives a work 
directive specifying the number of items required and the amount of money apportioned. The plan used to obtain funds in the budgetary process is not included with this work directive. The budget analyst makes no attempt to obtain such a plan and, as a consequence, no plan is forwarded to the procurement specialist; only the work directive is forwarded.

The person with the procurement plan is the production specialist. The only contact the procurement specialiat must have with the planner is when obtaining engineering specifications and is the only contact formally addressed in the written procurement procedure. This contact may be with someone in the planning section responsible for preparing the procurement plan; consequently, the procurement specialist may never see the plan because there are no guidelines regarding this information. Similarly, there are no guidelines instructing the production specialist to submit a prepared plan to the procurement specialist. It is possible that one may not know what the other is doing because there is no formal and routine procedure for coordination.

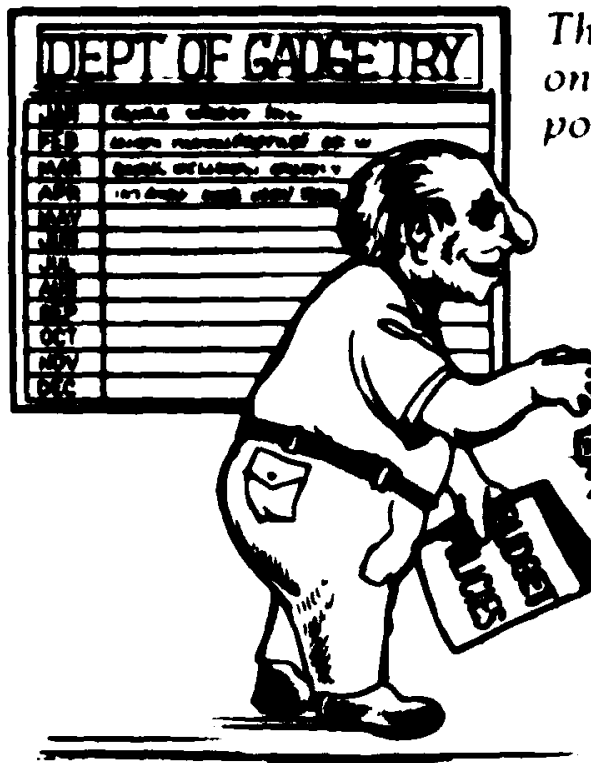

Any effort to link planning and implementation procesues in the procurement activity is not routine or systematic. The effort to coordinate relies on the presence of informal power relationships. Although neither the procurement specialist nor the production specialist is formally respon-

FIGURE 3. PROCUREMENT POWER RELATIONSHIPS

WIDGET VS RAX

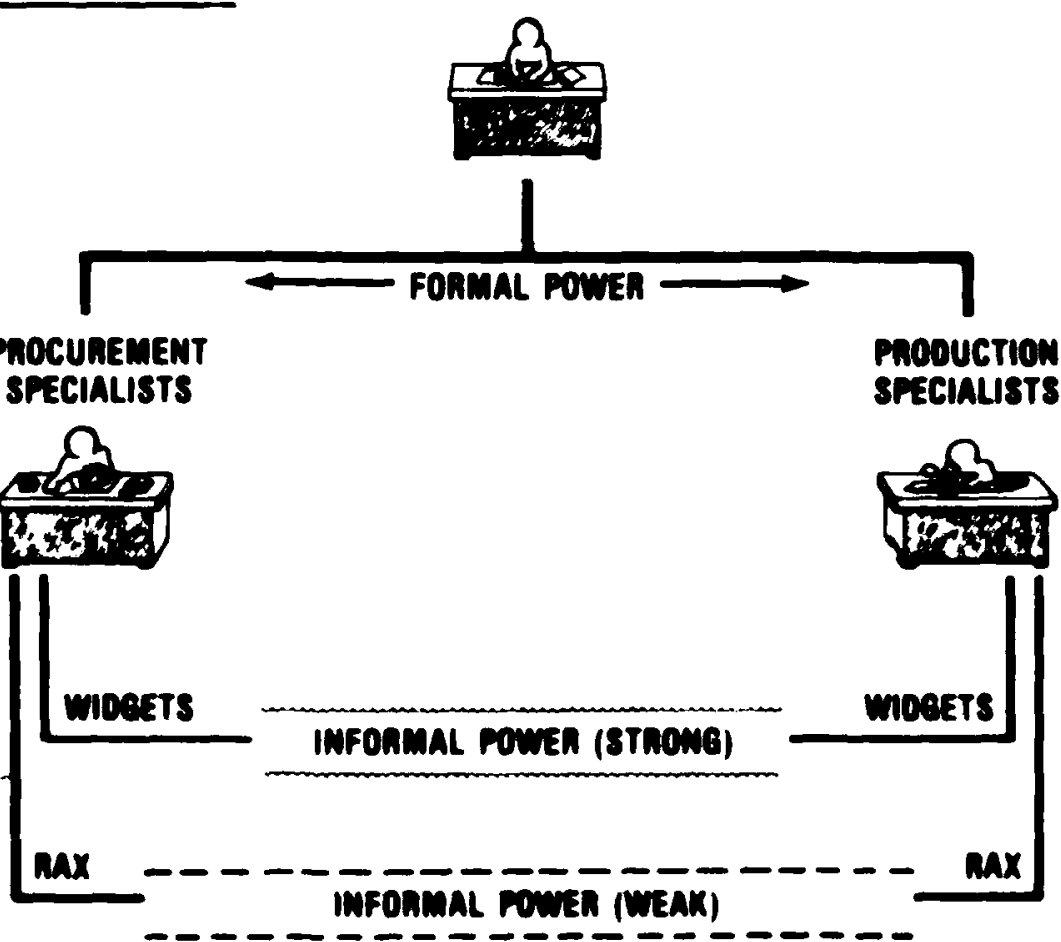

The effort to coordinate relies on the presence of informal power relationships. sible for coordination, they may work together based on their respective strengths of informal authority.

The procurement epecialist or supervisor, seeking information from the planner to make the job easier, may eatablish an informal workine relationship. The production specialist exercises informal authority based upon expertise and access to information. Yet, in the implementation procese, the production pecialiat may use informal power based on personality and atatus to initiate the coordination, and may volunteer information to influence decisions of the procurement specialiat so that the program may take a course similar to the planner's.

The degree of informal power relationahipe may be seen by comparing and contrasting the plight of two production pecialists dealine with different procurement epecialiats. The analyais empharizes the significance of pernonality and status in the composition of informal power.

\section{Wideat Vs. Rax}

Responsibility for procuring widects has been with the Widget Bureau since its inception. (See Figure 3) Many involved in managing and procuring widgets have worked together for 20 long that it is possible to know "certain" people who can "help" - whether or not they are formally axioned to do so. Someone with a special problem. which may not be articulated. may know who to see to resolve a problem. 
Working closely together for an extended period helps form a "bureau philosophy." which is:

the sum total of the group values, the accepted ways of doing things, that grew up in an administrative unit, and which the members of the unit identify. An agency working with a stable program over a long period of time develops a definite philosophy and point of view. It develops strong tendencies to harmonize its present decisions with past ones, and both present and past decisions with future ones. 7

Bureau philosophy may overcome incidents because group decisions prevent anarchy.

The widget planner, who is known by employees, is able to solicit counsel from procurement specialists. This recognition may be attributed to personality. status or expertise; possibly this person could be considered an institution within the procurement activity. David Mechanic says the greater the length of time within an organization, the greater the influence. This is not always true. Many older employees are not up-todate on new policy: sometimes, their energy levels are low and they do not plan for the future. Because of this recognition and the informal power attached to it, the "known" widget planner can get counsel from the procurement specialists while preparing the procurement plan. and influence behavior after they initiate the procurement action. He may assume the initiative to influence the course of procurement-or the procurement specialist may seek advice. The procurement specialists know questions about funding for the requirement for the current and subsequent years can be answered by this planner. who possesses considerable informal power and can coordinate planning and implementing for procuring the widgets

The procurement of rax. on the other hand. is a new responsibility for the Widget Bureau. Many participants planning and implementing processes are totally new or untamiliar with the surroundings. These people do not enjoy the same informal relationships as do their widget counterparts. Each time a new question arises they must find people with answers; minor questions may become major undertakings. No bureau philosophy has developed to sustain these newcomers through troubled times. Eventually, informal relationships will develop similar to those in the widget workforce; this takes time.

The rax planner does not have the same recognition as the widget planner, or the special knowledge and skills. This comprises a weak base from which to exercise informal authority. Perhaps the greatest asset for this planner to establish informal power relationships has been resources of time and attention devoted to a given iseure. These resources are important because procurement specialists may not want planning problems. The

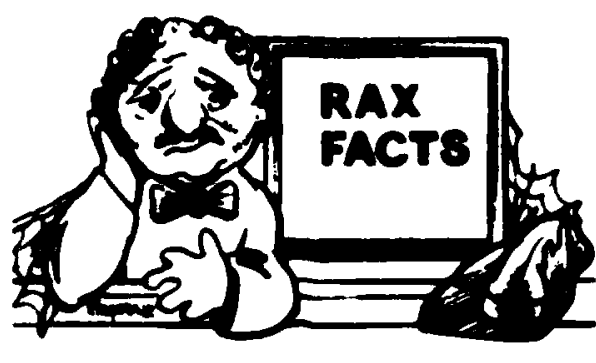

The rax planner hopes to volunteer the same information the widget planner imparts but the procurement specialist does not solicit this counsel.

production specialist must persist to obtain counsel and may have to use this time to coordinate plans with the course the procurement specialist is pursuing. He hopes to volunteer the same information the widget planner imparts but the procurement specialist does not solicit this counsel. The procurement specialist may want the data. but may not know the production specialist can provide it. The production specialist must assume the in itiative, but usually doesn't. While these efforts may increase this planner's informal power, in the meantime the race is to obtain the same level of coordination the widget planner ef fects. Since the rax planner cannot influence the implementation process in the manner he wishes, it is possible that certain procurement programs may not be implemented in the best ways; there may be costs involved due to this inability to influence the implementation process.

\section{Concluation}

The Widget Bureau procurement activity has distinguished the planning from the implementation process and has separate offices for each. In the organizational alignment, procurement specialists are preoccupied with the procurement at hand and do not have time for long-range planning; but, the supervisor or branch chief should because it's their job. If the procurement activity reorganized to make the same person responsible for planning and procuring an item, it could be possible to formulate plans that would be accepted and implemented. This could be gained while losing planners expertise and of reducing the executor's time to specialize. The Widget Bureau's procurement activity has elected not to make this sacrifice; instead, it has accepted the coordination problem imposed by the separation of planners and implementors.

Since the procurement activity opted to separate planners from implemen. tors, its next concern should have been to establish procedures to bridge the gap. However, it did not. No formal mechanism or procedure were established to ensure coordination, and certain programs, on occasion, were overlooked. Neglecting to systematically coordinate actions of planners and executors fosters a false sense of organizational autonomy, and fails to recognize interdependency of the two missions.

Neglect costs money. The production specialist's plans outline a procurement to acquire items at a reasonable time and for a reasonable price. while using minimum administ rative effort. These plans should be an efficient and economical means of procurement. Without a mechanism to ensure coordination, the procurement specialist may never learn of such plans and may proceed to formulate another procurement plan based on a traction of available intormation. This could mean a duplication in planning and a higher contract price for instance. 
knowing of consecutive-year requirements for a widert, the production specialiat's plan will accommodate this by proposing an option to increase quantity. On the other hand, the procurement specialist may know of the consecutive-year requirements and not include such provision in the contract; when the following year program is ready to be procured, the procurement specialist must award another contract-usually at a higher price. This can happen repeatedly because the procurement specialist is denied planning information available to the production specialist.

Informal power relationships in the procurement activity have solved problem coordination in planning and implementing processes. Nthough establishing a formal procedure and using formal policy would be preferable, informal power relationships have been acceptable. The problem with informal power relationships is that disparities in the strength of these bonds, as illustrated in the case of widgets vs. rax, create varying results among programs. This is not to deny benefits of informal power but to stress the need for formal power relationships.

In this study. I have argued that formal power relationships can create routine procesues and effect better coordination than informal power relationahips. Formal power relationships define positions within a system. Informal power relationships roles are not defined; they are leamed, and roles depend on personalities, not a system. Informal power can undermine the operation of a system. but it can enhance formal power and system effectivenes. An adminiatrator with formal and informal power will be outstanding.

Even if the procurement activity created a formal relationship between planning and implementation, disparities in power would exist; this is unavoidable because informal power cannot be meted out. Neverthelese, with the definition of roles and the acquisition of formal authority. the planner and the executor may have access to some power and influence and a minimum of coordination may be effected: the disparities in power may then affect only quality of coordination.

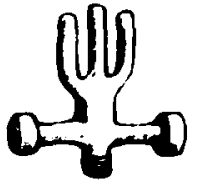

The problem with

informal power relationships is that disparities

in the

strength of these bonds create varying results among programs.

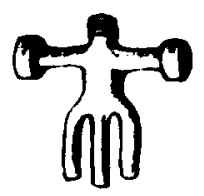

I offer a suggeation to the Widget Bureau. The Bureau's procurement activity should include in its mission statement an explicit requirement for conaultation between planners and implementors constituting a formal phase in the budget submisaion and contract award procesces. Nloo, the miscion statement of the planning function should specify that the production specialist submit procurement plans to the budget analyst at the beginning of each fiscal year.

Finally. the budget analyst should be required to include the appropriate procurement plan with each funded work directive forwarded to the procurement specialist. In this way. neceseary lines of communication would be extablished and the link between planners and implementors within the procurement activity would be formalized.e

\section{Bibliography}

Bunker, Douglas K. "Policy Sciences Perspectives on Implementation Processes," Policy Sciences, 3, (1972), 71-80.

Kolb, Eugene. "A Framework for Political Analysis," unpublished pamphlet. Alma College, undated.

Mechanic, David. "Sources of Power of Lower Participants in Complex Organizations," Administrative Science Quarterly. 7, (June 1962-March 1963) 349-364.

Pfiffner, John and Sherwood, Frank. "Organizations as Overlays," Public Administration, ed. Golembiewski, Robert T., Gibson, Frank and Cornog, Geoffrey Y. Chicago: Rand McNally College Publishing Company, 1976.

Snarkansky, Ira. Public Administration-Policy Making in Government Agencies. Chicago: Rand McNally Publishing Company, 1975.

Simon, Herbert A., Smithburg. Donald $W$. and Thompson, Victor $A$. Public Administration. New York: Alfred A. Knopt, 1956.

Weinberg, Martha Wagner. Managing the State. Cambridge: The MIT Press. 1977.

\section{Cited References}

1. Herbert A. Simon, Donald W. Smithburs, and Victor $A$. Thompson, Public Administration. New York. 1956, Pp. 123-424.

2. Douglas R. Bunker, "Policy Perspectives on Implementation Procesues," Policy Sciences, 3, (1972). p. 73.

3. The Random House Dictionary of the English Language. College Edition, (New York, 1968), p. 1039.

4. Eugene Kolb, "A Framework for Political Analysis," unpublished, no date, p. 8.

5. Simon, Smithburg and Thompson, p. 179.

6. Ibid. p. 446.

7. Ibid, p. 543.

8. David Mechanic, "Sources of Power of Lower Participants in Complex Organizations." Administrative Science Quarteriy. 7. June 62-March 63. p. 353. 


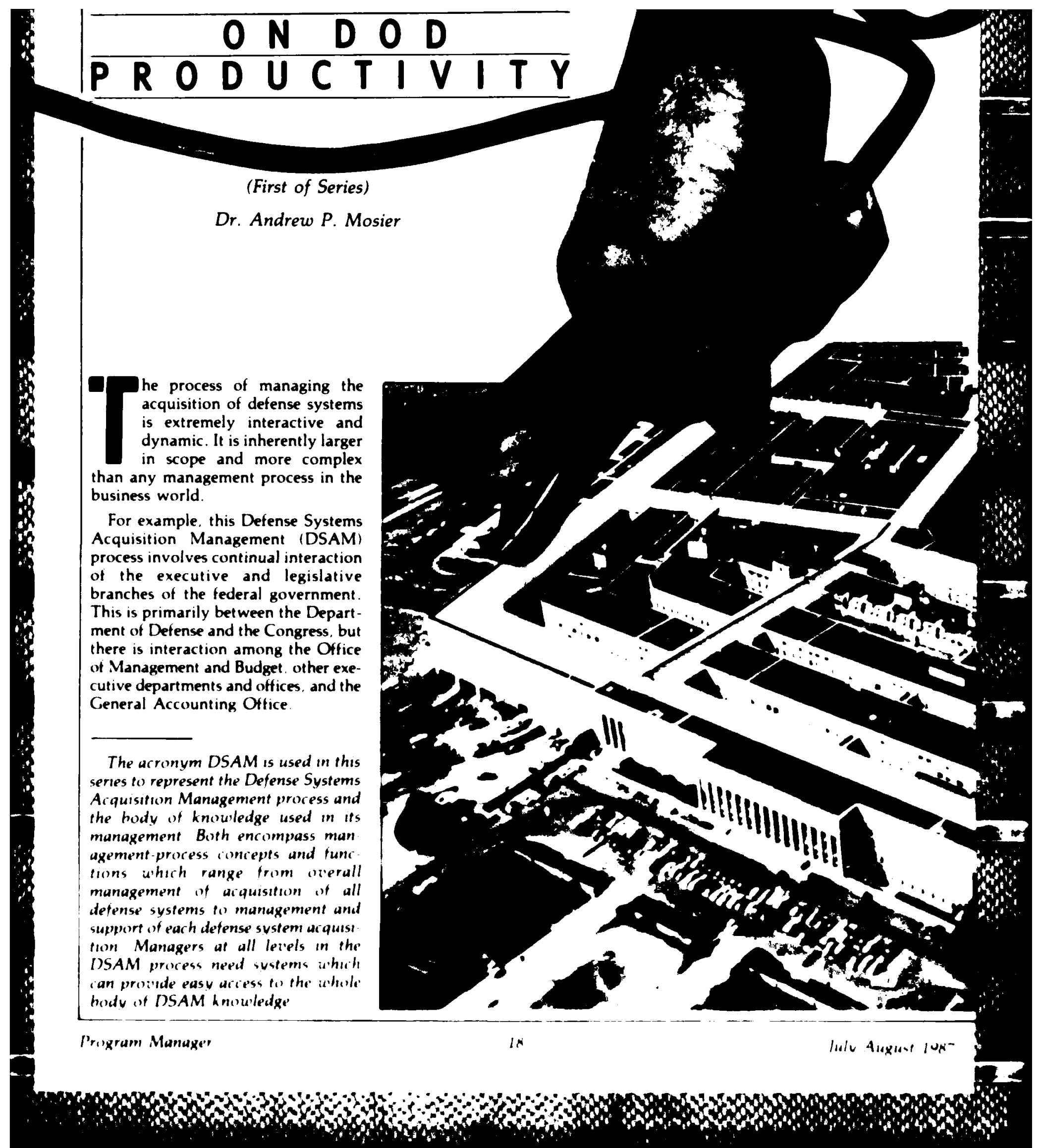




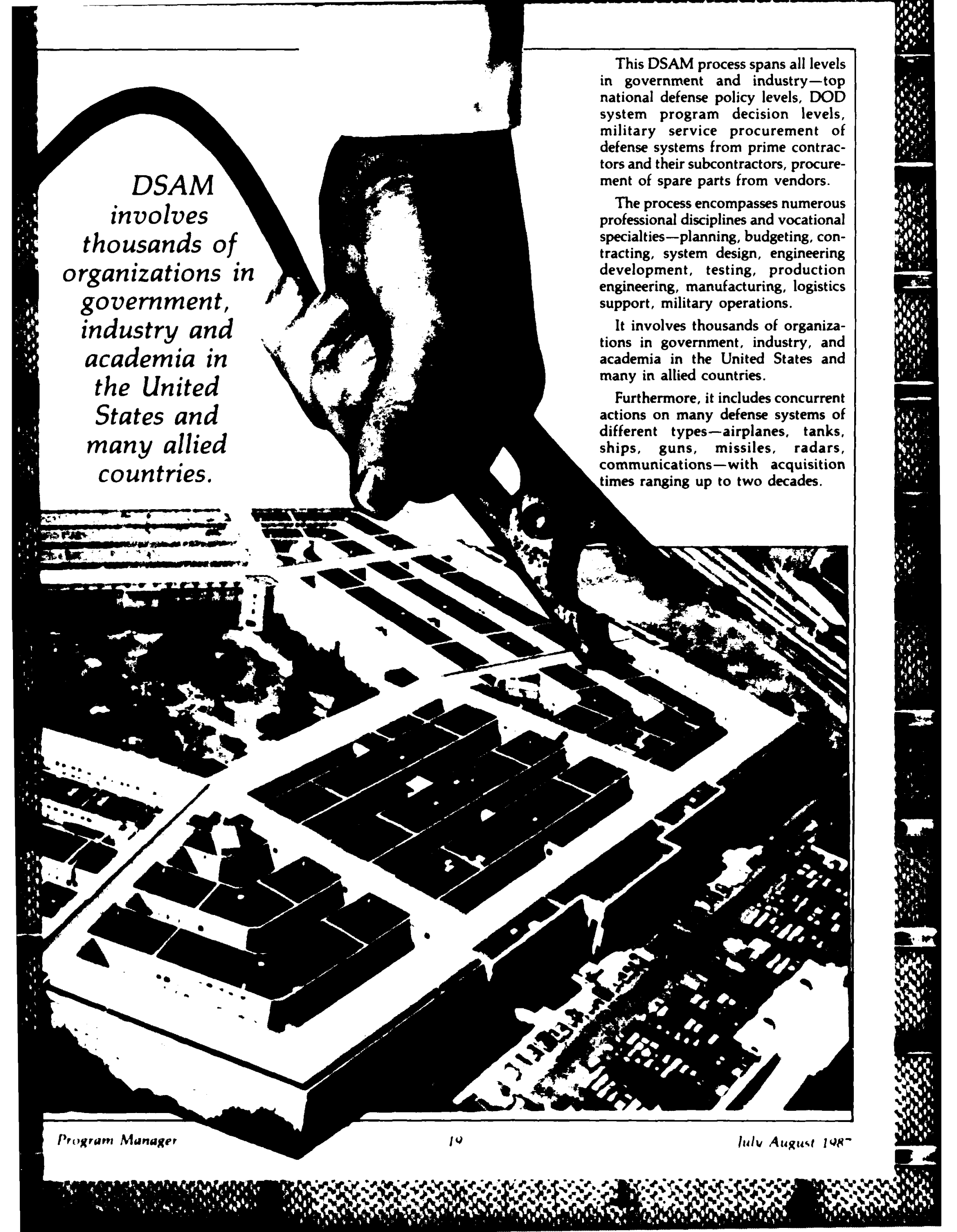


Success of the DSAM process depends upon an adequate industrial base of trained people and appropriate facilities. So, another important aspect of the DSAM process is assuring that this base is maintained for producing the types of defense systems that may be needed in the future.

Millions participate in, or influence, the DSAM process including government professionals, defense contractors, news reporters, legislators and taxpayers. Many are concerned about the current management process for acquiring defense systems. They are demanding improvements in management productivity throughout the acquisition process to reduce defense costs, to improve quality, to shorten acquisition times, and to assure that systems acquired perform as expected. Many others are more concerned about budget deficits. They are demanding lower defense budgets to reduce the national deficit or to allow more for domestic programs.

Given the inherent large scope, great complexity and extreme "interactiveness" of the DSAM process, and the growing concern about defense costs, can productivity in the management of defense systems acquisition be increased? "Yes! and significantly!" This is the only acceptable answer if we are to maintain an adequate national defense under Gramm-Rudman or any other mechanism for overall deficit control.

In this article, I begin an examination of how to increase productivity significantly throughout the DSAM process by increasing productivity of DSAM professionals. ${ }^{1}$ In turn, this will increase productivity of the thousands of organizations which interact in the DSAM process.

First. I discuss two critical consequences of the inherent scope, complexity and "interactiveness" of the process. which combine to limit productivity of DSAM professionals and organizations. I identify two serious limitations of past efforts to improve acquisition management. Then 1 describe a modern concept of productivity which considers all factors that influence it, and propose a framework of elements of DSAM-organization productivity which can be used to analyze efforts to increase DSAM productivity and to identify opportunities for significant improvement.
I will use this framework in the second article of this series for an illustrative review of past efforts to improve the acquisition process. Considering this framework-based review in the third article, I will identify new opportunities to increase productivity by developing and using DSAM knowledge systems.

In the fourth and final article, I will document the need to begin now to develop networks of DSAM knowledge systems which, I believe, will enable DSAM educational and research institutions to perform their missions better: that is, to assemble useful old and new DSAM information and disseminate particular information to DSAM professionals when each needs it. Using networks of DSAM knowledge systems, institutions could provide organized knowledge and timely "right" information; they could provide either, whenever needed, to a DSAM professional to perform the current DSAM job, prepare for the next job, or accomplish immediate tasks.

I urge immediate development of three prerequisite subsystems which I believe:

- Are required in the evolutionary development of all DSAM knowledge systems

- Would enable effective networking of DSAM knowledge systems (manual and automated) to increase productivity throughout the acquisition community

-Will begin immediately to improve DSAM communications and increase productivity throughout the acquisition process.

\section{Coping with Consequences}

The large scope, great complexity, and "interactiveness" of defense acquisition present critical management problems limiting productivity in the DSAM process. All are inherent.

Little has been done, or can be done. to reduce the scope. Reviews of past efforts to improve acquisition management indicate that, if anything. "interactiveness" has increased. However, past Administrations have made progress on complexity reduction in areas of the DSAM process that were largely under Administration control. During the past several decades, for example, they have established program mana- ger and higher-level-decision focal points (e.g., DSARC and service SARCs), and have evolved programcharters and prescribed-reporting to simplify communications between focal points. (DSARC has been replaced by DAB, the Defense Ácquisition Board.)

More recent is the present Administration's ongoing effort to reduce complexity in the DSAM process via the streamlining initiative. Deputy Secretary of Defense William H. Taft IV reported at the second DOD-Industry Acquisition Streamlining Conference in January 1986 that streamlining had begun to pay off. ${ }^{2}$

Continued increasing payoff will depend upon help from the Congress and from industry. Many of the good ideas in the streamlining initiative have been around a long time. One wonders why it has been so difficult, and still is, to put them into practice. My observations indicate that there are longstanding obstacles to streamlining which stem from inherent conflicts among objectives:

-Objectives of maintaining product quality standards

-Objectives of increasing competition in procurement

-Self-interest objectives of firms lobbying the Congress on behalf of regional-based programs.

Streamlining includes parts of the DSAM process which are not under control of the Department of Defense. The DOD and the Congress have interests in each of these objectives and their interests are not always based upon the same perspective. For example, commenting on the difficulty of putting good ideas like streamlining into practice, Dr. Donald A. Hicks, former Under Secretary of Defense for Research and Engineering, questions how candid and realistic are many firms when they lobby the Congress on behalf of their existing or proposed programs. He states that if the DOD is to avoid doing anything dumb in the area of competition, it will "need help from the congressional/industrial complex." 3

Achieving a workable balance among the objectives above to simplify the DSAM process by putting streamlining into practice will not be easy. A workable balance will require simultaneously maintaining product 
quality standards, maximizing benefits of competition, and minimizing political self-interest considerations in decision-making. To be successful, the streamlining initiative will require closer, long-term cooperation of Administrations and Congresses than was evident in the past - and than is evident today to former Senator Barry Goldwater. He feels that "many members . . . deal with defense issues mainly in terms of currying favor with their constituents." 4

Even with the streamlining simplification, the DSAM process will be complex because defense systems are complex products. No streamlining or other management simplification technique can make it simple.

We need a complementary initiative. Why not, simultaneously, seek a better way to cope directly with critical consequences of inherent scope, complexity and "interactiveness" of the acquisition process? Two crucial consequences are false perceptions and misunderstood communications.

Every professional involved in the DSAM process could cope better if each could develop truer perceptions of realities of the whole process; and if each could help reduce the frequency of misunderstood communications in interactions. An Indian fable and a Bible story about similar perception and communications problems in lesscomplex processes may provide useful insights on coping better.

\section{Developing Truer Perceptions}

In the Indian fable, six blind men living together had never seen an elephant. They decided to learn what an elephant was like through first-hand experience, by touching it. The first felt a smooth side of an elephant, the second the round trunk, the third a sharp tusk, the fourth a tall leg, the fifth a wide ear, and the sixth the thin tail. Each developed a perception of an elephant, based upon personal experience. But their perceptions were different. They argued loudly: "A wall!" "A snake!" "A spear!" "A tree!" "A fanl" "A rope!"

A wise rajah intervened: "The elephant is a big animal. Each man touched only one part. You must put all the parts together to find out what an elephant is like."

The blind men listened and reasoned: "The rajah is right. Each one of us knows only a part. To find the whole truth we must put all of the parts together."5

\section{Insights from Fable}

Each individual in any large, complex, interactive organizational process can "touch" only one part. To "see" the whole of a process they must put all of their perceptions together.

To do this, each needs aids to perceive how parts of the process each can "touch," interrelate and interact with the parts that others can "touch." Else, all may have false perceptions of the whole.

\section{We realize the} whole process is large in scope, highly interactive, complex and dynamic. It comprises many interdependent hierarchies of subprocesses in
thousands of
organizations.

These insights are particularly applicable to the DSAM process in defense acquisition. From past examples, we realize the whole process is large in scope, highly interactive, and complex and dynamic. It comprises many interdependent hierarchies of subprocesses in thousands of organizations. It requires many types of professional knowledge. Furthermore, consequences of size and complexity are exacerbated by high turnover of professionals in key management and policymaking positions; changes in top-level appointees with changes of Administration, tour rotation of military members, unpredicated civilian transfers.
If individual DSAM professionals could integrate their perceptions, then each could have a truer perception of the whole process as a basis for organized decision-making and coordinated action.

More than concerned DSAM professionals need truer perceptions about defense systems acquisition. Although not directly involved in the DSAM process, many people try to influence it because the process competes for resources with other programs they believe are more important, or because of personal and special interests. Both of these groups comprise people with different backgrounds who interact in many overlapping subgroups. These interacting subgroups include:

-Congressional/industrial/constituent complex (senators, congressmen, staffs, committees, GAO, politicians, PACs, lobbyists, prime contractors, vendors, constituents)

-Executive Branch (Department of Defense, OMB, other departments including State, Energy, Commerce, Labor, Transportation and Treasury, NASA and other agencies, Inspector General)

-Military/lndustrial Complex (military services, prime contractors, vendors, bankers, investors, workers. unions)

-Media (newspapers, radio, television networks, publishers, reporters, editorial writers)

- Professional groups (engineers, scientists, managers, analysts, accountants, educators, lawyers, doctors)

-Associations and special interest groups

- Concerned taxpayers.

Reports from these Americans describe respective concerns about defense acquisition. Sometimes it seems everyone, like each of the aforementioned fabled blind men, has a different perception of the acquisition process "elephant," with what is wrong with the process, and about what would improve it. This should not be surprising when considering the Indian fable and the acquisition process' scope and complexity.

Additionally, the DSAM process is dynamic. It is always changing because of evolutionary improvements by those involved, and in reaction to media-spotlighted "horror stories" of "waste, fraud and abuse." 
New Administrations develop new acquisition policy and process initiatives. Presidents appoint a blue ribbon commission or panel to recommend structural reorganizations and process improvements. The Congress reacts to its constituencies and enacts new laws; i.e., trying to reduce costs by directing increased competition and establishing new positions to support recommended changes in DOD organizations and processes. The Office of the Secretary of Defense and military services continually promulgate new and revised policies, directives and regulations, trying to integrate all of the changes into the dynamic acquisition process.

Yet, like one of the fabled blind men, each concerned American can "see" only those parts of the whole dynamic acquisition process touched at a few points in his or her lifetime. To develop a perception that approximates the whole "elephant" of defense acquisition, each must depend upon information from, and communication with, other concerned "blind men." Every concerned American needs communications aids and, because of high turnover in key jobs, most DSAM professionals need corporate memory aids.

Perceptions determine actions and are important in any process, particularly in a complex one like defense acquisition.

True perceptions result from complete information and full knowledge; they reflect reality. They are developed through personal experience and unambiguous communications, aided by a good corporate memory. True perceptions are essential for high individual productivity.

False (incomplete or incorrect) perceptions, at the other end of the spectrum, result from incomplete or incorrect information and inadequate knowledge. False perceptions are a primary cause of low productivity in a complex process like defense acquisition, which requires initiative, not slavish execution of directed steps.

The DSAM professionals need knowledge systems that can serve as corporate memory aids and unambiguous communication aids to help develop truer perceptions of the defense systems acquisition process. Truer perceptions, in turn, would help each professional increase productivity. Increased individual productivity amplified by good communications, would significantly increase productivity of all organizations managing or supporting the acquisition of defense systems.

I believe that DSAM knowledge systems can be developed which can serve as corporate memory and communications aids to DSAM professionals throughout government, industry and academia. In 1985, I proposed research to improve the productivity of acquisition managers through development of such knowledge systems. ${ }^{6}$ In the final article of this series, I will discuss refinements of the concepts of DSAM knowledge systems and prerequisite subsystems presented in my research paper.

Next, let's focus on communications problems of not only DSAM professionals but all people concerned about defense acquisition.

\section{Reducing Misunderstood Communications}

The men of $i$ abel, in the Bible story, could see but had a different limitation. Initially, all had the same perception of the project objective, a Tower of Babel "whose top may reach unto heaven." All understood the common objective. All knew the building process. They could communicate, and were making good progress on the Tower when God confounded their language. ${ }^{7}$ After that, no man could understand the other's language. They could no longer communicate to maintain a common perception and to plan, organize and coordinate job responsibilities and task efforts. The Tower of Babel syndrome-lack of a common language and the resultant inability to communicate-stopped progress on the Tower.

\section{Insights from Bible Story}

To be highly productive in a dynamic environment, an organization must maintain a common language, all words having the same meaning to all people.

A common language is essential for unambiguous communications which, in turn, are necessary for developing truer perceptions of a complex process and for planning, organizing, and coordinating all jobs and tasks.
The story shows that, at one extreme, lack of a common language will prevent organization productivity because it prevents communication. At the other extreme, an ideal completely common language-understood by all-would support high organization productivity. It would facilitate unambiguous communication with complete understanding, and enable coordinated action to achieve the organization's objectives.

Between these extremes lies the insidious "common" language that is almost common but not completely-a chief source of misunderstood communications. A familiar example is the "common" English language of the United States and Great Britain. English terms that are identical in Great Britain and the United States can have different meanings in each country. Alternatively, different English terms in Great Britain and the United States can have the same meaning.

An example of the "common" language of defense acquisition management is provided by the AFIT Compendium of Authenticated Systems and Logistics Terms, Definitions and Acronyms. ${ }^{8}$ Many DSAM terms in it have several different definitions, each authenticated by a different DSAM organization.

The "common" language used in DSAM communications is insidious because those involved believe they understood what was communicated, not realizing each may have used different definitions for identical terms. The "common" DSAM language can strike with severe results. Misunderstood communications of ten are not discovered until adverse consequences appear unexpectedly; i.e., after misunderstood directions are implemented or unnecessary projects are completed or incompatible products are produced.

Consequences of misunderstood communications are serious, decreased productivity, evidenced in many different forms; scrapped production rejects, inadequacies of equipment performance, time lost in recovery, additional costs for reworks, decreases in quality, delays in program schedules, wasteful increases in acquisition program costs. This adds to waste of millions of defense dollars and crucial delays in delivering new defense capabilities. 
The larger and more complex the process, the more likely are misunderstood communications. Coupled with false perceptions, they seriously limit organization productivity in large complex processes like defense systems acquisition.

I believe that misunderstood communications are the major source of "waste" in government and industry and a major cause of decreased productivity in organizational processes. Such management-caused "waste" is not reported as widely in the media as "fraud and abuse," not because it is less sensational, but because it is not as easily documented. It is difficult to identify and aggregate aforementioned wasteful costs of decreased productivity on a program, and hard to document and separate them from appropriate program costs. Few, if any, accounting systems can identify and aggregate wasteful costs of productivity decreases on a program as well as they identify cases of fraud and abuse. Furthermore, disclosure of a serious waste-generating, misunderstood communication is not in the interest of either party; neither wants to look stupid. Clearly, occurrences are more prevalent than public disclosure indicates.

The solution for overcoming the misunderstood-communications consequence of acquisition complexity is not to develop systems that can detect low-productivity waste caused by misunderstandings - which may be impossible. Rather, it is to develop aids to help DSAM professionals avoid misunderstood communications per se, analogous to Dr. Fleming's successful approach to improving product quality by avoidance, not detection and repair.

Making DSAM language more common would help avoid misunderstood communications. An aid, similar to an on-line unabridged dictionary. developed and maintained as a standard DSAM reference, would at least reduce the frequency of misunderstood communications. An available standard DSAM reference would reduce misunderstood communications among Americans concerned enough to improve their communications and understanding.

A standard DSAM reference would not help everyone trying to influence defense systems acquisition; i.e., would not help those more concerned about private agendas than maintaining an adequate defense. It would, however, limit the influence of people who, through intent or ignorance, make false assertions about defense acquisition issues. The standard DSAM reference would be available to help assure an issue is accurately stated and correctly understood by everyone.

My research shows developing an abridged DSAM glossary is one prerequisite for developing the knowledge systems indicated above. Extended beyond its prerequisite specifications, an unabridged glossary of authenticated terms would be a powerful tool toward a common DSAM language.

\section{A review group \\ often is unable,} from its collective personal experience, to perceive complex management problems. The group is unable to perceive all acquisition sub-

\section{processes, par- ticularly critical in- teraction among subprocesses.}

Early development of an unabridged DSAM glossary would enable faster development of needed DSAM knowledge systems, and bolster progress toward a common language in defense systems acquisition. Resultant improvements in communications about specifics of defense acquisition, combined with truer perceptions, would significantly increase productivity throughout the whole DSAM process.

\section{Limitations on Past Improvements}

During the past several decades, the Administrations and the Congresses have tried to cope with the scope and complexity of defense management by improving the organization and management of defense processes, including management of acquisition.
President Richard Nixon's 1970 Blue Ribbon Defense Panel on defense organization, and President's Ronald Reagan's 1986 Blue Ribbon Commission on Defense Management, conducted overall organization and management reviews. At lower levels, military services and acquisition commands have appointed panels of functional experts to deal with functional area problems.

They have recommended management changes in the Department of Defense and service organization structures, communications channels, and functional subprocess parts of the acquisition process. Many recommendations have been implemented by administrative directives and several have required new legislation.

Commissions and panels have been used widely in government to identify management deficiencies and recommend improvements. Since the Department of Defense was established, this has been a major source of significant improvements in managing defense acquisition. I believe, however, that overall- and functional-management reviews by all of the commissions and panels had two important limitations. Both need attention if we are to see desperately needed productivity increases in the future.

\section{Perception Limitations}

First, they were limitud by a variation of the handicap that limited the fabled Indian blind men. A review group is often unable, from its collective personal experience, to perceive the whole "elephant" that is encompassed in the complex management problems it was appointed to review; most group approaches to solving large complex problems have this limitation. The group is unable to perceive all acquisition subprocesses, particularly critical interactions among subprocesses that are included within boundaries of the large, interactive, complex problem under review. Development and inappropriate applications of Total Package Procurement in the 1960s, and misapplications of Fly Before Buy in the 1970s are examples.

More recent is the congressional effort to assure more competition. In their zeal to increase competition, congressional procurement experts seem to recommend applications of competi- 
tion, based upon their experience alone. It often appears they do not perceive, and thus cannot anticipate, undesirable interactions of the procurement subprocess and other processes in the larger acquisition process; for example, increased problems in assuring that the system scheduled for delivery years later by the winning competitor will meet all essential quality standards, or that the system will perform as required.

Many management improvements in subprocesses were made without sufficient realization of the inherent scope and "interactivenmess," as well as the complexity, of the whole DSAM process. The process comprises many major complex interdependent subprocesses such as setting national security objectives, forces planning, systems decision-making, programming, congressional appropriations and oversight, military construction, systems procurement, system quality assurance, operational training, systems operations and support. An intended management improvement in one subprocess can produce unexpected reactions and adverse effects in other subprocesses.

These subprocesses require joint planning and coordinated actions among DSAM professionals throughout the acquisition community, and in thousands of system acquisition organizations in government and industry. Each planning and coordinating activity needs DSAM knowledge and information, especially where no expert or group can "see" and thus perceive correctly the whole process. This condition usually exists.

We must learn to cope with this widespread consequence of the inherent scope, complexity, and "interactiveness" of the DSAM process. We must provide DSAM professionals with DSAM knowledge and information aids. These professionals need aids to develop truer perceptions of each interactive process. Truer perceptions are necessary for more productive decisions and actions. These aids will help future groups overcome perception limitations when trying to improve defense acquisition management.

\section{Deficient Concept of Productivity}

The second limitation stems from a deficiency in traditional management theory and practice, specifically failure of its concept of productivity to consider all factors influencing productivity. The serious result: overlooked opportunities for improvements in acquisition management that could increase productivity of the DSAM process significantly by increasing the productivity of DSAM professionals and organizations.

Few reports of past improvement efforts indicate an explicit objective to increase the productivity of acquisition managers or other professionals. Productivity concern focused on manual workers. Acquisition managers sought to enhance worker productivity by increased capital investment in better labor saving equipment, 9 and with training in better use of the equipment in office work, production, and other manual operations.

Judging from media reporting of increasing calls for greater U.S. productivity, this limited view of productivity seems prevalent in government and business. Some economists, meeting March 8, 1987, in New York said the major economic issue facing the United States in the next decade is keeping the standard of living rising while reducing the trade deficit and paying interest on foreign money that is financing it. They said, "the only answer is to find a way to increase U.S. productivity-output per hour worked." They urged policies that "would lead to more business investment, which in turn raises productivity growth."10

Peter Drucker notes in his book, Management: Tasks, Responsibilities, Practices, that traditional factors of productivity considered by economists and accountants are labor, capital and materials. Although important, these are not sufficient for analyzing productivity of organizations; particularly those doing knowledge work, and depending on initiative and active decision-making rather than on standard operating procedures. Drucker discusses other factors which, although never becoming visible costs, substantially impact productivity. These include knowledge, time, the manager himself, product mix and process mix (Drucker could have added, information). Drucker says we "not only need to define productivity so as to embrace all these factors affecting it, but also need to set objectives that take all these factors into account."
Drucker proposes a concept of productivity which considers the balance of all factors of production. He explains, "This is quite different from productivity per worker or per hour of work; it is at best distantly and vaguely reflected in such traditional standards." He states further, "The greatest opportunities for increasing productivity are surely to be found in knowledge work itself, and especially in management. The vocabulary of business-especially of accountingin relation to productivity has become so obsolete as to be misleading." 11

The following is my application of Drucker's concept of productivity to the DSAM process in any acquisition organization.

Productivity in the DSAM Process results from that balance among all elements of the process, including all inputs, which give the greatest output for the organization.

To increase productivity we must, first, identify all productivity elements that can influence the organization's output, particularly intangible inputs. These often are overlooked. Then, we must concentrate resources on elements promising the largest increases in the process output.

As the first step, I have identified important DSAM-process productivity elements for an acquisition organization. Although new technology might reveal new factors to add, this framework is sufficient to identify opportunities to increase organizational productivity. My framework is based on a productivity concept that considers all factors of productivity having significant impacts on productivity of an organization. It is based on the management concept that views acquisition management as a productive organizational process which has resource inputs, is controlled by objectives and a strategy, and whose output is measured against its objectives. This framework can be used to review past efforts to improve the DSAM process, and to identify new opportunities to increase the productivity of DSAM professionals.

The following is my proposed framework of organization productivity elements organized into three organizational process elements and two types of process inputs:

\section{.}


Organization Objectives, Constraints, Priorities, and Strategy. These comprise the "brain" element controlling an organization's processes including acquisition management goals considering constraints, milestones, and scheduled outputs, and how they will be achieved-its acquisition strategy.

Systemutic Organizational Processes and Subprocesses. Managers and other DSAM professionals interact through these processes to carry out the acquisition strategy and achieve the objectives. Examples are interrelated processes for planning, approving, programming, funding, directing, communicating, contracting, controlling, designing, developing, producing, testing, deploying, supporting and operating.

Efficient Organizational Structures. The purpose of any organizational structure is to support organizational processes.

Understanding the role of organizational structures in productivity analysis is important. The main purpose of the selected structure is to support all of the organization's subprocesses in a manner that assures greatest productivity for the larger process comprising all of the interacting subprocesses. If this larger process does not correspond to the organization's stated mission, adjustments are needed in the mission, subprocesses, or structure of the organization. Another purpose is to provide channels for hierarchical line management communications. (Essential channels for fast vertical and horizontal communications, to transfer quickly DSAM knowledge and information wherever needed can be provided better by other means.)

Organizational structures are not ends in themselves; organizational structure changes should make processes more productive. Structural change is not an effective means for improvement when the fundamental problem is the process; i.e., if the problem is in an oversight process, or in a communications process, the solution is in a change in the process and not a change in the structure, which could worsen the problem.

Traditional Tangible Resource Inputs

- Trained people

- Appropriate facilities and equipment
- Required materials

- Adequate funds.

These tangible resources are recognized as required inputs to an organization's processes. The means for obtaining, managing and assuring their appropriate input into organizational processes are well understood by managers, economists, accountants, lawyers, contractors and other professionals.

Job- and Task-related Intangible Transitory Resource Inputs

-DSAM knowledge

-DSAM information.

\section{Why are these DSAM knowledge and information resources less understood than traditional resources? Why do we need different mind-sets and means for managing
and putting them
into DSAM} processes?

These intangible job- and taskrelated resources are required inputs to an organization's processes if the organization is to be productive. They are not as well understood as tangible people, facilities, equipment, materials and funds resources. They require different disciplines and means for obtaining, managing and assuring their appropriate and timely input into an organization's processes. Frequently. they are not adequately considered in assuring all critical resource inputs to a process.

Why are these DSAM knowledge and information resources less understood than traditional resources? Why do we need different mind-sets and means for managing and putting them into DSAM processes?
First, these job- and task-related inputs are intangible and transitory, requiring a different mind-set and understanding of how they are put into a process. The DSAM knowledge resources are intrinsic in DSAM professionals and are subject to frequent transfer, from or to a job, as an inherent part of a reassigned professional. The DSAM information resources, inherently ephemeral, are required for tasks and must fit each professional's timing and approach to each task. Both have different input attributes for management and support of job processes. The attributes include:

DSAM Knowledge, something a DSAM professional must possess to manage or function well in all defense acquisition subprocesses of his/her job. For example, DSAM contracting knowledge is put into the contract decision-making process by assigning to the decision-making job a "knowing" professional having intrinsic knowledge of the contracting process.

DSAM Information, something selected by an incumbent DSAM professional as immediate DSAM informational input to a job task. For example, appropriate DSAM information, needed as input to a specific task in a contracting job, is selected and applied by the "knowing" professional having the task as part of his/her job. Different professionals may require different information to do the same task.

Second, different means always have been needed to manage and assure useful and timely knowledge and information resources, but few effective means were available. By default, obtaining them depended mainly on each manager's initiative and ingenuity. However, recent advances in computer and communications technology can make these jobrelated-knowledge and task-relatedinformation resource inputs readily available to all DSAM professionals, and thus to defense systems acquisition processes.

Dr. Mosier, a private consultant, joined the DSMC faculty in 1972 and served in many capacities until retiring in 1983. His career includes experience in military operations, industry, management of military $R E D$. and in education. He is a retired Air Force Officer. 


\section{Closing Thoughts}

The scope, complexity, and intense "interactiveness" of the dynamic process of acquiring defense systems are givens in efforts to maintain an adequate national defense. Their inherent and ubiquitous consequences have been high costs, long lead times, and often inferior quality. New systems do not always perform as expected, further increasing costs and time needed for improvements to meet requirements.

These consequences, which seem to be inevitable and frustrating experiences in acquisition, are formidable. But, we must develop better ways to cope. Either they will restrict the capability to defend America because budgeted dollars needed to maintain an adequate defense are diverted to support needed domestic programs; or they will reduce rewards of our way of life when too many dollars are diverted from social programs because acquisition management productivity is not sufficient to assure defense at an affordable cost. The only way to escape these outcomes is to increase productivity in the management of defense system acquisitions.

-Identify all elements of crganizational productivity and concentrate on improvement projects promising greatest increases in DSAM productivity.

-Give high priority and adequate resources to acquire means to help DSAM professionals develop truer perceptions of the defense acquisition process and reduce misunderstood communications.

- Provide every professional with more organized and readily available DSAM knowledge for the current or impending job, and more timely and relevant DSAM information for each task.

Results from progress in these directions should increase the productivity of every DSAM professional. Increasing their productivity will increase the productivity of all acquisition organizations and of the whole defense systems acquisition management process.

Consider again the question: "Can productivity of the DSAM process be increased?"

"Yes, and significantly!" This is the only acceptable alternative. It can be done by providing better organized DSAM knowledge, and more timely and relevant DSAM information to all DSAM professionals.

\section{Cited References}

1. The term DSAM professional, as used in this article, includes any government, contractor, academic or other professional who uses DSAM knowledge and information in his/her job in the defense systems acquisition process; i.e., policymakers, program/project managers and staffs, support managers, educators, researchers, decision support system (DSS) developers and operators, and information managers including librarians with DSAM information sources.

2. Taft, William H. IV, 1986, "Streamlining Has Begun to Pay Off," Program Manager: The Joumal of the Defense Systems Management College, Vol. 15 (March-April) pp. 18-20.

3. Hicks, Donald A., 1986, "Streamlining Initiatives: They've Been Around for a Long Time," Program Manager, Vol. 15 (March-April) pp.24-26.

\section{Ulsamer, Edgar, 1987,} "Goldwater's Parting Shot," Air Force Magazine, Vol. 70 (February) pp. 78-82.

5. Retold by L. Quigley, 1959, The Blind Men and the Elephant, New York: Charles Scribner's Sons.

6. Mosier, Andrew P., 1985, "A Proposal for Research to Improve the Productivity of Defense System Acquisition Managers throughout Government and Industry," Proceedings. November 1985 Federal Acquisition Research Symposium, pp. 5-12.

7. The Bible, King James Version, Genesis, Chapter 11, Verses 1-9.

8. School of Systems and Logistics, 1981. Compendium of Authenticated Systems and Logistics Terms, Definitions and Acronyms," WrightPatterson Air Force Base, Ohio: Air Force Institute of Technology, AUAFIT-LS-3-81, DTIC ADA 100655.

9. Mosier, Andrew P.. 1982 , "Enhancing Productivity through Increased Capital Investment," Concepts: The Journal of Defense Systemis Acquisition Management, Vol. 5 (Summer) pp. 190-213.
10. Berry, John M. 1987 "Policymakers Urged to Seek Ways to Increase Productivity in U.S.," The Washington Post, Business, February 10, 1987, p. E2.

11. Drucker, Peter F., 1973, Management: Tasks, Responsibilities and Practices, New York: Harper \& Row, Publishers, Inc., pp. 67-71.

\section{AFGC Aceepes Gystem for valletertion}

The Environmental Systems Research Institute Management Control System (MCS) has been reviewed and accepted for cost schedule status report (C/SSR) validation by the Headquarters Ballistic Missile Office, Air Force Systems Command. The MCS is used to manage the Institute's geographic database development projects under subcontract to the Air Force. The entire project management process from work authorization to final performance assessment is monitored using this system. The MCS, a set of procedures and tools for outlining the time limit and budget for each project task, evaluates performance and provides status reports to the customer. A major component of MCS is the DEKKER TRAKKER project control system that produces reports conforming to the cost schedule control systems criteria (C/SCSC).

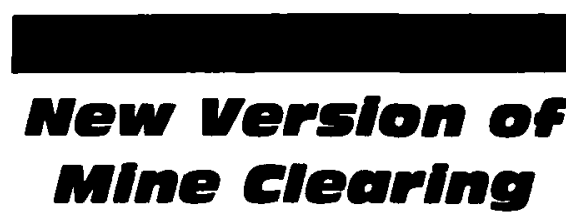

Foreign mine clearing "flail" technology is being evaluated by the Troop Support Command's Belvoir RD\&E Center to determine its effectiveness and suitability for the U.S. Army. A vehicle designed by a firm in Scotland will be tested by the U.S. Army Armor and Engineer Board, Fort Knox, Ky. Data could result in a tankwidth vehicle mine clearing system for combat engineers. 


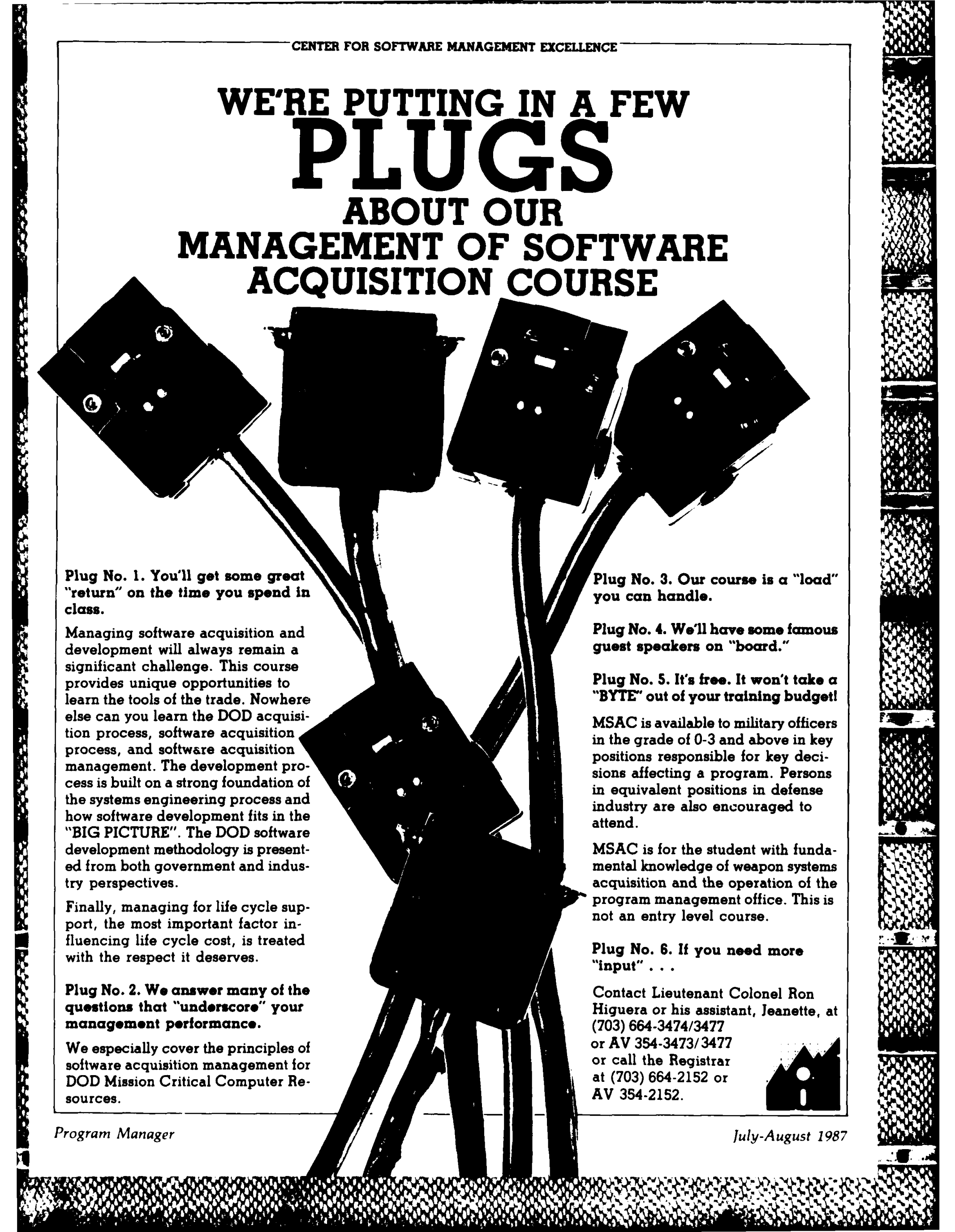


hat's a buming question these days and you probably have an opinion. I'd be very surprised if you didn't. I'm not going to try and give you an answer. Rather, I'm going to tell you how we in the Air Force spend your tax dollars-some of the facts will probably surprise you, and some may shock you. In the final analysis. I hope you will be better informed to answer the question yourself.

By anyone's yardstick, your Air Force is in better shape today than it was at the beginning of this decade. In fact, we are better prepared and more capable than ever before. That's what deterrence is all about. We've spent a great deal of your money to get to this position, and it is reflected in more forces-on-the-ramp, more spare parts-and yes, some of those parts were over-priced-and improved quantity and quality of combat equipment and training.

These capabilities haven't come cheap. But when you realize the scope of Soviet spending power, you may gain a different perspective. The Soviets have outspent us by nearly $\$ 500$ billion during the past 12 years. That's more than all the money the Air Force has spent this decade.

Let me put it another way. The difference between their spending and ours - this $\$ 500$ billion-is enough to buy 100 new B-1 bombers, 1,000 new F-15 fighters, 100 Peacekeeper ICBMs, 50 new attack submarines, 1,000 M-1 battle tanks, and still have half the money left over for balancing the budget.

I am not advocating that we attempt to match the Soviets. Our priorities as a nation are vastly different. They build more than three tanks for every one of ours, more than 13 artillery pieces for every one of ours, 70 surface-to-air missiles for each of ours, and two-and-one-half fighters for each of ours.

What we need to do, and are doing. is to procure the right number and $\mathrm{mix}$ of weapons to deter aggression-no more and certainly no less. We size our programs to respond to the threatwe are not interested in buying what we don't need. We don't have to match them one for one if our force is technically superior. Let me give you some Air Force examples:
I) I I I RRI $\backslash($ I

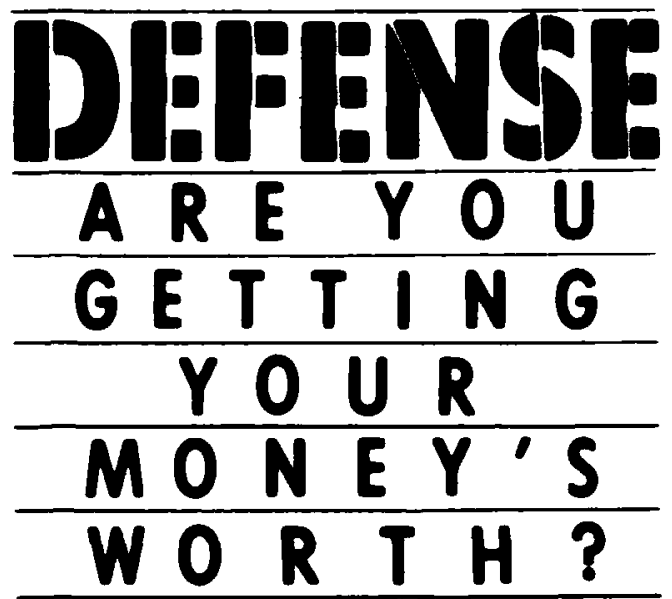

Lieutenant General Bermard P. Randolph, USAF
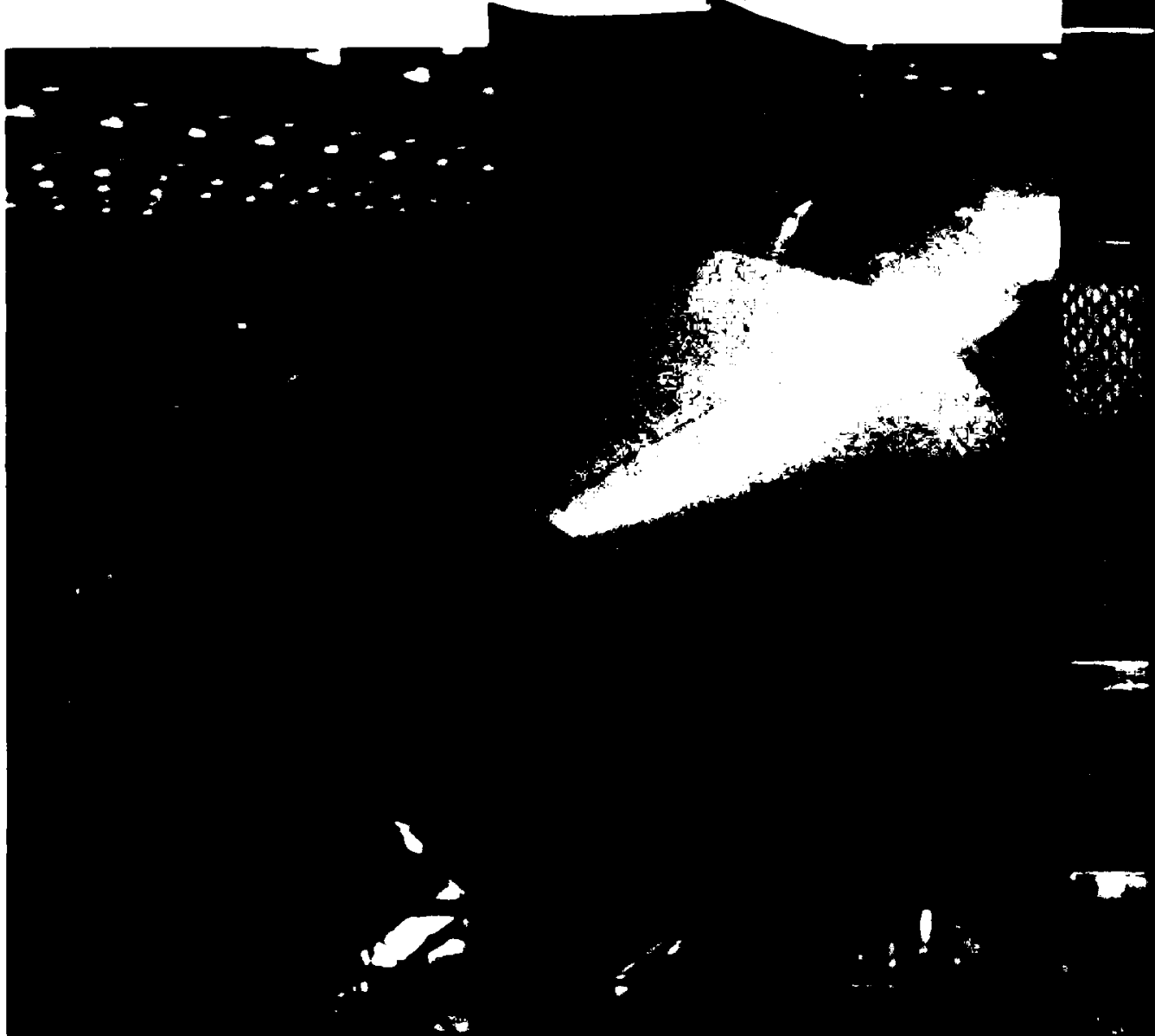

What we need to do, and are doing, is to procure the right number and mix of weapons to deter aggression - no more and certainly no less. We size our programs to respond to the threat. 
- The F-10 highter-bomber is perhaps the most successtul single-engine aircraft ever developed. Our most recent bombing competition says it all: Our top pilot dropped tive of six bombs insicke an area the size of a manhole cover This year's last-place F-16 team would have won the competition in 1981

- Our Advanced Medium Range Air(1)-Air Missile (AMRAAM) is having the most successtul test program ever tor such a weapon. With its own builtin radar the pilot doesn thave to continue to track the missile to target. That means during any potential tuture dogtight our outnumbered pilots could take on more than one attacker simultaneously. The AMRAAM will double the capability of

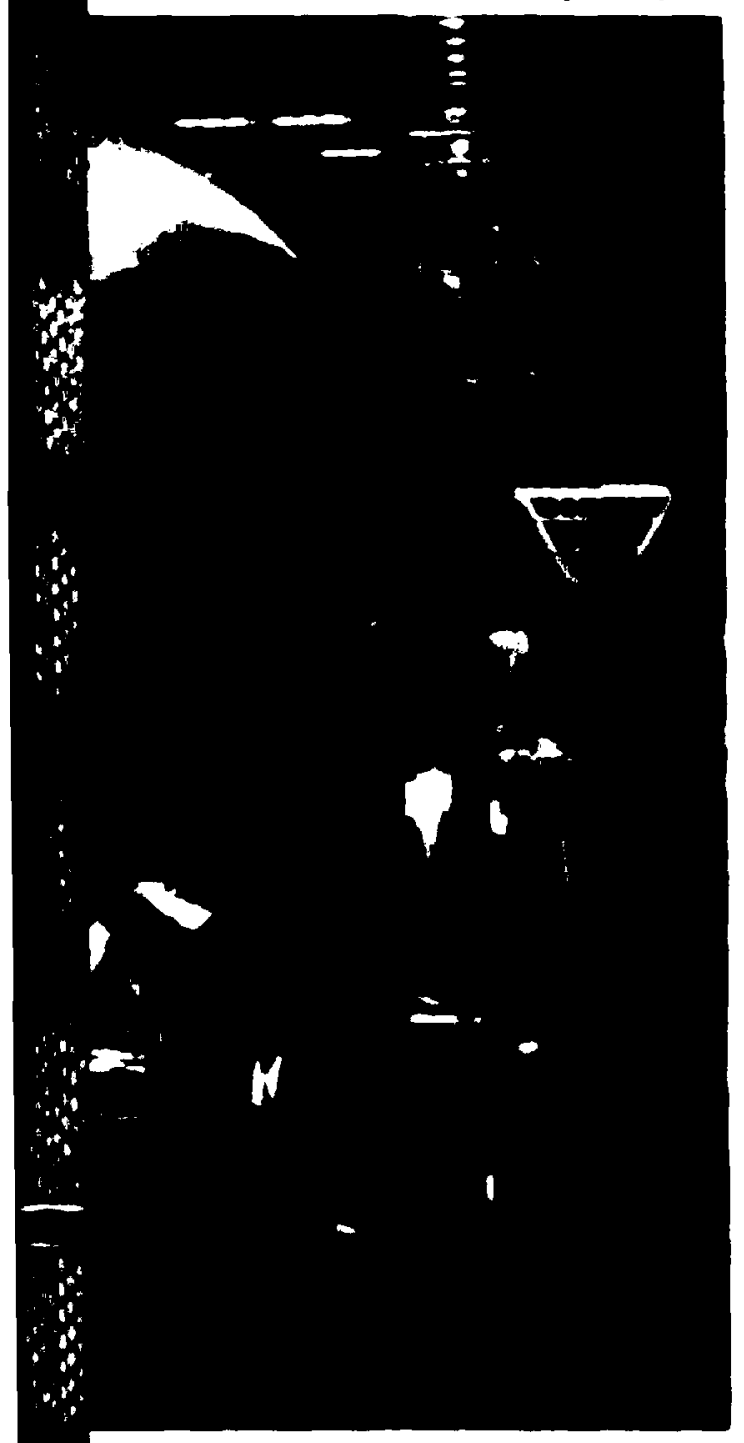

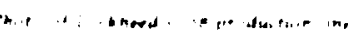

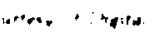

Program Manager the F-15 and increase the effectiveness of the F-10 by a factor of six. But the missile is also costing us more than we expected mostly because we underestimated the technological challenge. The only alternative. however, is a great deal more expensive - build a lot more airplanes instead

-For the longer term. we are developing the Advanced Tactical Fighter (ATF), which, when fielded, will be our first new air superiority fighter in 20 years. It will have many more capabilities than its future Soviet counterpart and will be much more difficult to see. Compared to today's hottest fighter - the F-15-the ATF will be three times more survivable in airto-air combat, and eight times more survivable against surface-to-air threats.

\section{Public Opinion}

Does the average American agree with the way we are approaching deterrence today? In other words, are we spending your money wisely? After all. public opinion is really a report card on how well we appear to be guarding our mation's investment in its future.

A little-known appendix to the President's recent Blue Ribbon Commission on Defense Management gives us that report card in the form of a survey of public attitudes. and it is not good.

First of all, the average American thinks we spend twice as much on defense as we actually do. The average American thinks we spend 40 percent of the tederal budget on defense. when the actual figure for last year, a year of growth in the defense budget. was only 20 percent. You have to go back to the 50 s to find detense consuming nearly half of the federal budget

What is even more disturbing to me is that the average American also thinks that fully 40 percent of every defense lax dollar could be saved. if only traud and waste were eliminated. Five years ago 71 percent of the na. tion tavored increased detense spen. ding: today that tigure has dwindled to just 14 percent

How could this happen? How could the American public come to the con clusion that we are wasting almost $\$ 100$ billion a year?
It s easy, really. When bombarded with "horror stories of overpricing on such things as diodes, coffee pots and allen wrenches. you become outraged

People understand what an ordinary household item should cost. but find it difficult to grasp concepts like multiyear procurement, zero overpricing and cost-avoidance measurement.

\section{Media Accounts}

Unfortunately, the initial media account of a "horror story" just gives you the shocking claim. When the full picture is known, usually days later. it never gets the same coverage. I believe the time has come for the military to insist that the whole story be told, and not just the eye-catching headline. Let me give you the whole story on the examples I just mentioned.

-Did the Department of Detense really pay $\$ 110$ for a diode that probably costs less than a dollar?

Yes: in fact. we bought two. Now this is not the whole picture. but the portion everyone has heard. That price was challenged, and a refund was received. Later, we bought 122.000 of those diodes for 4 cents each!

Every Air Force member has the right to challenge prices they believe to be unrealistic: there were 10,000 such challenges in 1985 . For example, a sergeant in Panama challenged the price of generator parts and saved the Air Force $\$ 3.5$ million. This is what we call the Zero Overpricing Program. and it began in 1979. The main point to remember: In almost every "horror story" that has occurred. a dedicated Air Force member made the discovery and started the challenge process rolling.

- Okay, but what about those $\$ 7.600$ coffee pots that several congressmen questioned?

Seventeen years ago, between 1969 and 1973 . we paid between $\$ 3,500$ and \$7. 400 apiece tor several replacement hot beverage units tor the C-5A aircraft. We are guilty in this one partly because of our own unrealistic specifications for the unit It had to withstand $40 \mathrm{Gs}$. produce 12 fresh batches per hour iunction in an unbelievable temperature range and be tield repairable 
We have since fought a war on overspecification. Such beverage units are now off-the-shelf items for which we pay $\$ 3,046$ each, less than most airlines pay for the same item. You can't get around it-they are expensive, even at a fair price.

We have instituted "streamlining That is any action we can take to reduce the cost and time of weapon system acquisition. while at the same time maintaining or improving product quality. The new $\mathrm{C}-17$ cargo transport is a great example: It now contains fewer than $\mathbf{5 0 0}$ specifications. That compares with 15,000 for the C-5A at a similar stage of development. This means that more off-theshelf components can be bought at lower cost

- "Okay, okay," you say. "but what about that $\$ 9.600$ you paid for a simple little allen wrench? Tell me you didn't do that

We didn't. That price was proposed. challenged and withdrawn. Instead, we purchased the design plans for 544 and manufactured the item ourselves at a cost of 12 cents each not $\$ 9.600$ !

\section{Changes}

The Air Force has since instituted more than 100 changes in support equipment procedures to break out simple items for competitive purchases and ensure that they are properly identified. screened and priced.

We buy many items from small. disadvantaged businesses. In the last 18 months, for instance, we have contracted for nearly 280 support equipment items this way. with a savings of some 30-70 percent below what we would have expected to pay. The cost avoidance is at least $\mathbf{\$ 1 0}$ million.

Those are the facts. I believe the Air Force owes it to the public to be more aggressive in telling our story

In 1986. I had the opportunity to write an article for Fortune Magazine for the "Other Voices" column. It was entitled Leave Defense Procurement Alone. i cited a number of examples of what we are doing right for America - what we are doing to pur chase the best weapons at the lowest possible cost

It is very possible that some fortune readers may have considered the art. cle self-serving Pentagon propaganda The facts, however, when duly considered, speak for themselves.

Air Force acquisition is big business The Air Force signs an average of more than 13,000 contracts every day. almost 5 million every year.

Last year the value of those contracts exceeded $\$ 53$ billion. Based upon this business volume, the Air Force would rank No. 4 on the Fortune 500 listing. Only Exxon. General Motors and Mobil did more business in 1985. Even if we are 99 and $44 / 100$ ths percent pure, there is potential for thousands of "horror stories."

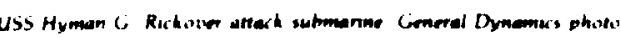

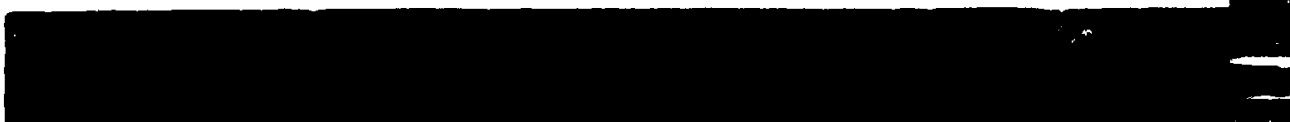

time maintaining or improving product quality. system acquisition, while at the same instituted streamlining to reduce the cost and time of weapon
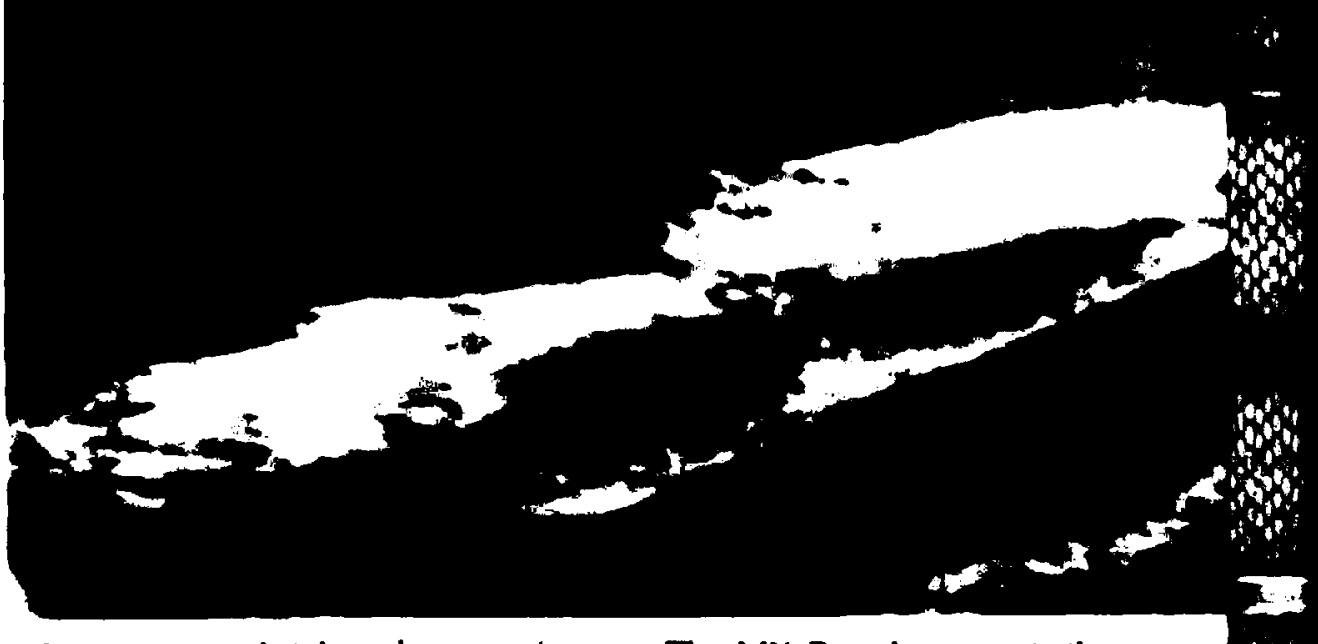


\section{The Future}

What does the future holdi Mostly more good news

- Competition is a key and we are doing very well. In 1985, we set a goal for one-third of all contract dollars to be let competitively. Thirty-nine percent was the number we reached. The 1980 goal was 42 percent, and through the first 2 months of the fiscal year, we sat at over 51 percent. Another 38 percent are follow-on contracts, primarily additional orders for items previously competed. Only about 10 percent of our dollars are not being awarded through competition. That's good news for the American taxpayer

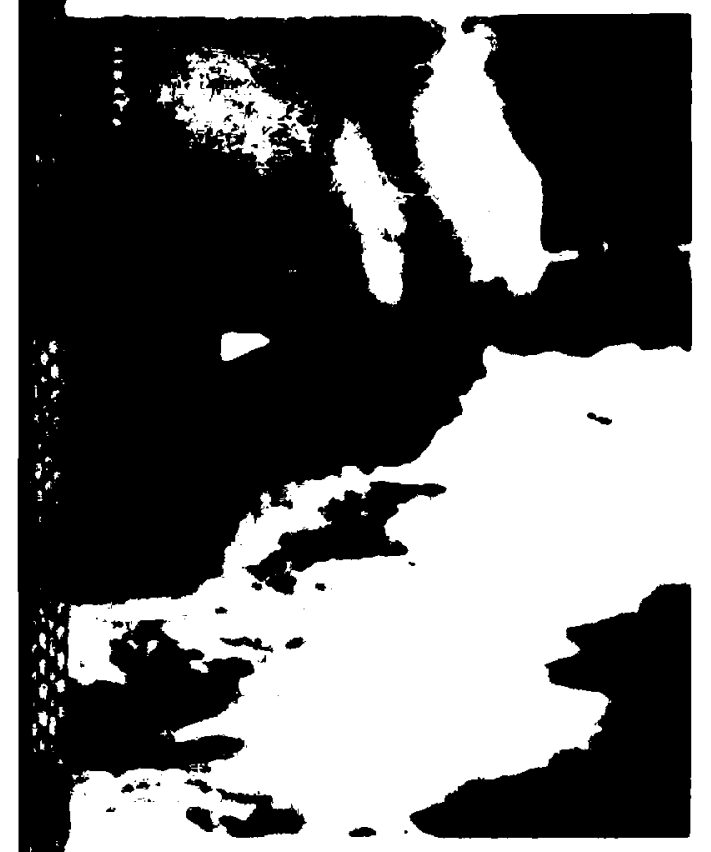

- Competition is nothing new to the Air Force. In 1971, we purchased the short-range attack missile from two competing suppliers. More recently. we used competition to buy an alternate engine for our F-15 and F-16 fighters.

- The small ICBM is another great example. Martin Marietta won the contract, bidding $\$ 500$ million less than the government's estimate and $\$ 300$ million less than its nearest competitor.

- We are a demanding customer, and the vast majority of our 100,000 contractors fulfill the terms of their contract. If they don't, we call them to task. In 1985, we suspended or debarred 60 contractors, double the number of the previous year. We received \$11 million in volutary refunds from contractors who overcharged us.
- We have strong emphasis on reliability and maintainability, what we call R\&M. We will buy only systems that opera.. reliably and can be reasonably maintained or repaired in the field. We halted a $\mathbf{\$ 2 5 0}$ million program for a radar warning receiver because the proposed system did not offer significant R\&M improvement over the older one in use. We still need a new system, however, and two companies are competing. I do not want to give you the impression that our relationship with industry is negative. Indeed, cooperation and interaction is essential to maintain the scientific and technological edge essential to our national security.

\section{Industrial Modernization Incentives}

We are engaged in a number of cooperative efforts under our Industrial Modernization Incentives program, which encourages contractors to increase capital investment, improve productivity and reduce costs. The program should yield more than \$4 billion in savings during the next 15 years; some in industry think it will save more money in an even shorter time.

A great deal more must be done. The Packard Commission made numerous recommendations designed to restructure the way we do business. We agree and are adopting recommendations.

Part of our national security depends upon getting our new systems into the hands of our operators sooner than we did in the past. This means giving our program managers more time to do their jobs. But, it is not easy. As oversight increases, so does paperwork and, ultimately, the costs. The net result comprises massive regulations, procedures, directives. documentation and review requirements imposed on each layer in the chain, from the Congress to the Office of the Secretary of Defense. through the Air Force to the program manager and to industry.

Ten years ago, four congressional committees wrote legislation in defense: Today the Department of Defense is overseen by 24 committees and $\mathbf{4 0}$ subcommittees.

It is a real challenge for uniformed witnesses to testify effectively. Frequently, we bring back requests for more information. called inserts tor the record. This takes a great deal of time.

In 1985. the Wall Street foumal reported that the Department of Defense responded to 84,148 written inquiries and 592.150 telephone calls trom Capitol Hill. To give you an idea of how involved oversight has become. the same article reported that the Congress intervened on the subject of whether or not our military clubs should serve margarine, butter or both.

I don't want to give the impression that the Congress doesn't realize the extent of the problem, because it does. More than 18 months ago. Senator Sam Nunn was asked by Aviation Week what he thought about the acquisition system, and this is what he said:

I really have the view that we've so encumbered the system with rules and regulations and red tape -- all with noble purposes -that the cumulative effect of it is just devastating. The way we're doing business now, if you came down from on high and you said your job was to devise the worst possible combination between the Congress, the Pentagon, and all the elements, I think we've got it

Continuing to work with the Congress, we are making the system better.

\section{Research and Development}

There is one other very important point and it has to do with the newest argument being used by the antidefense establishment. They expect us to believe that research and development designed to deter war is immoral and costly. But now, they also tell us that the tremendous potential military research and development has always had for improving our daily lives is nothing but delusion. To say that is to ignore decades of scientific fact. I assure you that the delusion is theirs.

During the past 30 years, militaryfunded research and development has spawned major new industries: created tremendous new opportunities for jobs and wealth: and brought a new safety, comfort and convenience to the average citizen that was beyond one's imagination a few years ago. "Spinotts of today give us only a glimmer of what the future can hold 
The mind bogles at the number of examples of civilian spinotfs just from Air Force-sponsond research and development. The perronal computer. maybe the world's facted growth industry. was once part of an Air Force research program into microminiaturization and the integrated circuit chip in the 1950. The dinital watch and the calculator, plus the timing and control circuitry for most home appliances. automobiles and computers. also evolved through Air Force-sponsored research in the 1960s. Solar cell technology that we began funding at the same time has led to similarly amazing developments

Modern ceramic cookware that doesn't burn. discolor or crack under sudden temperature changes comes from the same material developed for our ICBM nose cones. Graphite composites used in Air Force aircraft and engines are now found in golf clubs. fishing poles. skis. tennis rackets and race car bodies. The automotive industry is exploring advanced composites to reduce structural weight and increase fuel efficiency in the family car

That's not all. The nickel cadmium battery that powers today's wristwatch: the "special cutting edge" of your razor; the carbon lining of man's favorite pipe: sturdy. lightweight non-breakable luggage: sunglasses that darken as the sun gets brighter: lightweight cold-weather

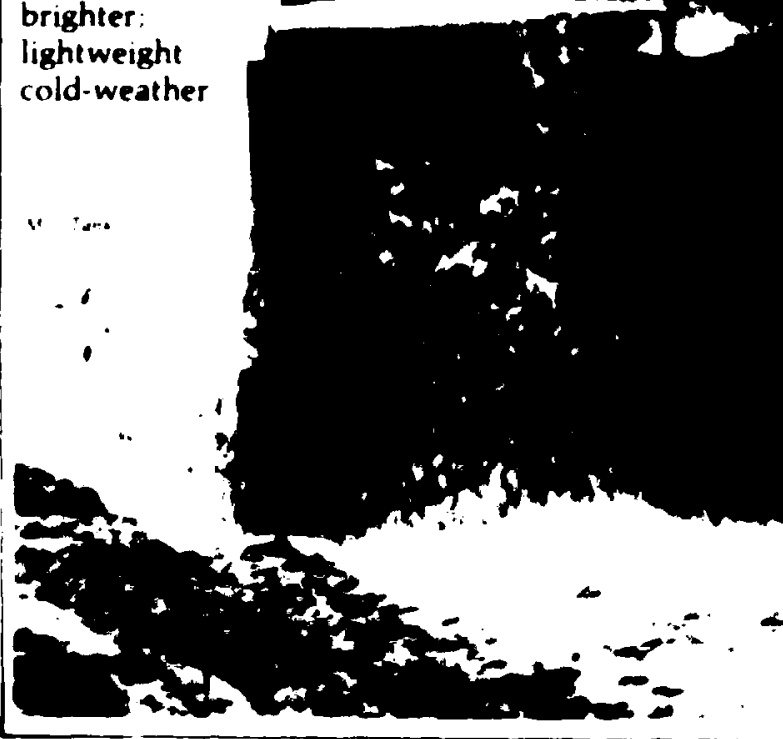

Program Manager clothing super-alloy yams in drapenes and bedapreads: and even the clothlike paper of cottee filters - are all spinotfs of Air Force research and development

\section{Military research} and development not only secures our strength and freedom,

but it enriches

our lives in ways that most Americans will never realize.
Let s not forget that the jumbo ret evolved from the military need tor a wide-bodied cargo carrier not vice versa And what about the tremen. dous impact of laser technology and satellite weather information. plus microwave ovens. transistonzed musac systems. electronk games and, the $N$ instant replay I could cite countless examples

These examples are just the isp of the iceberg The future promises even more than the past has provided. Looked at from this perspective. military reseanch and development not only secures our strength and freedom. but 11 enriches our lives in ways that most Americans will never realize

The Air Force goal is to ensure that Americans continue to reap maximum benefits from their tax money

Americans should ask for nothing less. and we will continue to demand if from ourselves.

- Lieutenant General Randolph Deputy Chief of Staff for Research Development and Acquisition. US Air Force has been nominated by the Prestdent for appointment to the grade of General and assignment as Commander Air Force Systems Command to sucreed General Laurence $A$ Shantze who is slated to refire Aug 1 198: This article is adapled from remarks made in Portland Ore the past Octuber

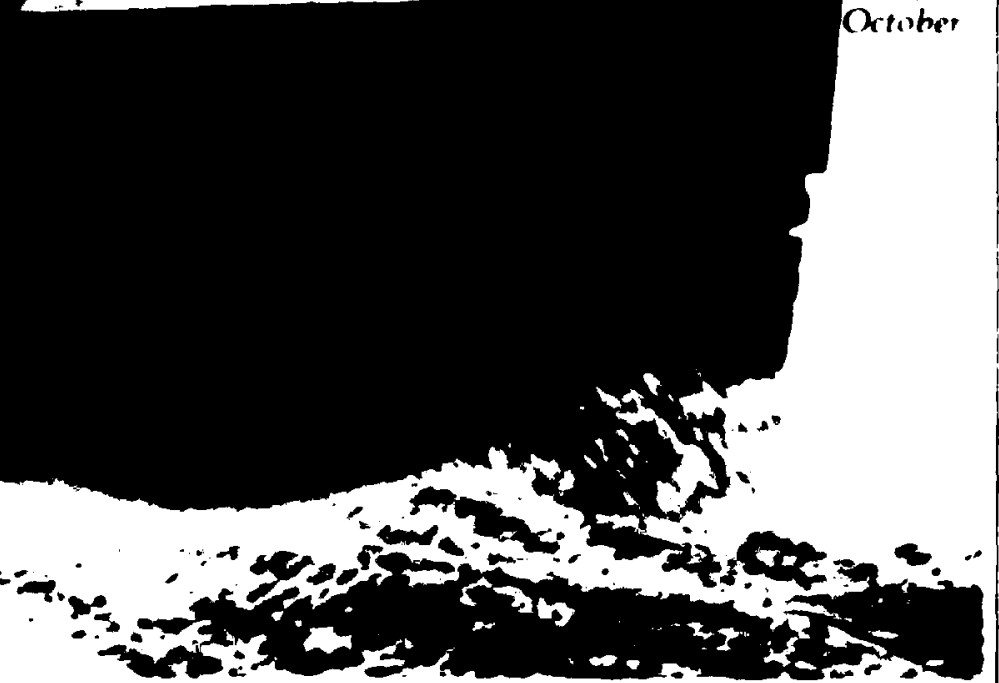

$$
32
$$

lalv Auguse lug- 


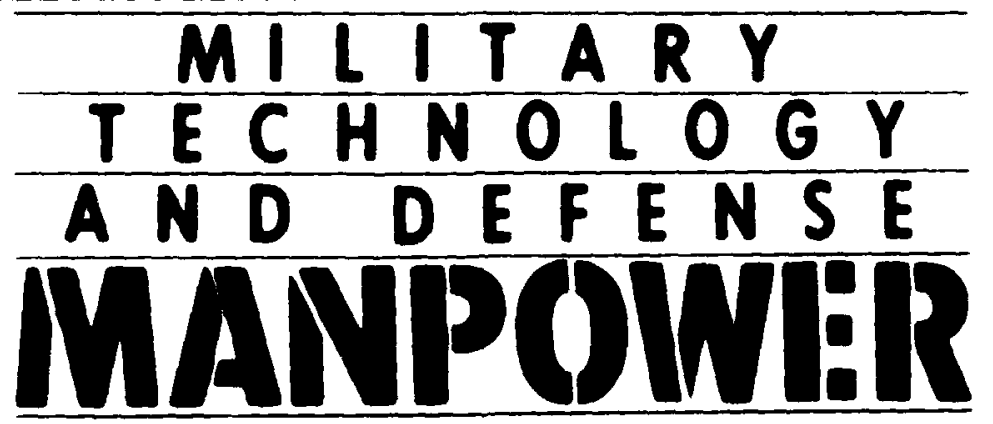

By Martin Binkin

The Brookings Institution. 1986

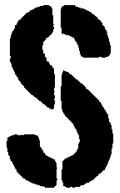

ince World War II, there have been numerous breakthroughs in the technology used for wartare. However, manpower implications are often overlooked. Martin Binkin, a senior fellow in the Brookings Foreign Policy Studies program. explores the relationship between military personnel and technology. The thesis of this book is that there is little underst anding of how technology will affect defense manpower requirements. Training. reliability and maintainability have taken a back seat to performance. schedule, and cost in the acquisition process. Binkin's book provides insights to the issues involved. They are:

- The relationsip between military echnology and defense manpower requirements

- A prospective lack of qualified people to deal with advanced weapon systems technology

-Understanding policy options such as improved equipment design. advanced training methods, and more efticient personnel utilization

Since 1945. the military occupation structure has included a larger percentage of skilled technicians and specialists While weapons will probably look the same during the next decade. there will be unseen embedded technologies in the weapons plattorm With a policy of qualitative superiority rather than numerical superiority. iechnical skills are crucial for operating and maintaining present and future weapons systems. There is concern that personnel estimates have been initially low. possibly to reflect lower life-cycle costs. Planners need to have accurate numbers on the skill $\mathrm{mix}$ and qualification levels.
Demographics are important to the program manager. Until 1995, there will be fewer people 18-23 years old to utilize. Based on some estimates, active and reserve forces will have to attract more than 50 percent of males qualified for military service (assuming there are no changes in force size).
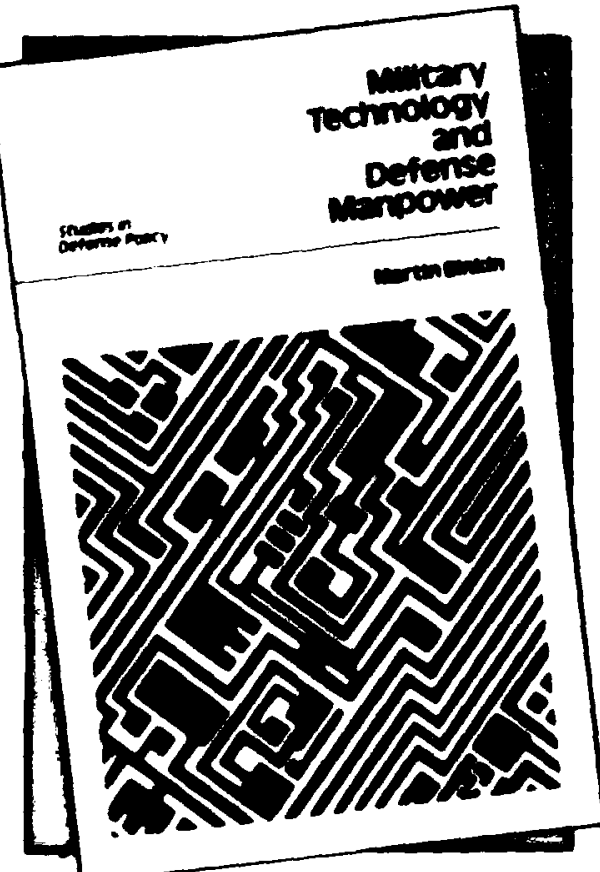

Moreover, academic performance las measured by the Scholastic Aptitude Test ) has declined in the past 20 years. If weapons become more complicated. there will be even fewer qualified personnel to use these systems. One way to minimize personnel shortages is to design and develop reliable and maintainable systems to reduce the maintenance wort load. Modulariza. tion. and remove and replace are iwo maintenance approaches, and very high speed integrated circuit (VHSIC) technology has the potential to im. prove reliability, increase self test and be user friendly. If this occurs, some personnel problems may be solved. While built-in testing and automatic test stations may reduce the time needed to isolate faults, there is a risk this equipment may make a system less reliable and more complex because more things can go wrong. This could lead to downtime and unavailable weapons.

Training technology can reduce some of the personnel gap. Instead of frontend training. there should be more on-the-job training, and a shift in classroom training from theory to a functional context. Job performance aids should be developed and used. For example. the Navy tested a system called NOMAD which was a shipboard maintenance aid. Fault isolation was completed three times faster, and mean time to repair was cut in half. However, the system was not retained.

Four primary options exist for expanding the manpower pool. They are a wider role for women. reduction in turnover, return to conscription, and greater use of civilians (federal and contractor). Binkin advocates less complex systems or training concepts which exploit modern training technologies. He discusses options such as reducing the demand for skilled people or expanding the pool of qualified candidates without increasing person. nel costs or unduly sacrificing military effectiveness.

As the military career has become more attractive, the cost of the replacement pipeline has become more expensive Conscription is one way to reduce the uncertainty of the number and qualifications of the volunteers However, it may do little to retain peo(Continued on page 40) 
n contracting, the risks assumed by the seller and buyer are balanced by the price and potential profit. There are easy-to-do jobs because participants are able to understand problems, and perceive alternative methods to handle the problem more satisfactorily than others can. They have mastered the technological risk and the cost to satisfy customers' needs with reasonable assurance of making a profit. The buyer has determined a reasonable price to pay to satisfy problem resolution through the free-market system. The government takes some issk in its purchase of products and services, and the contractor takes some risk in estimating the cost to deliver. The balance of risk between government and contractor has shifted, however, during this political administration. The shift increases the risk to companies selling to the government through the Federal/DOD procurement process.

Let's look at some changes in the aerospace industry environment for some identification of the problem that may have been aggravated during the past 6 years to cause that shift. The following are facts used in examining the problem.

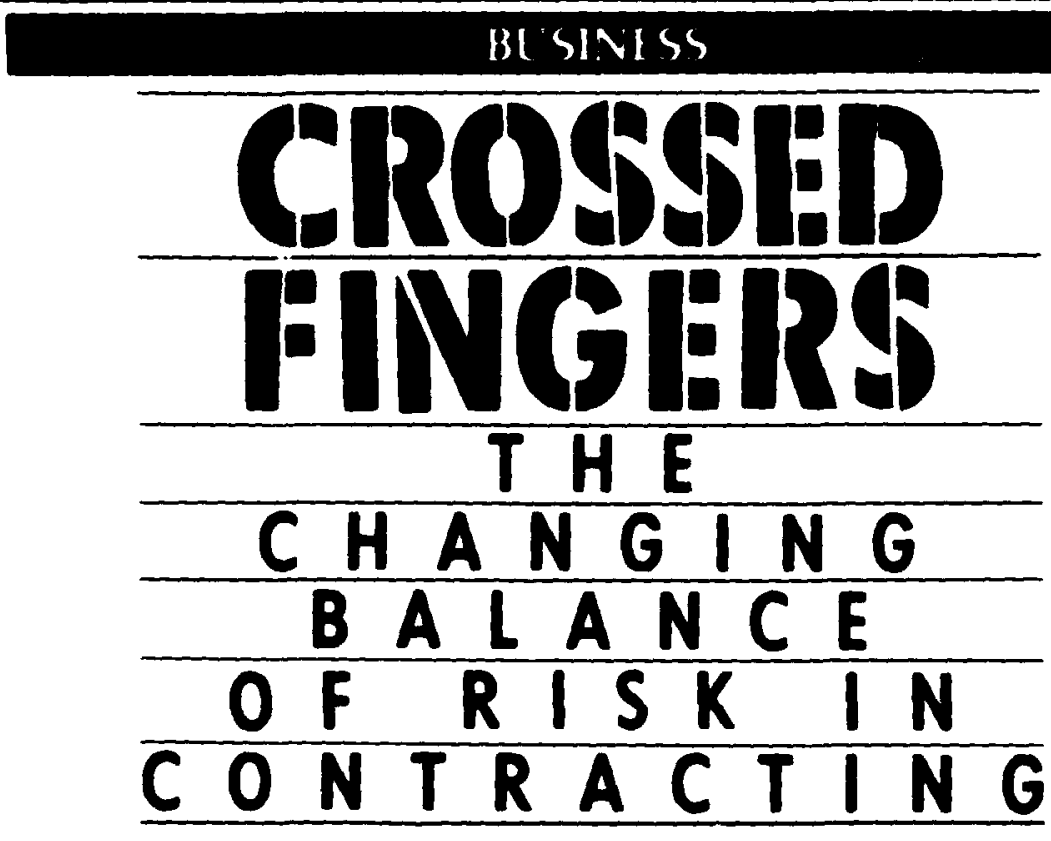

Troy V. Caver
- The DOD aerospace market is dominated by one large buyer, the Department of Detense.

- Sellers to the DOD aerospace market must adhere to Federal Acquisition Regulations (1984).
- Recent legislation directed changes in the DOD procurement policies; Competition in Contracting Act, July 1984.

- Procurement contracts of major programs in DOD exceeded $\$ 50$ billion in

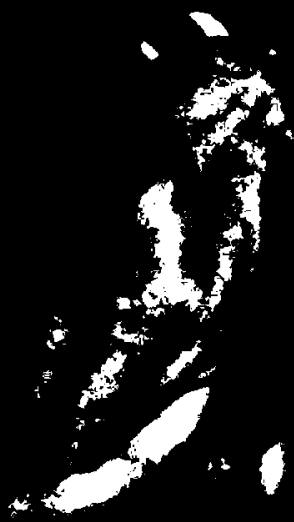

$\Delta$ 
1986 (they exceeded $\$ 50$ billion in 1980 dollars for the major selected acquisitions alone per DOD program, Analysis and Evaluation Office).

- Risk is being used as a term having some probability of an occurrence that will provide measurable consequence. Combining probability of occurrence and consequence, given the occurrence, yields risk.

The following are not facts, but are assumptions considered reasonable and relevant to the issues.

- The price for the exchange between a buyer and seller represents the known or anticipated risk.

- The risk in contracting with the government is discovered during a long time period based on lessons learned from the contracting organization, its customer, and other contractors.

-Federal Acquisition Regulations have been developed throughout the years based on conflicts arising between perceived objectives and goals of the three branches of government; Executive, Legislative (often representing the large contractors in congressional districts), and Judicial.

- The continued sconomic success of any contractor doing multibillion dollar business with DOD will require an understanding of the risk undertaken in the contracting instrument and procedure.

Several items appear to have contributed to the change in risk. The following were identified in either the government environment or contractors' business environments that are likely to impact on either risk to the contracting company or the contracting government agency. The probability of occurrence and the impact or consequence of the occurrence is likely to be adverse; this could happen if the government or contracting company are not aware of the change or how to react to that change, given that it is undesirable and does, in fact, occur.

\section{Changes in DOD/Industry Relationship}

From my observation, there are two opposing philosophies driving guidance to industry and to government program managers-productivity and legalism.

Productivity initiatives appear to be headed up, according to production "gurus" in the government. Their policies emphasize quality and shared accountability. This is demonstrated by ideas like "gainshare," where savings are to be shared with industry participants. Other examples of this thinking are found in the following federal programs or initiatives:

-Industrial Modernization Incentives Program (IMIP)

-Acquisition Streamlining Initiative - Value Engineering

-DOD/Defense Industries Quality Excellence Program

- Promotion of Contractor Manufacturing and Productivity Improvements.

These initiatives, relatively new as a package, also are reflected in the thinking of Japanese industry, which encourages:

- Workers to assume responsibility for quality

- Integrating and dealing with suppliers to get higher dependability in supplies delivered

-Making investments as necessary to get results of improved producibility; i.e., robotics or flexible manufacturing systems

-Dedication of management to drive down cost and decrease defects -Early concentration of productionworker efforts to remove errors from

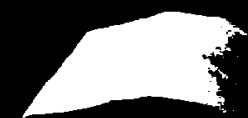


production design and drawings, thus yielding steeper learning curves.

On the other hand, we have contracting and accounting advocates approaching the problem from a legalistic point of view. They are authors of the competition in contracting act, the writing and delivery of detailed design and production specifications, the evaluation of "cost realism," arms length negotiations, and testing each batch of items received for the required quantity and quality. The advocates also want to establish a measurement standard for what a worker can do, and hold the company to achieving that, rather than providing for the producibility of the design to make it easier for the worker to produce. The philosophy is to establish criteria and audit to verify its compliance. The advocates will maintain a "level of fear" over subordinate or supplier to possess a "real threat" should the company fail to perform as contracted. Failure is met with punishment-debar, fine, penalty, no further business. The company evaluates success by knowing, legally, how to survive getting the product accepted during the acquisition process, rather than by the evaluation of the product delivered.

In Japan, the first philosophy has been shown to breed a partnership perspective with a sense of responsibility for the product and a long-term accountability for the process and relationship. The second philosophy, as demonstrated by U.S. Government contracting experience, breeds a single objective of profit maximization based on the single contracted transaction as long as the company operates within written constraints. From McGregor's management perspectives, we would probably label advocates of the first philosophy as "Theory $Y^{\prime \prime}$ practitioners and the second group as "Theory $X$ " practitioners.

Trends and Future in Contracting With the Government

The trend in production is away from the manual mechanical task, with limited job descriptions where bluecollar workers are the source of principal value added. Replacing the mechanical task is a larger contribution from the management team, putting teams together having better flexibility in job actions with broader job definition, more and better communications, continual finding and remov- ing of roadblocks, and an ability to manage complex and "intellectual" automated systems. Therefore, following are specific areas of change based on these guidance trends.

\section{Technology Skills}

American children study one-third to one-half the math and science studied by their Japanese and Russian peers. In 1983, one in five American adults lacked minimal reading and writing abilities necessary to meet demands of daily living. Yet, the need is toward greater skill requirements in mechanical and electrical engineering for operations and service of the new technology production processes. The result is an estimated $35-40$ percent unfulfilled increase expected in required workers with electrical and mechanical skills by year 2000 .

\section{Labor Relations}

The role of labor unions is shifting from extracting the highest labor payment from the organization to getting greater worker participation in the method of work and job team operations, with training of existing workers to remain employed and competitive as an industry. Without a cooperative approach in long-range/strategic planning, jobs and profits will be taken from this country by foreign competitors willing to work for less for the short-term. Expect conflicts and possible strikes in organizations not willing to make needed changes.

\section{Training}

The number of workers 18-24 years old entering the work force annually will drop 20 percent from 1983 to 1993 , from 28-23 million per year. The present trend toward more automation will make the unskilled worker less compatible with projected needs; a shrinking availability of capable workers will require a shift toward more in-plant training to obtain required skills. More companies are likely to require increased in-house education and training programs to teach basic skills and speciality requirements.

\section{Service Centers}

With the capabilities of personalsized computers, and communications via normal telephone lines, it is possible to employ a portion of the workforce not now contributing to the gross national product. These include mothers with small children who want to work but can't leave children alone at home, elderly people not willing to commute to designated work location, and handicapped people not able to fit constraints of work location. More can be allocated to these potential workers with automation delivering completed products; i.e., market analysis, plant capacity optimization, better written job descriptions, strategic planning options, product mix opportunities, training plans, profitability analysis, specification reviews, and producibility evaluations.

\section{General Management Perspective}

As emphasis changes toward total system optimization, management will need more generalists as opposed to specialists. However, focus needs to shift toward the manufacturing, marketing and communication skills and less toward financial analysis.

\section{Cost Realism}

The government is putting more emphasis on cost realism of both cost estimates from contractors and realistic total program cost estimates from program managers. There is a late 1985 handbook for program management and source selection personnel sponsored by the Navy Office for Acquisition Research which is applicable for all military services. This book, which spells out policies for each service pertaining to source selection, purposely provides methodology for evaluating contractor cost proposals for realism. The book concentrates on government cost estimates being a baseline, similar to "should cost," as well as surfacing the risk of program complexity and uncertainty for inclusion in the evaluation. Program managers and contractors who don't understand the importance of providing cost estimating "wedges" for unknowns are likely to cause their programs and/or their futures to be terminated.

\section{Shift to Fixed-Price Contracts}

Recently, there has been a tendency for DOD to make greater use of fixedprice contracts even for research and development work. The main reasons for this have reportedly been to make contractors more realistic in their cost estimates for research and development work, and to encourage them to make greater efforts to control their costs once the work is under way. However, DOD contends that its poli- 
cy is to choose the type of contract that is appropriate for the work to be performed. If a contractor is required to perform beyond estimated effort, the impact may be significant. The larger the contract, the greater the impact the failure is likely to have on the economy of a congressional district; therefore, the more important the performance is likely to be perceived by the congressional representative.

\section{Fewer but More Intensive $R \& D$ Efforts}

The Navy, in 1986, cut 500 separately funded R\&D programs to 395 . The House Armed Services Committee staffers are pressing in the 1987 budget to get the number of programs reduced and to develop more and stronger support for surviving programs. Expect the contractor to be required to participate in risk sharing in full-scale development phases with fixed-price contracts.

\section{Design to Cost}

The government now requires contractors to design items to stay within predetermined cost constraints. The term, "Design To Cost," has been used often, with emphasis 10 years ago being on Design to Unit Production Cost. More recently, with 1983 publication of DOD Directive $\mathbf{4 2 4 5 . 3}$ on Design to Cost, emphasis in words shows a shift in concern to the long-term affordability of the item being operated and supported. There is also guidance in that directive that design should be for reduction of life-cycle cost. This document is being supplemented with DOD 4245.3 H, which is a handbook for the directive. Emphasis from other studies encourages identification and fewer high-cost tests.

\section{Streamlining}

Since the end of 1985, each military service has assigned advocates to oversee streamlining initiatives. These start with a scrub of the requirement when a program gets initiated; this happened with the T45 Navy air trainer when 50 percent of $R \& D$ funds were reduced from the program. Then, the effort will be to tailor reports and requirements to get only what is required. Early industry involvement is encouraged to get different ideas regarding what can be done to achieve a better product. One effort included in streamlining is moving away from telling industry "how to do it" and, in- stead, telling "what" is needed. This approach for major systems is similar to "form, fit and function," often used for subcontracting subsystems. The documentation on streamlining has many government programs targeted to implement this new concept. Streamlining includes promoting use of commercial products, including nondevelopmental items and pre-planned product improvements.

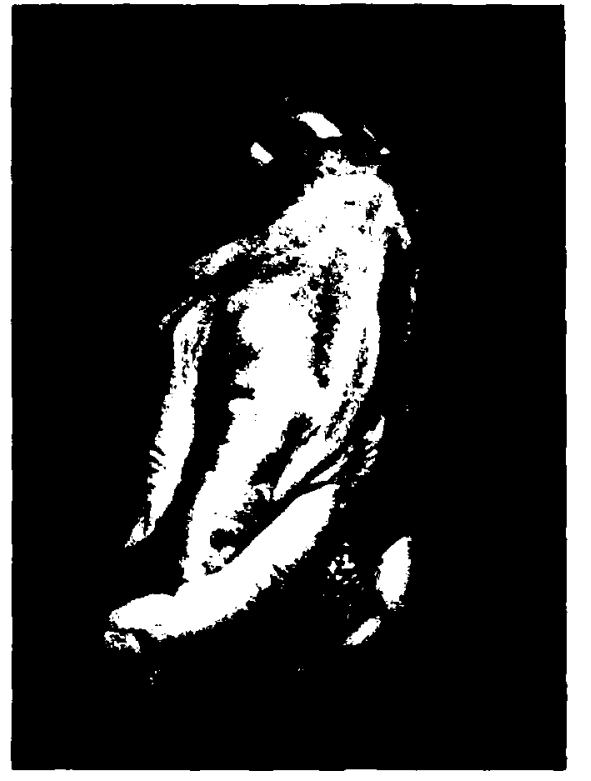

Since the end of 1985, each military service has assigned advocates to

oversee

streamlining, including promotion of commercial products.

Present plans for at least one DOD service, the Army, includes reducing concept exploration and demonstration validation into a single effort, proof of principle, to be completed in 1-2 years and a combination of fullscale development and production "prove out" into a single period of approximately 4 years.

The acquisition plan of all programs is being reviewed by streamlining advocates before approval.

\section{Production Investments}

Recently, there has been experimentation with DOD, particularly by the Navy, with requiring contractors to provide initial funding of production special tooling and production test equipment. The Congress also encouraged this approach in the FY 1987 DOD Appropriations Art. However, there has been substantia! opposition by members of OSD, service chiefs other than Navy, and some members of the Congress to adoption of this approach as standard DOD policy, and it is unclear at this point how this issue will be resolved. The risk in this area is being reevaluated in both OSD and the Congress. In December 1985. guidelines were published discussing "gainsharing," which is a potential for a company to make more money by taking action early to reduce cost. The successful company gets a share of the savings. Other production efforts deal with promoting the use of producibility engineering and planning, quality, and excellence programs. Emphasis is being placed on criteria used in decision reviews by the Defense Acquisition Board (DAB), and source selection criteria for program and contractor approvals in examining their ability to produce in a cost-effective manner. Expect future profit objectives for negotiated contracts to give increased weight to the magnitude of a constructor's investment in plant and equipment. Greater emphasis is likely to be placed on the evaluation in production readiness reviews.

\section{Industrial Modernization Improvement Program}

The government is emphasizing improved profit potential through the Industrial Modernization Improvement Program (IMIP). This program is an ongoing effort to upgrade manufacturing capabilities of government contractors. Funds may be provided through a program contract to improve the manufacturing capability and will most likely be funded at a greater level if met with matching funds from the company. This subject was addressed in a GAO Report dated Sent. 6, 1985 (NSIAD-85-131).

\section{An Amendment}

The Gramm-Rudman-Hollings Amendment requires cuts in the monetary outlays to meet predetermined budget targets to reduce the federal 
deficit. Amendment language assures that cutbacks in budget funding to meet deficit targets not impact one, large program. Implementation of this congressional amendment to reduce the federal deficit across-the-board has the potential to impact every program. The military services and program managers are being told that reductions in cost are not to result from reducing the quantity of items. Any programmed funds not obligated early in the appropriated year are likely to be at risk. If these are funds that have a high-leverage payoff and can't be obligated immediately, they should be protected by "spelling out" the impact their loss would have. A viable "fall-back" position at varying levels of funding for every major program under contract should be developed jointly by government and industry program managers. The potential enforcement would make future funding of new-start programs high risk; there appears to be a question about the willingness of the Congress to enforce all provisions. It is a "sleeper" in terms of future funding risks.

\section{Another Amendment}

The Nunn-McCurdy Amendment requires any federally funded program having an average unit program acquisition cost, or average unit procurement cost increase beyond 15 percent since the last baseline (annual), to be reported to the Congress. The impact is a function of whether the right budget was developed to begin with, or whether the program was underestimated and must be continued with underestimated and budgeted funds. Most at risk are training and support because they are areas most often not included in the early estimate and are first to be sacrificed when program funds are scarce. The loss or reduction of spares are risks. In both cases, the real impact of losing funds falls on the user in operations, long after production is under way. Should this be the case, the contractor should offer to provide a warranty, properly priced, for the period required to recover from the neglect.

\section{Data Rights}

Data rights are the proprietary ownership of contractors protecting their inventions and procedures. In the past, independent research and development (IR\&D) efforts by a company permitted it to retain data rights of any work performed through that effort. Recently, some within DOD have suggested that the government should receive certain rights to data developed by contractors with independent research and development funds, provided that a substantial portion of those funds resulted indirectly by DOD contracts being performed at the time of their expenditure. At this point, it is not clear how this issue will be resolved. However, if Defense Department policy in this regard is changed, this may result in contractors doing less independent data research and in contractors refusing to provide rights to the government. Investment of funds with expected retention of data rights is now a higher risk use of funds. The DOD aggressiveness appears to be based on a desire to provide for technical data to enhance competition.

\section{Risk \\ Management}

Since 1967, there has been the necessity to manage the risk of major technological, financial and contractual outcomes. This was recognized by DOD leadership as important for assessing the effect of trade-offs and technologies pursued. Senior general officers in the military services are instilling a sense of management concerning not only the cost or technical performance resulting from decisions, but the risk of those decisions. With the advent of streamlining and several budget reduction actions, senior management has recognized that industry not only has been forced into early decisions but that these decisions may have increased the risk in program success. Program managers in the government must be made aware of these risks and of those transparent to the industry (budget, political, user advocacy, changing threat, etc.) before they can work the program in its totality for success.

In 1985, the Government Accounting Office visited more than 25 government programs and many industry program offices to identify their uses of risk in decision-making and system design trade-offs. The GAO wrote a report in April 1986 and showed the results of their examination of Office of Secretary of Defense implementation of risk policies. The Department of Defense chose to develop a response to the report by developing a guide which will provide common risk definitions, "how to" guidelines, and policies on decision-making with risk. The DOD Risk Management Guide is expected to be available through the Defense Systems Management College in 1988.

\section{Budget \\ Continuance}

Many changes in the federal government the last 2 years are likely to shift the congressional funding of the DOD budget at the requested level. The Reagan Administration provided major increases in the DOD budget for 1980-86 with the initiation of many new systems. In fact, it is unlikely that the Congress can afford to provide the planned funding for many of the major research and development or procurement programs started during the first 6 years of this Administration. In addition to the risk of continued funding to complete the required procurement actions initiated, the operations and support burden is usually twice the cost of the combined R\&D and procurement cost of a system. The initiation of so many new programs in an environment of future budget constraint will force voluntary cancellation of some programs, continued expansion of an already record deficit, or loss of congressional or governmental advocacy. Any contractor or military service advocate with a new program requiring long-term continued funding should develop alternative fall-back positions for survival with reduced funding levels.

\section{Delegated \\ Decision Levels}

The DOD initiated a policy of delegated decision-making to lower levels with reduced formal requirements; history dictates that the Congress will continue to use program funds for regional economic leveling decisions. Expect government and contract program managers to have more latitude for conflict resolution, and expect them to have a requirement to keep abreast of congressional advocacy on programs of concern to reduce risk of loss of funds. For example, a low-rate initial production report must be received by $\mathrm{HAD} / \mathrm{SAC}$ and HASC/SASC before the Secretary of Defense can approve the decision memorandum for full production. 


\section{Industries' Changes}

Will Impact DOD

The U. S. marketplace is open to the outside world. It is estimated that 70 percent or more of U. S. goods now compete with equivalent goods made abroad. The production workforce emanates from lower-cost labor sources; it is expected that, by 1990 . 85 percent of the 36 million people entering the workforce annually will be from Third World nations.

In this international competition, the U. S. advantage appears to be technology advancement and flexible production systems producing whatever customers want. This is an advantage because these systems require skills and education not yet available from developing nations. The U. S. disadvantage is higher cost for wages, materials, and labor productivity. Additionally, since most industrial highcost capital processes have been installed recently in developing nations, many comprise more recent technology. It is estimated that the United States needs $\$ 60$ billion to upgrade facilities in the next 10 years to be competitive in steel production alone.

Design for production is a key to reducing cost. This requires a focus on design for ease of assembly in the early stages of a systems development. Japan, with a labor shortage, focuses on designing for automation which requires early detection of cost-reduction techniques before installing the automated equipment. The United States has a labor surplus and often is opposed by labor unions protecting the workforce when automation is planned.

The United States represents the biggest market in the Free World for manufactured goods. It appears that international competition is real and has very few barriers in this country. Yet, funds spent by the Department of Defense are still used by the Congress for economic leveling throughout the United States. While this may make the United States distribution of business more equitable, it provides business to other than most efficient producers; i.e., not the most cost effective (disregard social value of the decision). It is the final price paid that is considered with outside competition. Hence, while a congressman or staff may be trying to protect jobs in the congressional district through the legislative process, we may be losing business to international companies producing and selling for lower prices. Recognizing this problem, the government said April 1, 1986, that import taxes would be imposed on products of emerging Third World countries. For contractors doing government business, there must be a recognition of higher risk in future market availability with the probability that other than U. S. contractors may compete for the contract.

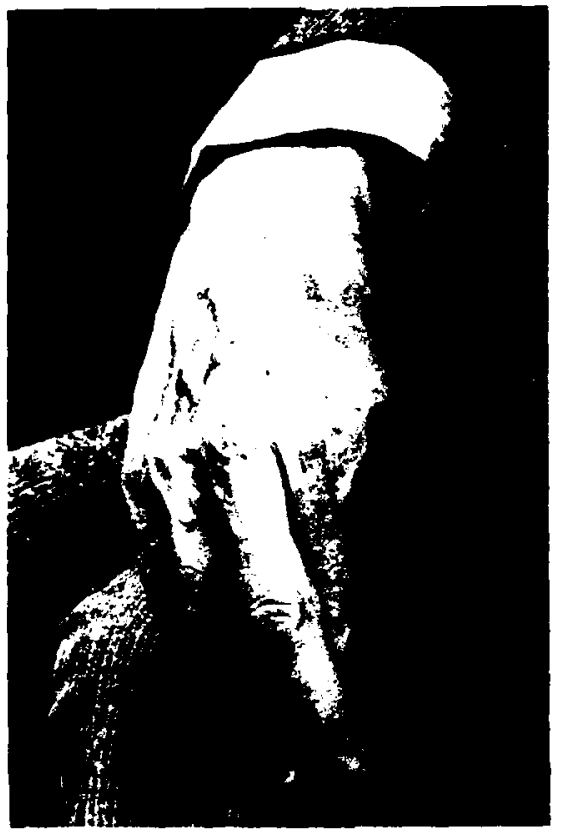

\section{Expect the}

contractor to be required to participate in risk sharing in full-scale development phases with fixed-price contracts.

\section{Completed Contract \\ Basis of Taxation}

Until 1986, contractors could report income after a contract was completed. This meant that for long-running production contracts, the period of contract completion might be 3-4 years after receipt of partial funding. Indications are that this will change in 1987. The input will be increased taxes and reduced cash flow to industry.

\section{Product}

Liability

A court decision in May 1986 (Washington Post, May 28, 1986), held that pilots killed in Bell helicopters due to design errors could not sue the manufacturer. This was due largely to Bell's having identified the problem and submission of three engineering change proposals (ECP) to correct it. The government turned down the first ECP and had failed to act on the other two. While this may not be a binding precedence for future product liability cases, it turns the tide in the face of large multimillion dollar claims awarded in recent lawsuits of commercial products.

\section{Macro \\ Projects}

Large programs requiring heavy corporate investment may be attractive but the chance of failure puts too much at risk. A growing technique for risk reduction is the international joining of forces for working major projects, such as:

-Space exploration

-Mining the sea floors

- Building a tunnel under the English Channel

- Space defense initiative

-Undertakings to make desert land fertile and usable

- International space travel

-Defense of common principles (World War II).

These projects are large and tax resources of organizations. Notice that most of the projects listed are national initiatives. However, individual companies or corporations may have a need for risk sharing and the concepts on how to do it may apply when undertaking projects too large or too risky for a single company. Motivation for such an undertaking may be:

-Financial

- Talent

- Smoothing of cash-flow limitations - Technology development and sharing

- Shared risks

- Aid in overcoming political barriers.

What can be concluded from the above? The contractor or government program manager reading and under-

Mr. Caver is a Professor of engineering management. Technical Management Department, DSMC. 
standing the impact of changing risks should understand that the shift of risk has changed. Some specific conclusions follow.

The changing laws and policies identified in the problem and analysis section of this paper provide evidence that the balance of risk has shifted to put the contractor at more risk. Since the government will use more fixed-price contracts, the price bid will require that the contractor cover any additional cost from risk areas under the bid contract price. This means that for the same price, the government is getting a better deal than before the risk shifts.

Due to the piecemeal way they occurred, these actions will not be known to many contractors; and will not be put in context by many others, even though they know about them, regarding impact on company or corporate future profitability. Consequently, many contractors can expect to be surprised during the next 3-4 years as they continue to bid on projects with the expectation of doing business as usualincluding making up reduced early profits on later phases of the development or production contract. What can you do after finding you must take action in an environment where risks have shifted?

Here are some ideas. Any contractor now having a contract with the government should make a thorough assessment of risks in proposed actions and the business environment of the contracted effort. This should be done before proposing a contract.

Future proposals should include sufficient information on the recognized risk to convince the government that you understand the problems. Presentations should identify areas where the government can aid in risk reduction; i.e., funding for early ordering of long lead times, approval of priority status.

The price bid should include not only products to be delivered but business and contractual risks incurred in bidding on new government contracts, commensurate with the increase in the competitive nature of the business.

Realize that any consideration for bid and proposal by contractors in the future should include an internal examination of not only the contractor's ability to identify risks, but of the competitor's ability to recognize risk and develop viable alternatives to handle the risk. The potential contract cost risk and business risk will restrict the market to only those who can survive the extra government requirements.

Greater profits are available for surviving contractors.

\section{References}

1. Bemis, John C., "A Model for Examining the Cost Implications of Production Rate," Concepts, pp. 85-94, Spring, 1981.

2. Black, Norma, "Probes of Defense Firms Increase," Washington Post, p. A9, Feb. 23, 1987.

3. Buffa, Elwood S., Meeting the Competitive Challenge: Manufacturing Strategy for U. S. Companies, Dow Jones-Irwin, 1984, p. 11.

4. Caver, T. V., "Cost Risk in Contracting Production," Program Manager, September-October 1986.

5. "CICA: What Price Competition?" Defense Electronics, pp. 43-48, November 1986.

6. Competition in Contracting Act, the Congress of the United States, 1984.

7. Cost Realism Handbook, Navy Office of Acquisition Research, Government Printing Office, 1985

8. Deficit Reduction Act, The Congress of the United States, 1984.

9. Humphreys, Kenneth K. and Paul Wellman, Basic Cost Engineering, Marcel Dekker, Inc., New York, N. Y., 1987.

10. Institute of Industrial Engineers, Aerospace Division Conference Proceedings, Feb. 11, 1986.

\section{Fernet Meelel}

Edmund T. Pratt, Jr. has been awarded the Henry Laurence Gantt Medal by ASME and the American Management Association (AMA). The medal is awarded annually for distinguished achievement in management as a service to the community. It was established in 1929 and memorializes accomplishments and community service of management engineer, industrial leader, and humanitarian Henry Laurence Gantt.

Pratt, chairman and chief executive officer of Pfizer, Inc., was recognized for "managerial skills in making his

\section{Book Review}

(Continued from page 33)

ple with experience, and may not help quantitatively. The greatest concern is that too many people have been retained in unskilled or semiskilled positions. This may be due to the concept of equal pay for the same rank and seniority.

Congressional ceilings on military and civilian manpower have encouraged the use of contract personnel. Overdependence is a concern. A Government Accounting Office study in 1981 found 6,000 contract personnel in overseas positions which were mission essential. There is concern they may seek to leave jobs should the potential of war increase; another concern is their relationship with the user. The contract personnel could recommend system modifications or contract changes which increase their firms' sales. Finally, since contract personnel work with uniformed personnel, pay differentials for the same work could cause morale problems.

Binkin points out that more research is needed on the costs and benefits of these options to hedge against shortfalls in quantity and quality of personnel. However, he says the greatest promise appears to be in applying new technologies to the training base to give a more productive technician corps and, perhaps, an expanded pool of technically qualified people.

Michael G. Krause

Professor, Educational Research $D S M C$

organization a leader in its field and creating a statement of corporate philosophy that sets high ethical standards and emphasizes the organization's responsibility to both individuals and groups as well as communities; for his continuing efforts to improve the economic climate of both the city and state of New York."

The ASME members on the Gantt Medal Board of Award are David D. Acker, Nathan H. Hurt, Jr., Frank S. Locke, William K. McAleer, and Robert Simmons. 
ACQUISITION STRATEGY

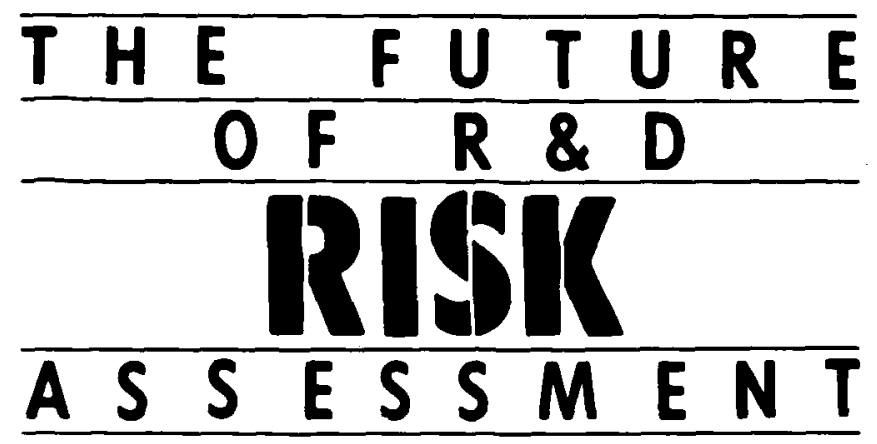

Colonel Gordon W. Arbogast, USA

Dr. Anthony Czajkowski

A major study, "Total Risk Assessing Cost Estimate" (TRACE) has been completed assessing effectiveness of an Army Materiel Command acquisition strategy. Total Risk Assessing Cost Estimate was introduced in the mid-1970s as a promising technique to improve management of research and development programs. Seventeen major Army research projects have used TRACE, and more than $\mathbf{4 0}$ major Army projects participated in evaluating this specific problem: Has TRACE reduced Army research cost overruns and development time? $A$ questionnaire was sent to all program management offices providing insights into program managers attitudes about TRACE.

This article concerns study results and makes inferences about the future of risk assessment in research and development programs.

Data collected concerned the largest research and development programs in the Army Materiel Command during the past 10 years. Subsequent analysis employed econometric modeling techniques to identify factors responsible for cost overruns and increases in development time. The study identified major causes of cost overruns and schedule slippages. For a complete list of programs included in the study see Table 1.

\section{Research Design}

The units of analysis or response variables used in the study were a particular program's annual cost overrun

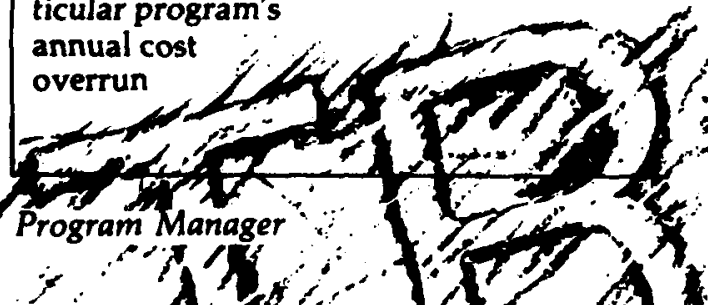

and schedule slippage. The 18 potential explanatory factors examined in the study included:

-Size of program in millions of dollars

-Degree of program technical risk

-Stability of program managers

-Stability of key program office personnel

-Education of program office key personnel

-Stability of operational

requirements

- Degree of contractor support

- Number of contractors

-Experience of program manage-

ment office personnel

- Amount of competition

- Resource and tudget support by

higher headquarters

-Estimated amount of contractor buy-in

-Accuracy of initial baseline cost estimate

- Realism of schedule

-Degree of testing

- Soundness of the program

manager strategy

-Use of TRACE or non-TRACE for each program

-Length of contract.

There was a survey of approximately one-half of the Army program offices. All Army program offices were asked by Army Materiel Command headquarters to provide historical data

from 1976 regarding respective programs. Included were TRACE and non-TRACE programs. To ensure all understood data requirements, all program offices were visited at least once. To obtain good quality control, direct channels of communications were established with key program office personnel. As a result, there was a response rate of 98 percent with 41 of 42 major projects participating.

\section{Results}

Models were designed to analyze the effect of each of the $\mathbf{1 8}$ factors.

Table 2 lists 12 factors examined and shows whether each had a significant effect on cost overrun cr schedule slippages. Unlisted factors were insignificant. Table 2 revealed that results were interesting and, in some cases, unanticipated. For the cost-overrun model, stability of the program manager and TRACE were variables expected to be significant; neither turned out to have much effect on cost overruns. Although there were programs with high cost overruns and a high degree of instability in program management, there were other programs with low cost overruns and instability in program management. On the other hand, technological risk and contractor buy-

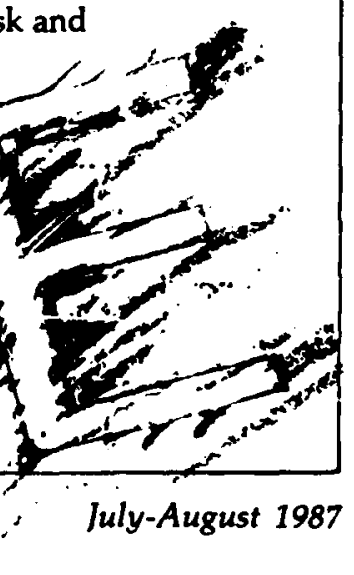


Program Otfice

Programs

Advanced Alteck Holicopter Arm Atk Hol (AAH); TAOS

Advanced Manpertable Meapon Systom VIPER; AMMS

Aireraft Survwablity Equipment -Various

Army Hellcopter Improvemont Program AHIP: ASH Army Tectical Communications System ATACS Bleckhawh Hollcoptor Biecknawk Bradley Fighting Vohich Systom IFVS; Bradiey Cannon Artilery Weapen System caus

CH-47 Modernization CH-47 Chinadk Choparral/Foar Chaparral; Far Cobra Cobra

Dofense Communications System Varbus Dhision Air Dofense GunDIVAD

Fiald Artillory Tactical Data System FATOS

Firofinder/Rembass Firofindor/Rembess Hawk - Hewk Hellfire/Ground Laser Designator Hellitire/Eld Light Armored Vehicle -LAV Multiple Launch Rocket System micks Modular Intogratod Comm \& Nav System MLRS Multi-Service Communications System MSCS Nuclear Munitions Various Operations Tactical Data System OPTADS

Patriot Patriot Parshing Pershing Position Lecation Reporting System PLRS; TIDS Satellite Communications - Various Single Channel Ground Airborne Radio SINGGARS Smoke/Obscurants Smoke/Obscurants Stinger Remotely Piloted Vehicle Stinger Tank Systoms - RPV

Tank Main Armament Systems XM1; Abrams

Tost Measurement Devices Equipment TMAS TOW TMDE US Roland Roland

in had been anticipated as significant explanatory factors for cost overruns. Both of these were confirmed as significant. The most surprising factors were education and experience; these variables were expected to have minor effects, but both proved to be significant.
In the cost-overrun model, cost overruns increased as the amount of risk, program management experience, and buy-in increased; and decreased as the level of education in the program office increased. Of these four factors, the effect of experience appears to be counter-intuitive. It was anticipated that more experience in the program management office would result in better management, hence a lower cost overrun. The reason for this counterintuitive effect can only be surmised: that is, a more experienced program management office may contain leadership that is more performance rather than cost oriented.

In the schedule-slippage model. technological risk and testing were anticipated to be major explanatory factors. They proved to be significant factors in this study, as were education and length of the research and development contract. Also, using TRACE had the anticipated effect of reducing schedule slippage. As more testing and longer research and development contracts were permitted, slippage was reduced. On the other hand, higher levels of technological risk increased schedule slippage. Education was the one variable not having the anticipated effect. In the cost-overrun model, it was shown that increasing the level of education in the program management office resulted in less cost overrun; however, the opposite was true in the slippage model, where more education resulted in more schedule slippage.

It is difficult to explain this result. Possibly, more educated personnel are conservative decision-makers, and tend to examine alternatives longer and are less inclined to make early decisions. This would reduce cost overruns but increase schedule slippage.

It was interesting to note the major effect of another variable included in the analysis; that is, the effect of the particular project office studied. The implication of a project producing a significant effect appears clear. Well managed projects tend to produce good results every year; projects with past problems do not get better. Instead, the analysis indicated they continue to experience problems.

Results of the questionnaire indicated program managers are uncertain of the TRACE effect on cost overruns and schedule slippages. Another research and development initiative, budget-to-most-likely cost, was perceived as a stronger program in accomplishing these same objectives.

\section{Conclusions}

This research considered the effect on program cost overruns and

8 
schedule slippares of many acquisition related factors, many of which are under direct control of Army management and others of which are partially controlled. Top management is concerned primarily with factors that are controllable and have significant influence on cost overruns and schedule slippages. It was clearly determined that the primary variable. technological risk, helped explain cost overruns and schedule slippage. This corroborated earlier research that concluded technological risk was a significant factor in cost overruns. Unfortunately, this variable is controlled only partially by Army management. Often, program requirement decisions are cast in a light that makes it difficult for Army decision-makers not to opt for a technological advanced solution to a systems development problem. This research suggests that management should carefully weigh benefits of high technology versus cost overruns and schedule slippages that appear likely to accompany such high technology alternatives; also, should fund advanced technology development to reduce technological risk in system development programs.

The value of TRACE as an aid in controlling schedule slippage appears to be another important result of this research; the primary model used demonstrated that approximately 1 month annually in schedule slippage can be saved by employing TRACE. Yet, fewer Army programs use it each year. If used properly. TRACE plays an important role in an acquisition strategy.

The role of education was highlighted. The Department of Army and the Department of Defense have been active in this area in the past decade. The value of graduate schooling and the Defense Systems Management College (DSMC) to educate program management personnel has been clearly identified. On the other hand, graduate programs and the Defense Systems Management College need to stress the importance of making timely decisions; this is in view of the many management information systems that are now available. These systems, often accompanied with attractive computer and graphics adjuncts, can slow decision-making as more data are sought to arrive at "optimal" solutions.

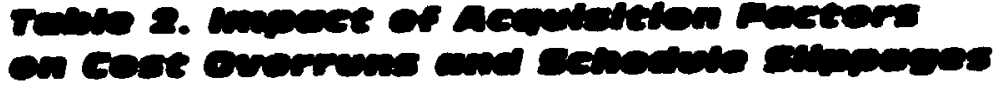

Facter

Cost Overruns

Schodub Stippages

Tecturiand Risk

$+(+)$

Elunetion

$+(-)$

$t(+)$

Exporinas

$\pitchfork(+)$

I

eming

$m(+)$

1

TMAcE

$+(-)$

Teotim

I

$\mapsto(-)$

Lengith of Cenirest

I

$\rightarrow(-)$

Stre of Pringem

1

I

starmy a Pa

I

1

Number of Subenofincturs

I

I

Dueres of Competivion

I

I

Amount of Resemes Stopert

I

I

Kcy: * Signiliean Imacet

I Ineigurilioant Imaset

The fact that project was significant in the model suggests management should not hesitate to make major changes within a problem program. Good programs tend to maintain good track records, while the opposite is true with less successful programs. Management should not hesitate to make major changes, including termination, if a program is doing poorly.

Due to the importance of contractor buy-in, management needs to focus on this problem. A partial remedy may be budget-to-most-likely cost to lessen the buy-in problem; another is lowering the technological risk of programs.

The value of testing in controlling schedule slippage was highlighted in the research. The Army needs to continue focusing major attention and resources on this important aspect of acquisition management.

Factors that do not appear to offer potential to control cost overruns and schedule slippage are important to management. Stability of program management has been noted as a fac-
$(+)$ mowes in sense dirvetion

(-) mowes in eppeselle direction

tor found insignificant in this research; however, other reasons exist emphasizing the importance of stabilizing the program office. Stability should be pursued when possible, but research suggests it is not as important as previously thought regarding cost overruns and schedule slippages.

Other factors not significant include dollar size of the program. Size does not appear to make a difference, and the same is true with respect to stability or requirements. Obviously, new requirements result in cost growth; this was taken into account by the research methodology. Measured in this research was the "multiplier effect" of new requirements, similar to the multiplier effect occurring in the growth of the money supply. The research suggests this relatively small effect will not contribute significantly to the growth of cost overruns or schedule slippages. The following factors did not appear to contribute significantly to cost overruns or schedule slippages; level of contractor 


\section{WE HAVE SOME EMPTY SHOES TO FILL \\ PROFESSORS OF RNGINERRING MANAGEMINT}

This is an excellent opportunity to make a valuable contribution to the efficiency of defense systems acquisition at all levels.

Middle managers from the Army, Navy. Air Force, Marine Corps, Civil Service and private industry attend courses at the Defense Systems Management College to improve their effectiveness in de fense systems acquisition. As a professor at the College, you will instruct, do research and consult within the Department of Defense (DOD) as a member of our Technical Management Department.

Salary range for these GS-14 excepted Civil Service positions is $\$ 45,763$ to $\$ 59,488$. Teaching ability, a baccalaureate degree in engineering or engineering management and at least 3 years of professional experience are required.

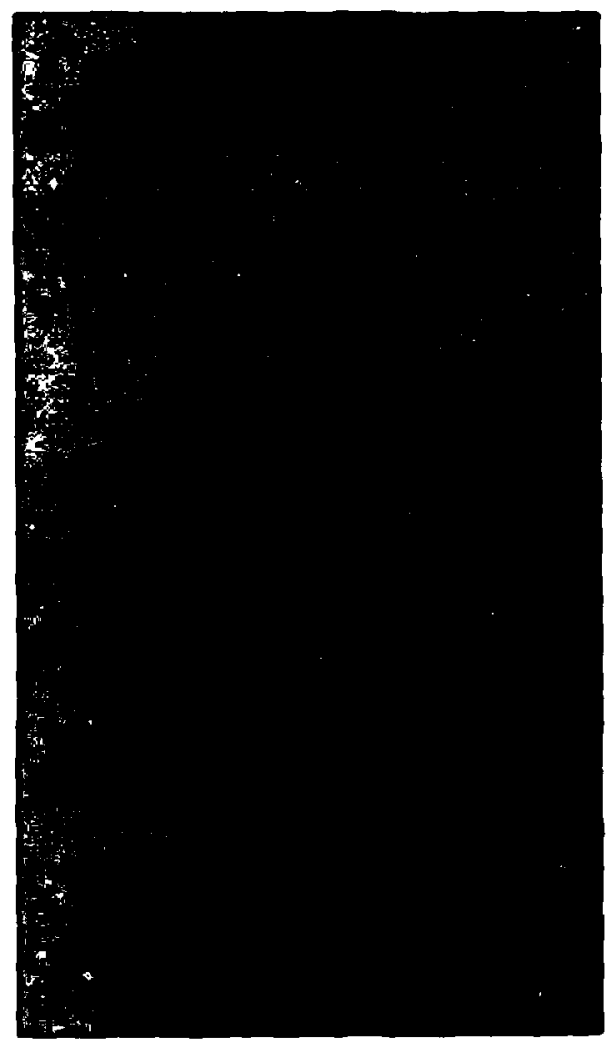

Military officers (05/05) may also be assigned through their detailer.

Understanding fundamental principles in one or more of the areas listed and their relationship with system engineering and DOD life-cycle management is required.

Interested civilians from government or industry should call Debbie Johnson (703) 664-3118 or AV 354-3118 or send a resume or SF.171 Personal Qualification Form to:

\section{DSMC \\ ATTN: DCOS-CP Blab 202 \\ Font Balmoir, VA 22060-5126}

Interested military officers should call LCDR Vicki Sanderson at (703) 664-1175 or AV 354-1175, before talking to their detailer.

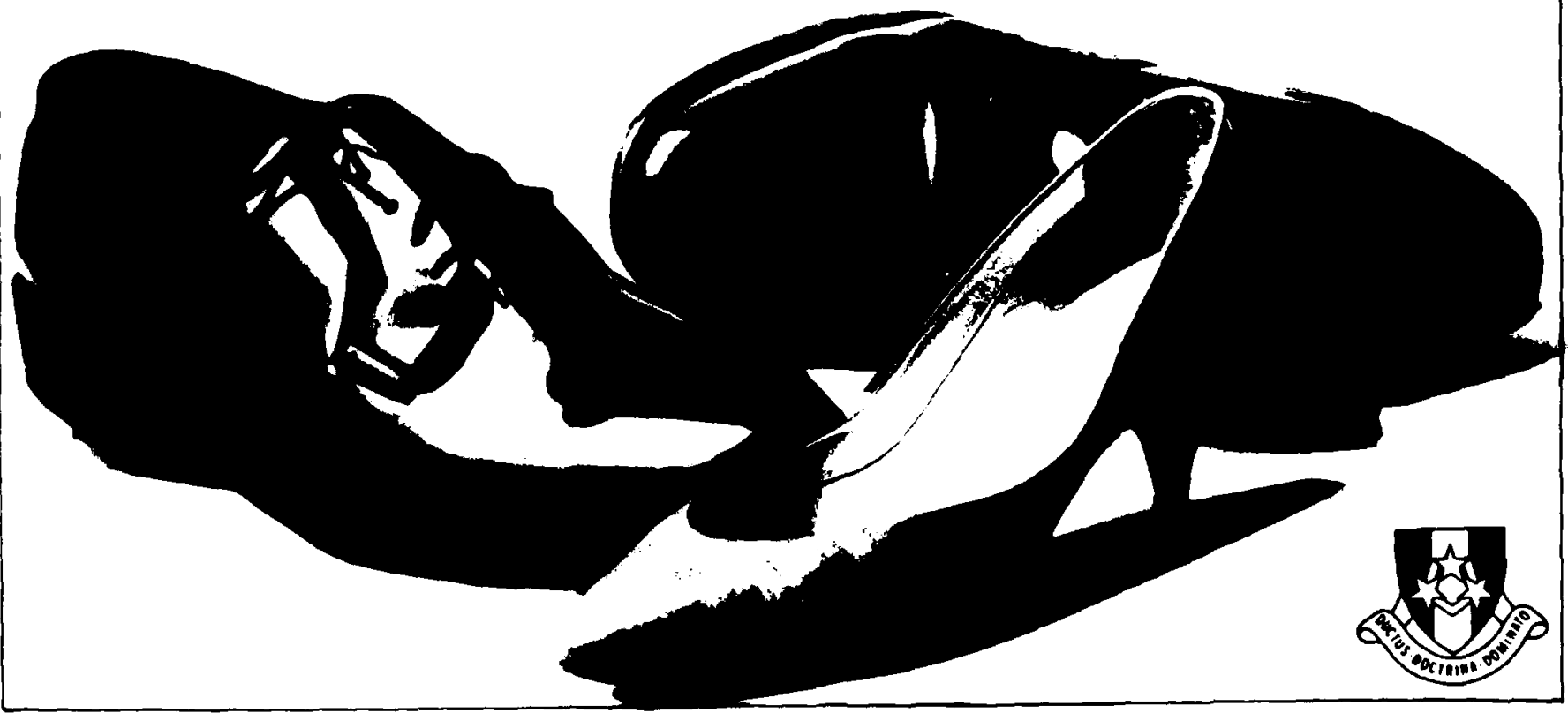


CPANTMENT OF OEFENSE

mosen mameng

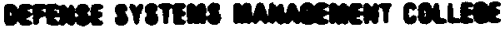

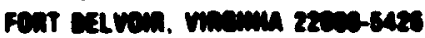

OFFICIAL DUsInEss

PEMALTY FOA PAIYATE USE $\$ 330$ 

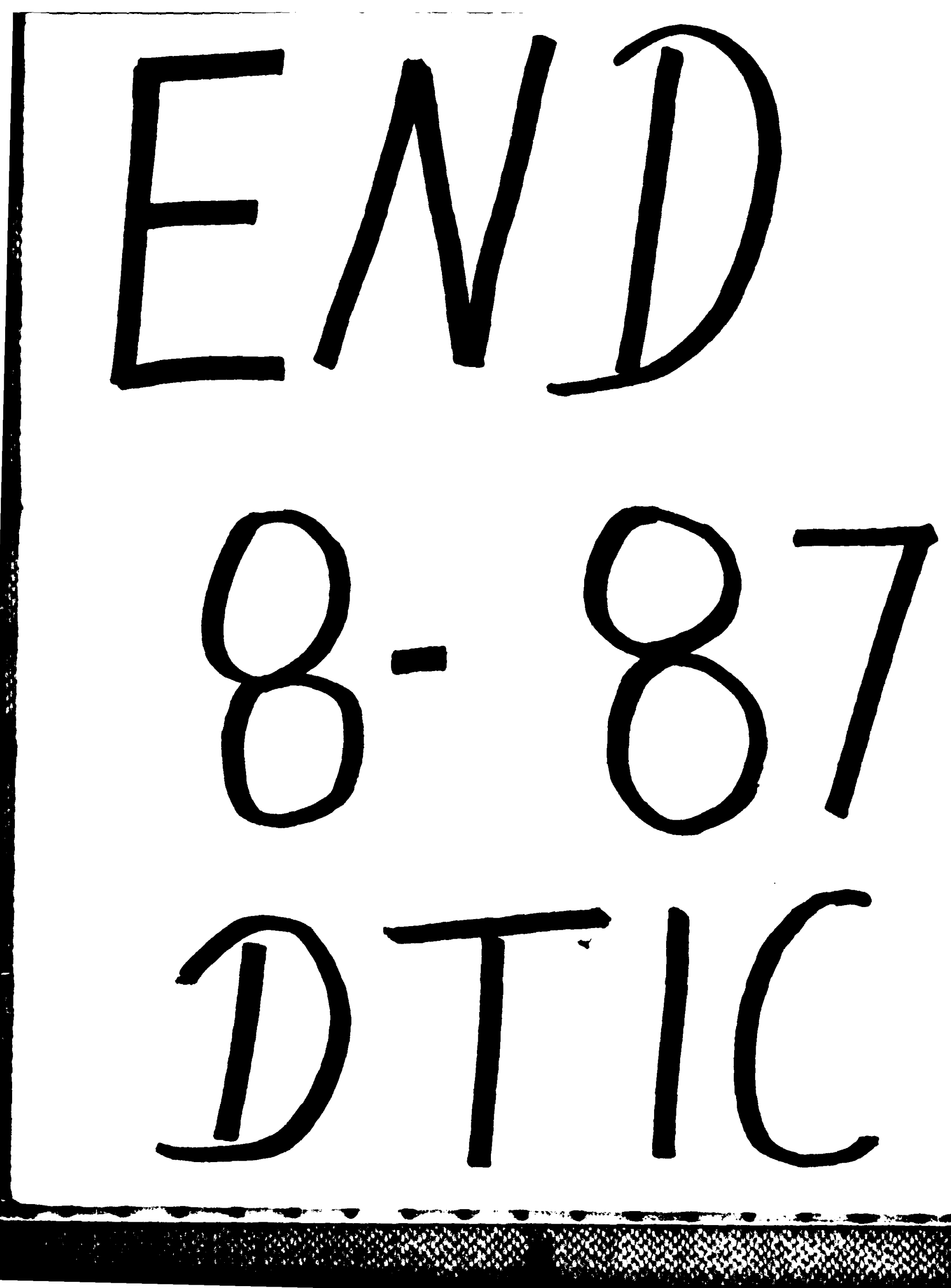